\title{
On the Australian Bark Crab Spider Genus Stephanopis: Taxonomic Review and Description of Seven New Species (Araneae: Thomisidae: Stephanopinae)
}

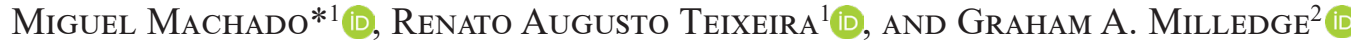 \\ ${ }^{1}$ Laboratório de Aracnologia-Escola de Ciências \\ Pontifícia Universidade Católica do Rio Grande do Sul (PUCRS), Porto Alegre, Brazil \\ ${ }^{2}$ Australian Museum Research Institute, \\ Australian Museum, 1 William Street, Sydney NSW 2010, Australia
}

\begin{abstract}
Here we present a revision of the Australian species of Stephanopis. The type species $S$. altifrons is redescribed and S. aspera, S. depressa, S. monticola, S. elongata and S. scabra are considered its junior synonyms. Males of S. altifrons, S. angulata, S. nigra, S. armata, S. fissifrons and S. longimana are described for the first time. We propose neotypes for S. nigra and S. barbipes and describe the female of the latter. Nine species are considered species inquirendae, S. thomisoides as nomen dubium and $S$. cheesmanae is transferred to Phrynarachne. Seven new species are described, new distribution records are provided and comments are made about the validity of the genus and its relationship with Sidymella species and other Stephanopinae genera from the Australian region.
\end{abstract}

\section{Introduction}

The family Thomisidae is composed of diurnal ambushhunter species commonly known as "crab spiders", due to the way they move and the size, proportion and disposition of their legs (Dippenaar-Schoeman \& Jocqué, 1997). The thomisids comprise the seventh largest family of spiders with 2163 species described in 170 genera (World Spider Catalog, 2019). Among the currently accepted groups in Thomisidae, the subfamily Stephanopinae has been the focus of many recent revisions (Benjamin, 2013; Benjamin, 2015; Machado et al., 2015; Benjamin, 2016; Silva-Moreira \& Machado, 2016; Machado et al. 2017; Machado et al., 2018; Prado et al., 2018). However, most of its component genera are still little known and poorly diagnosed, resulting in a lack of resolution and the consistent recovery of a polyphyletic phylogeny (Benjamin et al., 2008; Benjamin, 2011; Wheeler et al., 2017). Despite these recent efforts to better describe the morphology and understand the phylogenetic relationships of the group, the genus Stephanopis, which gives name to the subfamily, remains in need of a taxonomic review and analyses to test its monophyly.

The genus Stephanopis O. Pickard-Cambridge, 1869 was erected for five newly described species, including $S$. altifrons, from Australia. It was characterized by the high cephalic region with unequally sized anterior eyes (ALE larger than AME) disposed in a strongly recurved row, opisthosoma ending in several spiniform projections and dorsoventrally depressed habitus (Pickard-Cambridge, 1869; Simon, 1895). According to Pickard-Cambridge (1869) himself, the single specimen used for the description of $S$. altifrons was dry-pinned and therefore could not be properly examined. It was not possible to determine if the specimen was adult. Moreover, this author states his own sketch of the spider as "hasty". This may explain why the somatic characters were inadequately described, genitalic features were not mentioned at all, and the illustrations were not detailed enough making the species unidentifiable. 
Simon (1895) already mentioned that Stephanopis may not be homogenous, pointing to some notable differences between its Australian and Neotropical species, especially regarding the length and height of their prosoma, as well as the shape of their opisthosoma and its projections. According to this author, there were at least four distinguishable groups within Stephanopis, which made him question the validity of the genus. In consideration of the issues regarding the morphological boundaries of Stephanopis, and its limited sampling in current phylogenetic analyses, the present work provides a taxonomic revision of the Australian species of the genus, updating descriptions and illustrating in detail their diagnostic features.

\section{Materials and methods}

For illustrating the frontal and dorsal habitus of the spiders, as well as the genitalia of both males and females, the Multipurpose Zoom Microscopes (Leica M205A) from the Museu de Ciências e Tecnologia of Pontifícia Universidade Católica do Rio Grande do Sul (PUCRS) and Australian Museum (AMS) were used. To clear the copulatory ducts of the female genitalia, epigyna were dissected and submerged in proteolytic enzyme (pancreatin), following the protocol proposed by Álvarez-Padilla \& Hormiga (2008). Epigyna were photographed in ventral and dorsal view while male palpi were photographed in ventral and retrolateral view. Scanning electron microscopy images were taken using a Philips XL 30 Field Emission ESEM at the Centro de Microscopia e Microanálises (CEMM) of PUCRS. All measurements are in millimeters and the abbreviations related to somatic and genital features are adapted from Machado et al. (2017) and Machado et al. (2018). Anatomical abbreviations: ALE, anterior lateral eyes; AME, anterior median eyes; PLE, posterior lateral eyes; PME, posterior median eyes; Pcym, paracymbium; PrsP, pars pendula; RTA, retro lateral tibial apophysis; RTAvbr, retrolateral tibial apophysis' ventral branch; CO, copulatory openings; the median area of the epigynal plate, previously called "median field" by the present authors, is reinterpreted and now called atrium (Fig. 2C). The term "macrosetae" is used for setae that are stouter, longer and heavily sclerotized following recent usage by Dr Benjamin (2011), Machado et al. (2017) and Prado et al. (2018) to describe robust, spiniform setae on the ventral surfaces of tibiae and metatarsi I and II of crab spiders. We acknowledge the arguments against such usage so offer this loose definition to circumvent possible confusion.

The material examined in this study is deposited in the following institutions: Australian Museum, Sydney (AMS, G. Milledge), Museo Argentina de Ciencias Naturales "Bernardino Rivadavia", Buenos Aires (MACN, M. Ramírez), Museum für Naturkunde der Humboldt-Universität, Berlin (ZMHB, J. Dunlop), Queensland Museum, Brisbane (QM, R. Raven), Museo Civico di Storia Naturale "Giacomo Doria" (MSNG, M. Tavano), Museum of Comparative Zoology, Cambridge (MCZ, L. Leibensperger), South Australian Museum, Adelaide (SAM, M. Shaw), Western Australian Museum, Perth (WAM, M. Harvey), Natural History Museum of the United Kingdom, London (NHMUK, J. Beccaloni), Oxford University Museum of Natural History, Oxford (OUMNH, Z. Simmons) and Naturalis Biodiversity Centre, Leiden (RMNH, K. van Dorp). The type material of all species was obtained through loans, examined in loco or through photographs. When not found in their home institutions or, confirmed as juveniles, the species were proposed as nomen dubium or species inquirenda.

\section{Systematics}

Thomisidae Sundevall, 1833

Stephanopinae O. Pickard-Cambridge, 1871

\section{Stephanopis O. Pickard-Cambridge, 1869}

\author{
Stephanopis O. Pickard-Cambridge, 1869: 61, pl. 5, figs \\ 33-39.-L. Koch, 1874: 495, pl. 38, fig. 1.-Simon, 1895: \\ 1054, fig. 1091.
}

Type species. Stephanopis altifrons O. Pickard-Cambridge, 1869.

Diagnosis. Stephanopis species somewhat resemble those of other stephanopine genera such as Isala L. Koch, 1876, Synalus Simon, 1895 and Borboropactus Simon, 1884 due to features such as their elongated body, bark-dweller habitus, crypsis by detritus adhesion and predominantly dark-yellow to brown body colouration (Fig. 1A-D). However, they can be distinguished from other stephanopines by their high clypeus and cephalic prominence (Figs 1A, 2B, 3B), dorsoventrally depressed prosoma and robust legs with dorsal acute projections along their patellae and tibiae (Figs 32A, 33B). The male palp can be diagnosed by a ventral pair of long filamentous setae on the tibia (Fig. 3C,E), a well-developed retro lateral Pcym directed towards to the tegulum, embolus with pars pendula, rigid and fixed at its basis but flexible at its distal half (Fig. 3C,E), and an acute RTA (Figs 1E, 3D,F). The female genitalia have a diagnostic shallow and flattened atrium on the epigynal plate, with slit-shaped CO (Fig. $2 \mathrm{C}, \mathrm{E})$; spermathecae asymmetrically coiled, with porous glandular-heads (Fig. 1F) and preceded by a wide and rounded pair of copulatory ducts looking like anterior chambers (Fig. 2D,F).

Description. Bark and litter-dwelling spiders with slight sexual size dimorphism and body colouration varying from green to black, brown, grey or orange) (Figs $1 \mathrm{~A}-\mathrm{D}$, $18 \mathrm{~A}-\mathrm{C}, 21 \mathrm{~A}-\mathrm{D}, 39 \mathrm{~A}-\mathrm{B})$. Both prosoma and opisthosoma have a rugose tegument and are covered by different types of specialized setae, with branches and barbs that increase debris adhesion in some species and help the spiders to be camouflaged on the substrate (see Gawryszewski, 2014). The cephalic prominence varies in height and shape, being more or less rounded and stout (e.g., S. altifrons) or split into two acute vertical ocular projections (e.g., S. bicornis). Legs I and II stronger than III and IV, femora with many setiferous tubercles and tibia and metatarsi armed with ventral macrosetae; opisthosoma varying from oval to trapezoidal in shape.

Composition. Twenty-two species distributed within the Australian region: Stephanopis altifrons O. PickardCambridge, 1869; Stephanopis angulata Rainbow, 1899; Stephanopis arenata sp. nov.; Stephanopis armata L. Koch, 1874; Stephanopis barbipes Keyserling, 1980; Stephanopis bicornis L. Koch, 1874; Stephanopis cambridgei Thorell, 1870; Stephanopis carcinoides sp. nov.; Stephanopis corticalis L. Koch, 1876; Stephanopis erinacea Karsch, 1878; Stephanopis fissifrons Rainbow, 1920; Stephanopis flagellata sp. nov.; Stephanopis lata O. Pickard-Cambridge, 1869; Stephanopis longimana Thorell, 1881; Stephanopis monulfi Chrysanthus, 1964; Stephanopis nana sp. nov.; Stephanopis nigra O. Pickard-Cambridge, 1869; Stephanopis palliolata Simon, 1908; Stephanopis rufiventris Bradley, 


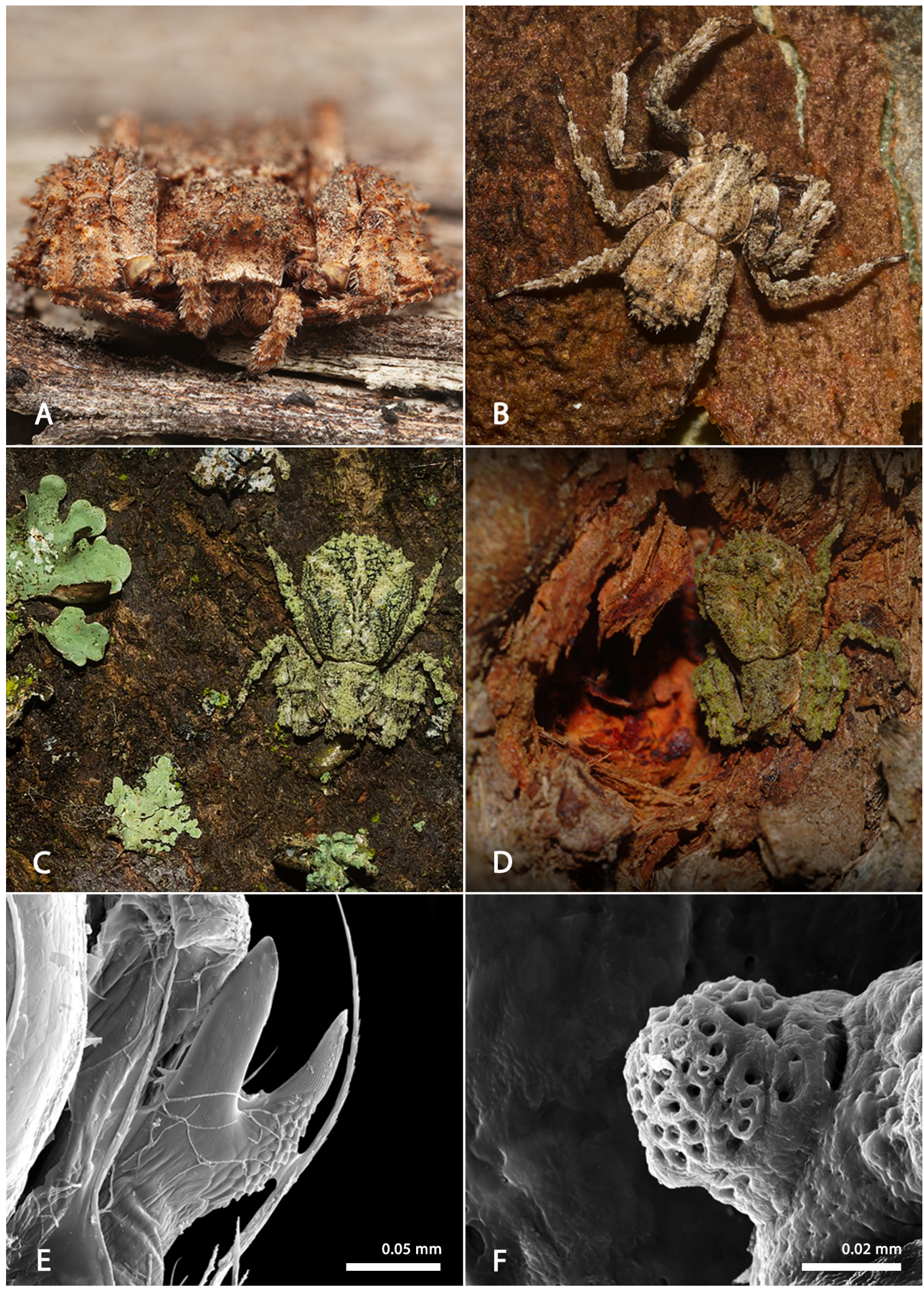

Figure 1. Stephanopis altifrons O. Pickard-Cambridge, 1869: $(A-D)$ colour variations in females covered by different types of detritus and; $(E)$ detail of the bifid RTA of the male palp (KS.108663); $(F)$ glandular head on the female spermathecae (KS.108668). Photos by (A) Billy Brown; $(B, C$ and $D)$ Nicholas Fisher. 
1871; Stephanopis similis sp. nov.; Stephanopis spiralis sp. nov.; and Stephanopis squalida sp. nov. There are more than 16 Neotropical species distributed along South and Central America and eight species from the Andean region, all beyond the scope of the present study.
Distribution. Australia (Northern Territory, Queensland, New South Wales, Western Australia, Victoria, South Australia and Tasmania), Papua New Guinea (Morobe, East New Britain, Western Province) and Indonesia (Papua) (Figs $13,24,35,42,49)$.

\section{Key to the Australian species of Stephanopis}

\section{Males}

1 Prosoma with cephalic prominence and high clypeus (five times the diameter of the AME or more) (Fig. 3B); opisthosoma obovate or pentagonal (Figs 3A, 20A)

Cephalic prominence absent and clypeus low (three times the diameter of the AME or less) (Figs 5B, 26B); opisthosoma trapezoid (Figs 5A, 8A); prolateral setae tuft on dorsal surface of cymbium present (Figs 9B,D, 15B,D)

2 Male palpi with RTA straight, notably bifid and acute; embolus hook-shaped and fixed at proximal portion (Figs 3C, 3D, 20C, 20D)

Male palpi with RTA curved, single-tipped and acute (Figs 17C,D, 46C,D); tibiae and metatarsi I with long and thin barbs (modified setae) (Figs 17A, 31A, 44A)

3 RTA and RTAvbr approximately equal-sized (length and width)

RTA and RTAvbr of different sizes

4 Opisthosoma obovate, posterior setae clusters present; prosoma longer than wide (Fig. 3A)

Opisthosoma pentagonal, posterior setae clusters absent; prosoma as long as wide (Fig. 20A) S. carcinoides sp. nov.

$5 \quad$ Well-developed PrsP; embolus whip-like, coiled and resting behind the tegulum; RTAvbr three times bigger than RTA (Fig. 27C,D) S. flagellata sp. nov.

Palpal apophyses short; RTA laminar and bigger than RTAvbr; Pcym ventrally curved and emerging distant from the tip of the apophyses (Fig. 38C,D) S. nigra

6 Acute ocular projections on ALE present (Figs. 5A,B, 15A,B) 7 Ocular projections on ALE absent (Figs. 26B, 33B)

7 Prosoma pear-shaped (in dorsal view), cephalic region narrowed (Fig. 15A); embolus short; RTA hook-shaped and RTAvbr squared and discrete (Fig. (Fig. 15C,D); femoral and tibial tubercles discrete

Pcym hyaline and vestigial; RTAvbr wide and pointing towards the RTA forming a "crab claw" structure (Fig. 5C,D); femoral and tibial tubercles well-developed (Fig. 5A) S. angulata

8 Dorsal projections on patellae and tibiae I present, welldeveloped (Fig. 33A); femur I enlarged (Fig. 9A)

Dorsal projections on patellae and tibiae I vestigial or absent; femur I not enlarged (Fig. 26A)

9 Opisthosoma wider than long (Fig. 33A); embolus sclerotized, RTA laminar (resembling the shape of an axe blade in retrolateral view) (Fig. 33C,D)

Embolus membranous, flexible at its distal portion and with welldeveloped PrsP 
RTA straight at the tip and RTAvbr truncated; Pcym obtuse

(Fig. 29C,D); dorsal leg projections acute (Fig. 29A)

RTA curved; RTAvbr absent; Pcym acute and curved (Fig. 9C,

D); femur I strikingly enlarged, bigger than femur II (Fig. 9A)

S. armata

11 Tibiae I with modified lamellar setae (Fig. 11A); RTA bifid and acute; embolus long, coiled at its distal portion and resting on the apical portion of the tegulum (Fig. 11C,D) S. barbipes

Tibiae I without modified setae; RTA single tipped or with discrete RTAvbr

12 RTAvbr present; cymbium short, thick and rounded (Fig. 26C,D) S. fissifrons

RTAvbr absent; RTA square-ended; cymbium oval-shaped;

Pcym hyaline (Fig. 48C,D) S. squalida sp. nov.

13 Prosoma, opisthosoma and legs covered by hyaline and thick bacillar setae; AME spherical (Fig. 17A,B)

Prosoma, opisthosoma and legs covered by long spiniform setae; AME elliptical and perpendicularly disposed (Fig. $40 \mathrm{~A}, \mathrm{~B})$ S. palliolata

14 Palpi well-developed, with cymbium bigger than chelicerae (Figs 17B, 46B); embolus filiform, long, emerging from tegulum at six o'clock and encircling it; RTA strong, dark and densely sclerotized (Figs 7C, 46C)

Cymbium smaller than chelicerae (Figs 31B, 44B); embolus short and laminar, emerging from tegulum in a different position; RTA not like the above (Figs 31C,D, 44C,D)

15 Prosoma yellowish-orange with a central and a lateral pair of darker longitudinal bands (Fig. 17A); RTA strongly curved towards the tegulum; cymbium and tegulum rounded (Fig. 17C,D) S. cambridgei

Prosoma without longitudinal bands; RTA slightly curved (almost straight) or sinuous; cymbium and tegulum longer than wide, oval 16

16 Bacillar setae predominantly brownish and long; body covered in sand, rock fragments and other soil particles (Fig. 7A,B); retro lateral margin of cymbium indented, forming a discrete Pcym; RTA almost straight; cephalic area strongly narrowed (Fig. 7C,D) S. arenata sp. nov.

Bacillar setae whitish and short (Fig. 46A,B); retro lateral margin of cymbium sinuous, following the RTA's curvature; Pcym absent (Fig. 46D) S. spiralis $\mathrm{sp}$. nov.

17 Embolus emerging from tegulum at seven o'clock, PrsP welldeveloped (Fig. 31C); RTA distally curved (retro laterally and ventrally towards the tegulum) (Fig. 31D); small individuals (body length not exceeding $4.40 \mathrm{~mm}$ ); first pair of legs remarkably stouter and longer than the rest, resembling the general appearance of a palpimanid spider (Fig. 31A) S. longimana

Embolus emerging at nine o'clock but hidden behind the tegulum, pointing distally at 12 o'clock (Fig. 44C); cymbium as wide as long; RTA stout and narrowed at dorsal extremity (Fig. 44C,D); tegulum membranous and hyaline; legs I and II subequal in length (Fig. 44A)

S. similis sp. nov. 


\section{Females}

1 Prosoma dorsoventrally depressed; cephalic prominence present; clypeus high (five times the diameter of the AME or more) (Figs 2B, 36B, 37B); opisthosoma obovate with setae clustered on the posterior region (Fig. 37A), or pentagonal without clusters (Fig. 19A)

Cephalic prominence absent (Figs 25B, 41B); opisthosoma trapezoid (Fig. 32A) or obovate without setae clusters (Fig. 43A); atrium depressed

2 Dark body colouration, predominantly brownish or black (Figs 2A, 37A)

Light body colouration, predominantly pale-yellow or greyish (Figs 19A, 36A)

$3 \quad$ CO disposed vertically (Fig. 2E); smooth aspect (weaklydeveloped setae sockets on legs and dorsum); body colouration predominantly brown, dark-yellow or greyish (Fig. 2A)

CO disposed horizontally (Fig. 37C), rugose/spiky appearance (well-developed setae sockets on legs and dorsum); body colouration predominantly dark-brown or black (Fig. 37A)

Prosoma as wide as long; cephalic prominence weakly-developed; projections on ALE absent (Fig. 19B); opisthosoma pentagonal without setae clusters (Fig. 19A)

Prosoma longer than wide; cephalic prominence well-developed; ocular projections on ALE present (Fig. 36B); opisthosoma obovate with posterior setae clusters; small sized females (body length not exceeding $8.20 \mathrm{~mm}$ ) (Fig. 36A) S. nana sp. nov.

Opisthosoma obovate (Fig. 16A); CO hidden by folds of the epigynal plate (Fig. 41C)

Prosoma, opisthosoma and legs with long, needle-shaped setae (Figs 10B, 23A)

Prosoma, opisthosoma and legs with short and hyaline setae

(Fig. 25B)

7 Posterior, lateral and anterior folds of epigynal plate enlarged and delimiting an elliptical atrium (Fig. 23C); femoral macrosetae absent

Atrium "incomplete", formed by the enlargement of posterior and lateral folds of the epigynal plate (Fig. 10C); triad of macrosetae on femora I present (Fig. 10A)

9 Spinnerets and anal region projected posteriorly (Fig. 14A); patellar and tibial projections (dorsal surface) of legs I and II discrete; $\mathrm{CO}$ slit-shaped and positioned on the sides of the epigynal plate (Fig. 14C); projections on ALE directed vertically (Fig. 14B)

Spinnerets and anal region not projected posteriorly; patellar and tibial projections (dorsal surface) of legs I and II welldeveloped and acute (Fig. 22A); CO wide, expanded horizontally (Fig. 22C); projections on ALE directed forward (Fig. 22A) 
$11 \mathrm{CO}$ far-between each other and C-shaped (Fig. 8C); median septum absent; anterior chambers enlarged, bigger than the rest of the spermathecae (Fig. 8D) S. armata

$\mathrm{CO}$ close to each other, separated by a median septum (Fig. $32 \mathrm{C}$ ); anterior chambers reduced, smaller than the rest of the spermathecae (Fig. 32D) S. monulfi

12 Body colouration predominantly dark-brown; rough surfaced tegument with irregular sized setiferous tubercles (Fig. 28B); CO slit-shaped S. lata

Body colouration predominantly light-brown, reddish brown or yellowish (Figs 25A, 47A); smooth surfaced tegument with discrete setiferous tubercles (Figs 25B, 48B)

13 Atrium elliptical and complete (anteriorly and laterally delimited by the folds of the epigynal plate) (Fig. 25C); anterior chambers spherical (Fig. 25D) S. fissifrons

Atrium "incomplete", not elliptical (Fig. 47C); anterior chambers irregularly globular (Fig. 4D)

14 CO disposed horizontally (Fig. 47C); atrium reduced; anterior chambers lung-shaped (Fig. 47D) S. squalida sp. nov.

$\mathrm{CO}$ disposed perpendicularly; atrium caliciform, well-developed and wider than long (Fig. 4C); anterior chambers lobed (Fig. 4D) S. angulata

15 Copulatory ducts membranous, hyaline and coiled (Figs 16D, 45D) 16

Copulatory ducts sclerotized (Figs 6D, 41D, 43D) 17

16 Body colouration predominantly orange with a pair of darker longitudinal bands on the median region of prosoma (running from the carapace slope until the posterior eye row) (Fig. 16A); a second pair is observed on the sides of carapace (placed close to the border of the prosoma and limited to the thoracic portion); whitish plumose setae on MOQ area (Fig. 16B); atrium "incomplete" (Fig. 16C); copulatory ducts dorsoventrally coiled (Fig. 16D) S. cambridgei

Body colouration predominantly dark-brown, without lines, bands or marks (Fig.45A); whitish cephalic setae absent; atrium complete, anteriorly delimited by the folds of the epigynal plate (Fig. 45C); copulatory ducts coiled anteroposteriorly in relation to the body axis (Fig. 45D) S. spiralis sp. nov.

17 CO C-shaped and apart from each other (atrium "incomplete") (Fig. 43C); copulatory ducts short (Fig. 43D); femora I with a single stout and sclerotized macrosetae each; large longitudinal and dark stain on the median portion of prosoma present (Fig. 43A) S. similis sp. nov.

Folds of the epigynal plate well-developed, connected anteriorly and laterally over the $\mathrm{CO}$ (atrium complete); macrosetae on femora I absent or, if present, in a shape of a pair of hyaline and flexible hairs; stain on prosoma absent or, if present, dual and short (only on the thoracic portion)

18 Folds forming the atrium are heavily sclerotized (Fig. 41C); muscular sigilla on the dorsum of the opisthosoma welldeveloped (Fig. 41A); femoral macrosetae absent S. rufiventris

Folds forming the atrium are thin and hyaline (Fig.6C); presence of a pair of hyaline and flexible macrosetae on the prolateral surface of femur I (Fig. 6A); body entirely covered by grains of sand, rock fragments and other soil particles (Fig. 6A) S. arenata sp. nov. 


\section{Stephanopis altifrons O. Pickard-Cambridge, 1869}

\section{Figs 1-3}

Stephanopis altifrons O. Pickard-Cambridge, 1869: 61, pl. 5, figs 33-39.--L. Koch, 1874: 495, pl. 38, fig. 1.-Simon, 1895: 1054, fig. 1091.

Stephanopis monticola Bradley, 1871: 234 (holotype, subadult female from Tia, New South Wales, Australia, OUMNH 619, examined). New synonym.

Stephanopis depressa Bradley, 1871: 236 (holotype, adult female, Cape York, Queensland, Australia, OUMNH 555, examined). New synonym.

Stephanopis elongata Bradley, 1871: 236 (syntypes, 1 adult male and 1 juvenile, OUMNH 551, examined). New synonym.

Stephanopis scabra L. Koch, 1874: 505, pl. 38, figs 5-6

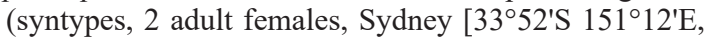
New South Wales, Australia], ZMB 3411, examined). New synonym.

Stephanopis aspera Rainbow, 1893: 471, pl. 22, figs 1-7 (cotype, adult female, Wombeyan Karst Conservation Reserve [34¹8'S $149^{\circ} 57^{\prime} \mathrm{E}$, New South Wales, Australia], AMS KS.6681, examined). New synonym.

Type material examined. Holotype + , OUMNH 118, South Australia [no other label data], pinned in the dry collection (only photographs examined).

Other material examined. Queensland: QM S104666, 1, Cairns

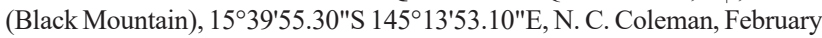
1972; QM S94020, 1, Mount Molloy, 16²0'27.71"S 145¹9'43.92"E, F. Little, September 1969; QM S94022, 1ㅇ, Shiptons Flat, 1544'20.14"S $145^{\circ} 13^{\prime} 32.81$ "E, M. Roberts, 1975; AMS KS.122150, 1ㅇ, Mount Carbine, $16^{\circ} 27^{\prime} 16^{\prime \prime S} 16^{\circ} 27^{\prime} 16^{\prime \prime E}$, T. W. Gamble, 1 August 1945; AMS KS.108650, 1 male and 1 , Kuranda, $16^{\circ} 49^{\prime} \mathrm{S} 145^{\circ} 38^{\prime} \mathrm{E}$, N. C. Coleman, 17 August 1969; AMS KS.108704, 1우, ibid., 1 January 1978; AMS KS.108665, 3 우, Kuranda, $16^{\circ} 49^{\prime} \mathrm{S} 145^{\circ} 37^{\prime} 60 \mathrm{E}, \mathrm{N}$. C. Coleman, 19 July 1976; AMS KS.108740, $10^{\wedge}$, Cairns, $16^{\circ} 55^{\prime} \mathrm{S} 145^{\circ} 46^{\prime} \mathrm{E}, \mathrm{N}$. C. Coleman, 1968; AMS KS.108654, 1 을 Mareeba, $17^{\circ} \mathrm{S} 145^{\circ} 26^{\prime} \mathrm{E}, \mathrm{R}$. Mascord, 11 May 1975; AMS KS.81292, 1 으, Edmonton, $17^{\circ} 01^{\prime} \mathrm{S} 145^{\circ} 45^{\prime} \mathrm{E}, \mathrm{N}$. C. Coleman, 5 October 1969; AMS KS.10872, 1ㅇ, 4 January 1970; QM S110052, 1웅 Forty Scrub NP, $18^{\circ} 5^{\prime} 21.53^{\prime \prime S} 144^{\circ} 51^{\prime} 43.63^{\prime \prime E}$, R. Raven \& V. Davies, 10-14 April 1978; AMS KS.81291, 1을 Edmonton, $17^{\circ} 01^{\prime} \mathrm{S} 145^{\circ} 45^{\prime} \mathrm{E}$, N. C. Coleman, 3 February 1970; AMS KS.108648, 1q, Gordonvale, $17^{\circ} 06^{\prime} \mathrm{S} 145^{\circ} 47^{\prime} \mathrm{E}, \mathrm{N}$. C. Coleman, 13 June 1969; AMS KS.109385, $10^{\Uparrow}$, Herberton, $17^{\circ} 23^{\prime} \mathrm{S} 145^{\circ} 23^{\prime} \mathrm{E}$, J. G. Brooks, 1951; QM S104668, $10^{\top}$, 1 \% Ravenshoe, $17^{\circ} 36^{\prime} 33.02^{\prime \prime S} 145^{\circ} 29^{\prime} 0.99^{\prime \prime E}$, P. Filewood, 15 July 1976; QM

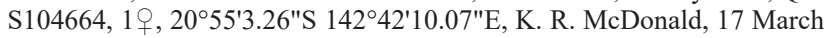

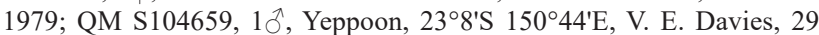
November 1973; AMS KS.110431, 1 \% , Eurimbula, 241'ㅇ $151^{\circ} 50^{\prime} \mathrm{E}, \mathrm{M}$. R. Gray \& C. Horseman, March 1975; QM S104652, 1ㅇ, 1 ऽ, Kroombit

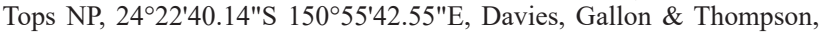
10-18 December 1983; QM S104661, 1ㅇ, Kroombit Tops National Park, 242' $40.14 "$ S $150^{\circ} 55^{\prime} 42.55^{\prime \prime}$ E, G. Monteith \& G. Thompson, 9-19 December 1983; AMS KS.51697-698, 1 ㅇ, 1ð̄, Frazer Island, 2533'S $152^{\circ} 59^{\prime}$ E, A.N.U., 1 February 1971; AMS KS.128900, 1옹, Brisbane, $27^{\circ} 23^{\prime} \mathrm{S} 153^{\circ} 01^{\prime} \mathrm{E}$, [no other data]; AMS KS.81294, 1 우, Moffat Beach, $26^{\circ} 48^{\prime}$ S $153^{\circ} 08^{\prime} E$, C. Chadwick, 29 December 1966. New South Wales: AMS KS.126051, 1 웅 Theresa Creek, $28^{\circ} 49^{\prime} 04^{\prime \prime S} 152^{\circ} 48^{\prime} 48^{\prime \prime E}$, G. Smith, 1 May 2016; AMS KS.65780, 19, Irishman State Forest, 30³3'43"S $152^{\circ} 42^{\prime} 12 " \mathrm{E}$, G. Milledge \& H. Smith, 25 November 1999; AMS KS.124778, 1 , , Oxley Wild Rivers NP, 3044'31"S 15200'58"E, D. Bray, 5 November 2015; AMS KS.124274, 1 ㅇ, 31 ${ }^{\circ} 02^{\prime} 38^{\prime \prime S ~} 152^{\circ} 13^{\prime} 17^{\prime \prime E}$. H. M. Smith, 14 November 2015; AMS KS.124617, 1 ô, ibid.; AMS KS.54012, 1 으, Fitzroy Tableland, $31^{\circ} 05^{\prime} \mathrm{S} 151^{\circ} 50^{\prime} \mathrm{E}, \mathrm{E}$. Tasker, 25 October 1998 ; AMS KS.97224, $1{ }^{\lambda}$, Lansdowne, $31^{\circ} 42^{\prime} \mathrm{S} 152^{\circ} 29^{\prime} \mathrm{E}$, G. Williams, 18 February

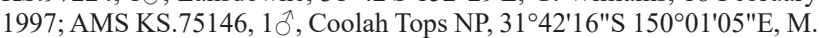
Gray, G. Milledge \& H. Smith, 8 November 2001; AMS KS.75135, 1웅 $31^{\circ} 44^{\prime} 06^{\prime \prime} \mathrm{S} 150^{\circ} 00^{\prime} 05^{\prime \prime} \mathrm{E}$; AMS KS.97217, 1 \%, Yarrat, $31^{\circ} 43^{\prime} \mathrm{S} 152^{\circ} 26^{\prime} \mathrm{E}$, 1997; AMS KS.104226, $1{ }^{\circ}$, Woko NP, 31 ${ }^{\circ} 47^{\prime} 59^{\prime \prime S} 151^{\circ} 47^{\prime} 48^{\prime \prime}$ E, H. Smith, 31 May 2007; AMS KS.64183, 1 \% , Carrowbrook, $32^{\circ} 17^{\prime} \mathrm{S} 151^{\circ} 18^{\prime} \mathrm{E}$,
J. Noble, 25 January 1999; AMS KS.32209, 19, Myall Lakes Natural Park, 32 $26^{\circ} \mathrm{S} 152^{\circ} 24^{\prime}$ E, D. Bickel \& G. Cassis, 22 November 1985;

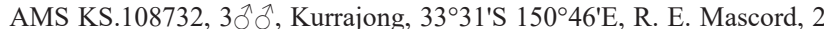
August 1965; AMS KS.108656, $1^{\prime}$, 1 웅 $33^{\circ} 33^{\prime} \mathrm{S} 150^{\circ} 40^{\prime} \mathrm{E}, 15$ October 1966; AMS KS.108736, $10^{\jmath}$, Sydney (Pittwater), $33^{\circ} 38^{\prime} \mathrm{S} 151^{\circ} 18^{\prime} \mathrm{E}, \mathrm{R}$. E. Mascord, 12 March 1966; AMS KS.54260, $1{ }^{\top}$, Beecroft, $33^{\circ} 45^{\prime} \mathrm{S}$ $151^{\circ} 04^{\prime}$ E, J. Noble, 5 March 1998; AMS KS.53362, 1 , , ibid., 5 November 1992; AMS KS.53363, 1ㅇ, ibid., 7 November 1993; AMS KS.53375, 1 , ibid., 6 November 1992; AMS KS.53376, 10, ibid., 6 November 1993; AMS KS.53377, 10, ibid., 15 March 1993; AMS KS.53378, 10, ibid., 6 November 1993; AMS KS.53379, 10, ibid., 6 November 1992; AMS

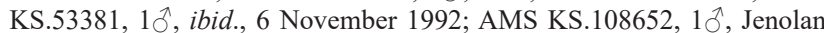
Caves, $33^{\circ} 49^{\prime} \mathrm{S} 150^{\circ} 02^{\prime} \mathrm{E}$, J. Child, [no collection date]; AMS KS.108658,

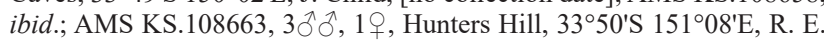

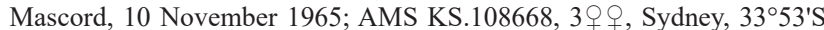

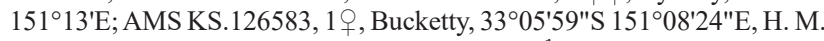
Smith, 19 November 2016; AMS KS.94555, 10, Glenwood, 33¹6'56"S $150^{\circ} 07^{\prime} 04 " \mathrm{E}, \mathrm{G}$. Milledge, J. Tarnawski \& M. Beatson, 21 February 2006; AMS KS.81286, 2 우, East Kurrajong, $33^{\circ} 31^{\prime}$ S $150^{\circ} 46^{\prime} E$, R. E. Mascord,

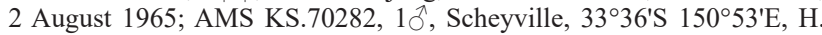

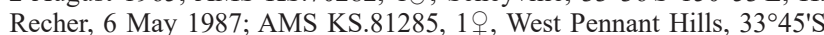
$151^{\circ} 02^{\prime}$ E, R. E. Mascord, 29 April 1967; AMS KS.70844, 1 \% , Turramurra,

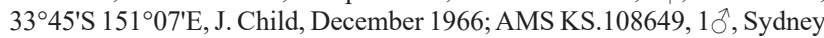

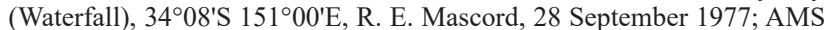
KS.108667, 1 을 Mittagong, $34^{\circ} 27^{\prime}$ S $150^{\circ} 27^{\prime}$ E, P. Rainbird, 12 January 1957; NHMUK 1850.117, 1ㅇ, 34²2'S $138^{\circ} 35^{\prime} \mathrm{E}$; AMS KS.108734, 1 우, Minamurra Falls, $34^{\circ} 38^{\prime} \mathrm{S} 150^{\circ} 44^{\prime} \mathrm{E}, \mathrm{R}$. E. Mascord, 01 February 1965; AMS

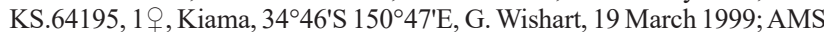
KS.108647, $10^{\wedge}, 1$ 으, Berry, $34^{\circ} 47^{\prime} S$ 150 $42^{\prime}$ E, R. E. Mascord, 28 August 1966; AMS KS.129617, 19, Namadgi NP, 35³2'53.94"S 149²'4.44"E, R. Raven \& E. Amsters, 4 December 2018; AMS KS.119717, 19, Bournda NP, 3644'17"S 14958'52"E, G. Milledge \& H. Smith, 25 December 2012. Tasmania: AMS KS.129616, 2 우오, Punch Bowl, 41 ${ }^{\circ} 27^{\prime} \mathrm{S} 147^{\circ} 10^{\prime} \mathrm{E}, \mathrm{V}$. V. Hickman, 17 January 1925; AMS KS.81283, 1우, Mount Wellington, 425' $147^{\circ} 14^{\prime} \mathrm{E}$, December 1903.

Diagnosis. Both males and females of $S$. altifrons are similar to those of $S$. carcinoides sp. nov. and especially $S$. nigra, in possessing a remarkably elevated cephalic prominence, a high clypeus and a flattened habitus (Figs $2 \mathrm{~B}$ and $3 \mathrm{~B}$ ). However, S. altifrons can be distinguished from these species by the shape, size and position of its genitalic features: Males have a long, approximately equal-sized, and retro laterally pointed RTA and RTAvbr; pointed cymbium and curved Pcym emerging at the height of apophyses tips (Fig. 3C-F). Females are easily differentiated from those of $S$. nigra and $S$. carcinoides sp. nov. by their hook-shaped $\mathrm{CO}$ directed vertically (Fig. 2C and E), asymmetrical and wide anterior chambers, glandular-heads laterally positioned and longer spermathecae (Fig. 2D and F).

Description. Female (AMS KS.108663): Anterior eye row strongly recurved and posterior row procurved (Fig. 2A and B), prosoma and legs predominantly dark-brown on their dorsal surfaces and pale-yellow on the sides (Fig. 2A). Femur I with a stout tubercle on its ventral surface; tibiae I and II ventrally armed with four pairs of macrosetae (Fig. 2A). Chelicerae pale-yellow with proximal brown spots; clypeus high and dark-brown; ocular rings pale yellow (Fig. 2B). Opisthosoma obovate, mostly dark-brown but with a significant portion having a whitish pigmentation; anterior surface strongly concave; posterior region bears many setiferous tubercles, each one sometimes with three or more gathered setae (Fig. 2A).

Measurements: eye diameters and interdistances: AME 0.07, ALE 0.17, PME 0.12, PLE 0.12, AME-AME 0.16, AME-ALE 0.10, PME-PME 0.18, PME-PLE 0.11, MOQ length 0.62, width 0.50; leg formula: 1-2-3-4: leg I-femur 3.94 / patella 2.20 / tibia 2.99 / metatarsus 2.03 / tarsus 1.11 / 

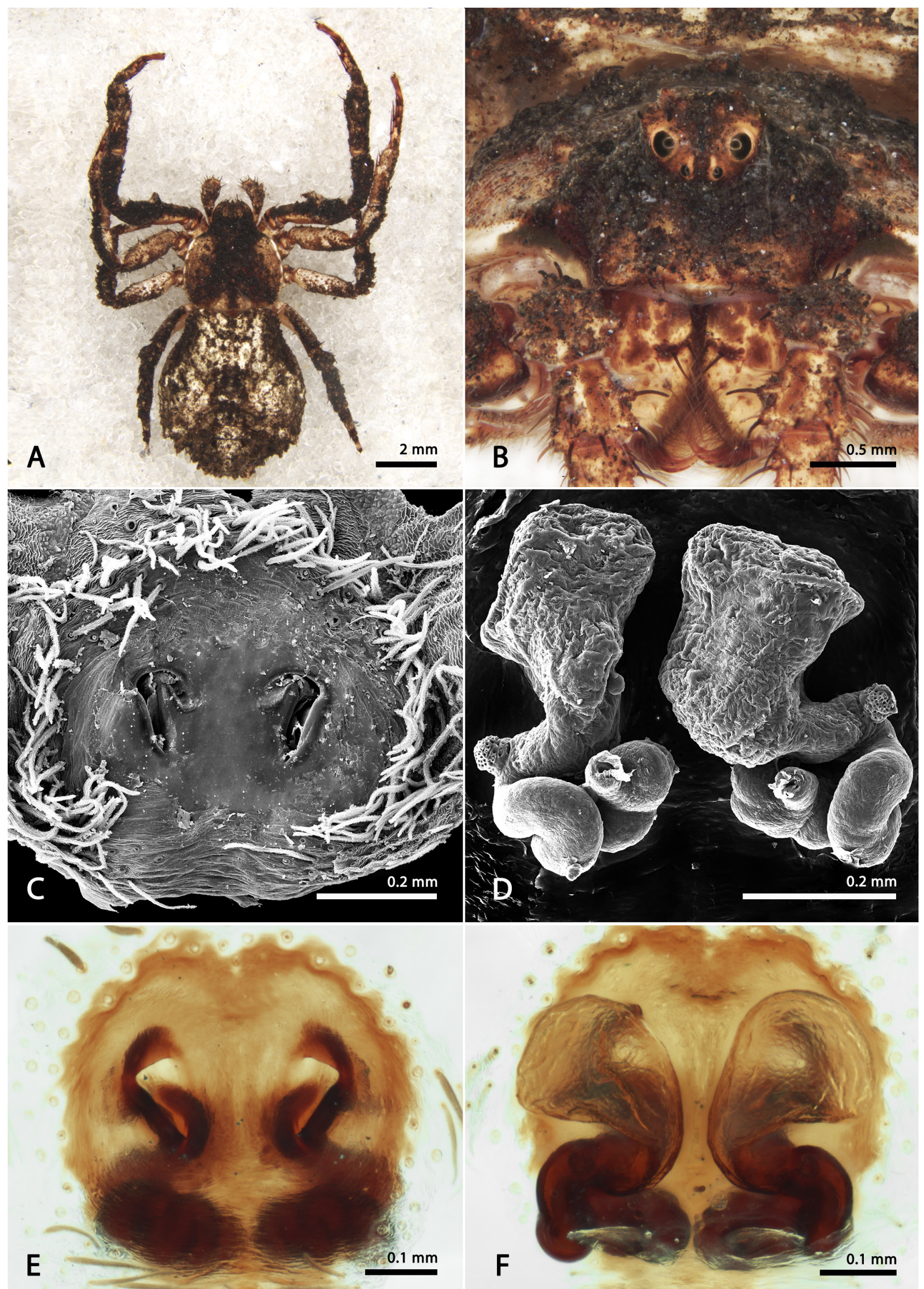

Figure 2. Stephanopis altifrons O. Pickard-Cambridge, 1869, female ( $A-D$, AMS KS.108663), ( $E-F, \mathrm{KS} .108647)$. (A) dorsal habitus; $(B)$ front; $(C)$ epigynal plate, ventral view; $(D)$ epigynal plate/spermathecae. In $(C), \mathrm{CO}$ (copulatory openings). 


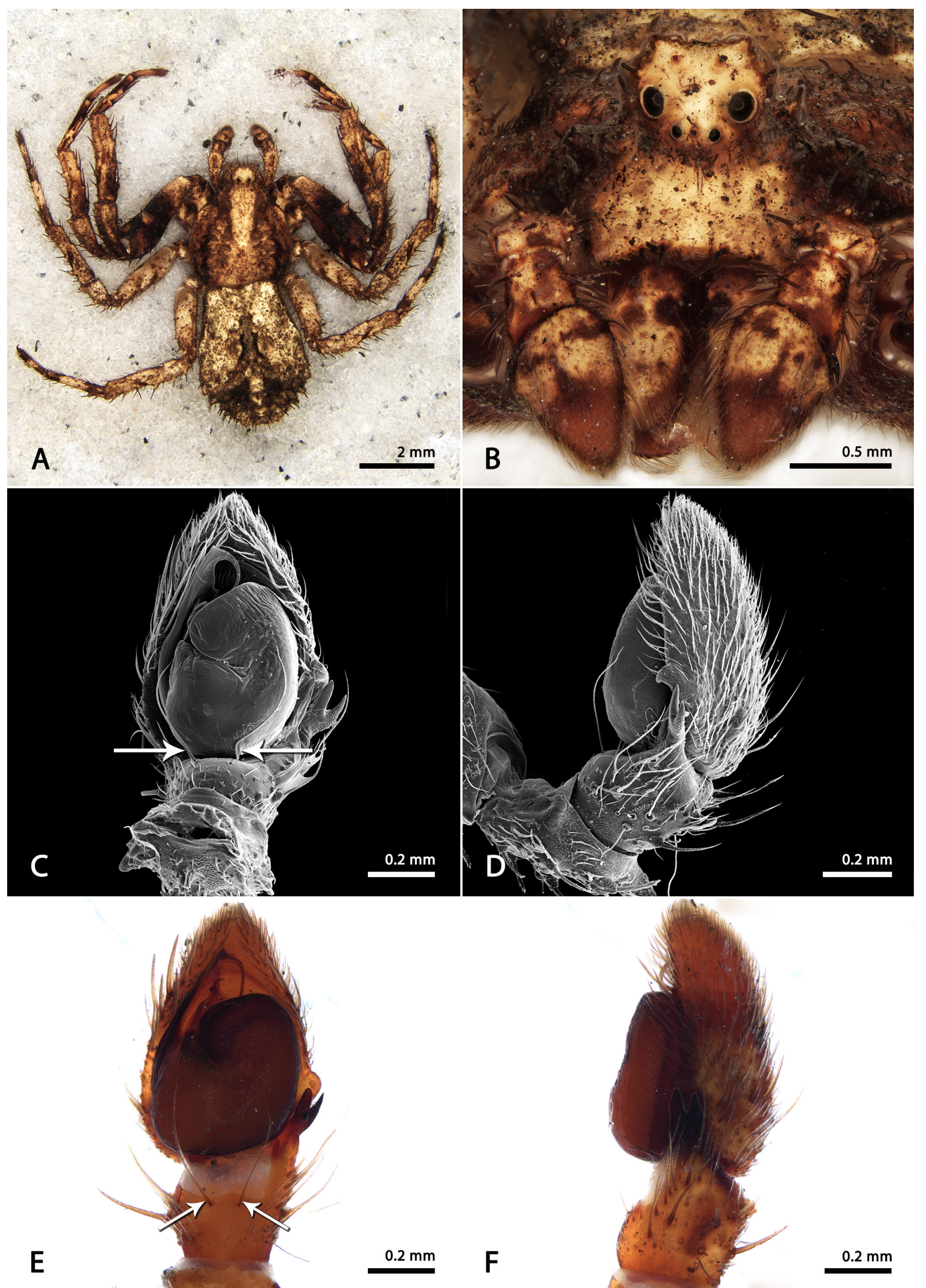

Figure 3. Stephanopis altifrons O. Pickard-Cambridge, 1869, male ( $A-B$ and $E-F$ KS.108647), (C-D, KS.108663). (A) dorsal habitus; $(B)$ front; $(C$ and $E$ ) left palp, ventral view; $(D$ and $F$ ) left palp, retro lateral view. In $(C)$, the diagnostic pair of ventral filamentous setae are highlighted in red; Prsp (pars pendula), RTAvbr (retrolateral tibial apophysis'ventral branch), RTA (retrolateral tibial apophysis). In (D), Pcym (paracymbium). 
total 12.27; II-3.40/ 1.93/2.59/ 1.92/1.04/ 10.88; III-3.07/ $1.42 / 2.48 / 2.33 / 1.14 / 10.44$; IV-2.46/ 1.30/ 2.35/ 2.47/ $1.04 / 9.62$. Total body length 9.95 ; prosoma length 4.88 , width 3.84; opisthosoma length 5.07; clypeus height 0.90 ; sternum length 2.18 , width 1.60 ; gnathocoxae length 1.05 , width 0.47 ; labium length 0.66 , width 0.69 .

Male (AMS KS.108647): Eye arrangement as in female; but prosoma with inverse colouration pattern, being lighter in its median cephalic and thoracic area and dark-brown on edges (Fig. 3A). Anterior femora (I and II) darker than any other leg segment; front pale yellow with a brown curved stripe under the anterior eye row; chelicerae predominantly pale-yellow with some brown spots (Fig. 3B). Opisthosoma dark-brown on its posterior and middle portions but whitish on most part on its dorsal surface. Other somatic features as in female.

Measurements: eye diameters and interdistances: AME 0.06, ALE 0.16, PME 0.10, PLE 0.12, AME-AME 0.10, AME-ALE 0.07, PME-PME 0.18, PME-PLE 0.05, MOQ length 0.46 , width 0.40 ; leg formula: 1-2-3-4: leg I-femur 2.64 / patella 1.41 / tibia 2.24 / metatarsus 1.73 / tarsus $0.90 /$ total 8.92; II $-2.46 / 1.30 / 1.86 / 1.56 / 0.89 / 8.07$; III-2.02/ $0.86 / 1.71 / 1.67 / 0.80 / 7.06$; IV $-2.00 / 0.79 / 1.61 / 1.76 /$ $0.77 / 6.93$. Total body length 6.42 ; prosoma length 3.03 , width 2.47; opisthosoma length 3.39 ; clypeus height 0.50 ; sternum length 1.35 , width 1.22 ; gnathocoxae length 0.71 , width 0.32 ; labium length 0.38 , width 0.40 .

Distribution. New South Wales, Queensland and Tasmania, Australia (Fig. 13).

Variation. Preserved specimens are mostly brown. However, live specimens are colored in a wide spectrum of shades of green and orange, depending on the substrate where the spider is found (Fig. 1A-D). According to Gawryszewski (2014) S. altifrons (senior synonym of $S$. scabra) match the colouration of the bark they are sitting on by having debris attached to their dorsal cuticle. These debris are retained on the spider's body due to their modified branched setae.

\section{Stephanopis angulata Rainbow, 1899}

\section{Figs 4-5}

Stephanopis angulata Rainbow, 1899: 144, fig. 3.

Type material examined. Holotype $q$, AMS KS.6680, Fly River, Papua New Guinea, 0800'S 142³0'E; MCZ 133894, 10̃, Wau, PNG, 7²0'13.69"S 14642'57.37"E, H. Levi, Y. Lubin \& M. Robinson, 7 March 1979.

Other material examined. QM S104672, 19, Wau, PNG, 7²0'13.69"S 14642'57.37"E, N.C. Coleman, 7 September 1971; MCZ 134025, 1ðَ, Gazelle Peninsula, East New Britain, 4³8'23.00"S 151 59 '5.00"E, S. Smith, 2 May 1979; MCZ 133892, 1ठ̄, 1ㅇ, same data except 2 May 1980.
Diagnosis. Females and males of $S$. angulata resemble those of S. fissifrons by their trapezoid opisthosoma, prosoma with lateral dark marks and projections on the dorsal surface of their patellae and tibiae I including a proximal setiferous tubercle on the latter (Fig. 4A). However, females of $S$. angulata can be distinguished by their narrower cephalic area, longer than wide prosoma, straight anterior border of the opisthosoma, epigynal plate with caliciform and wider than long atrium (Fig. 4C); lobed anterior chambers, and glandular-heads oriented medially rather than laterally (Fig. 4D). Males can be recognized by their longer than wide prosoma, distal edge of tegulum sinuous, well-developed PrsP, vestigial Pcym and short and wide RTA (Fig. 5C and D); the RTAvrb is also wide and points towards the RTA, forming a "crab claw" like structure with the latter (Fig. 5D).

Description. Female (QM S104672): Anterior eye row strongly recurved and posterior row straight (Fig. 4A and B); prosoma and legs I and II light-brown, legs III and IV predominantly dark-yellow (Fig. 4A). Cephalic prominence absent and ocular projections above the ALE reduced (Fig. 4B). Femur I with seven stout setiferous tubercles on ventral and prolateral surfaces; anterior tibiae (I and II) with four ventral pairs of macrosetae (Fig. 4A). Chelicerae light-brown proximally, lightening to yellow, distally. Opisthosoma whitish-yellow, squared-ended, almost trapezoid, with a pair of rounded posterior projections (Fig. 4A). Spermathecae irregularly globular and preceded by well-developed glandular-heads and wide, lobular chambers (Fig. 4D).

Measurements: eye diameters and interdistances: AME 0.10, ALE 0.21, PME 0.14, PLE 0.14, AME-AME 0.15, AME-ALE 0.17, PME-PME 0.26, PME-PLE 0.16, MOQ length 0.46 , width 0.29 ; leg formula: $1-2-4-3$ : leg I-femur 3.67 / patella 1.88 / tibia 2.76 / metatarsus 1.85 / tarsus 0.96 / total 11.12; II-3.50/1.71/2.48/1.66/0.96/10.31; III-2.27/ $1.11 / 1.79 / 1.18 / 0.54 / 6.89 ; \mathrm{IV}-2.63 / 1.03 / 1.85 / 1.31 /$ $0.72 / 7.54$. Total body length 7.56 ; prosoma length 3.92 , width 3.54; opisthosoma length 3.64 ; clypeus height 0.24 ; sternum length 1.77 , width 1.39 ; gnathocoxae length 0.97 , width 0.45 ; labium length 0.57 , width 0.66 .

Male (MCZ 133894): Eye arrangement as in female but the ocular projections above the ALE are a little more conspicuous (Fig. 5A). Prosoma reddish-brown, legs lightbrown; prolateral surface of femora, patellae and tibiae I suffused by whitish setae (Fig. 5B). Opisthosoma light-brown and trapezoid; other somatic features as in female.

Measurements: eye diameters and interdistances: AME 0.09, ALE 0.14, PME 0.12, PLE 0.12, AME-AME 0.09, AME-ALE 0.07, PME-PME 0.17, PME-PLE 0.09, MOQ length 0.35 , width 0.31 ; leg formula: $1-2-4-3$ : leg I-femur 2.30 / patella 1.15 / tibia 1.68 / metatarsus 1.15 / tarsus 0.68 / total 6.96; II-2.04/ 1.06/ 1.49/ 0.99/0.62/ 6.20; III-1.19/ $0.63 / 0.87 / 0.56 / 0.49 / 3.74$; IV $-1.40 / 0.59 / 0.90 / 0.67 /$ $0.44 / 4.00$. Total body length 4.55 ; prosoma length 2.21 , width 2.06; opisthosoma length 2.34; clypeus height 0.20 ; sternum length 0.90 , width 0.86 ; gnathocoxae length 0.47 , width 0.26 ; labium length 0.24 , width 0.38 .

Distribution. Morobe and East New Britain, Papua New Guinea (Fig. 13). 

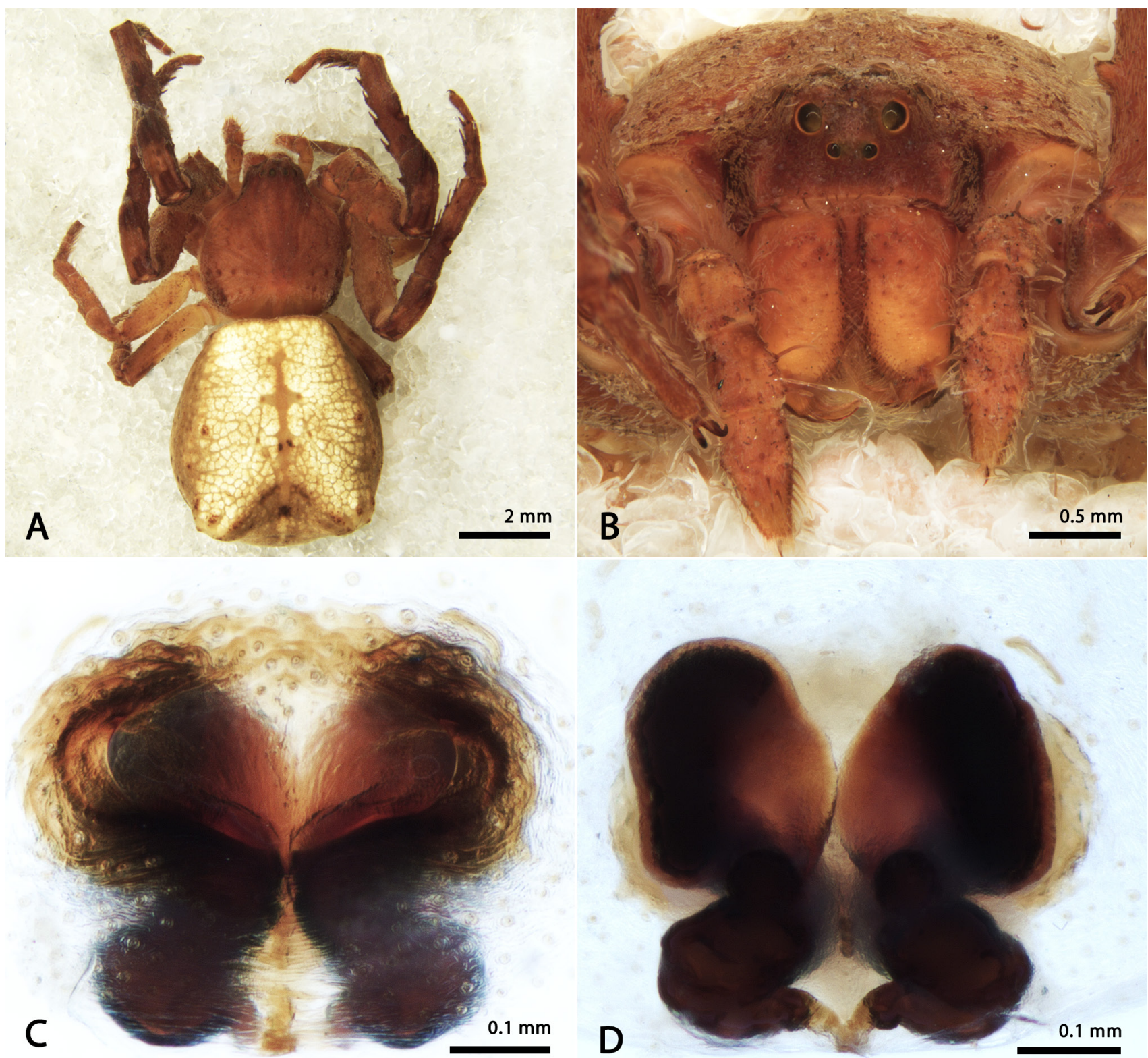

Figure 4. Stephanopis angulata Rainbow, 1899, female (QM S104672). (A) dorsal habitus; (B) front; (C) epigynal plate, ventral view; (D) epigynal plate/spermathecae.

\section{Stephanopis arenata Machado sp. nov.}

http://zoobank.org/NomenclaturalActs/308FC57E-3514-4687-804B-C623DBF5A92C

\section{Figs 6-7}

Holotype $\odot$, AMS KS.128001, Scotia Sanctuary, New South

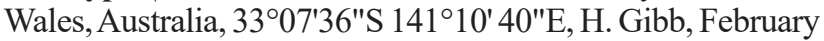
2009, (designated here). Paratypes: AMS KS.66762, $1 \hat{\jmath}$, Lower Murray-Darling Region (Warrakoo Station),

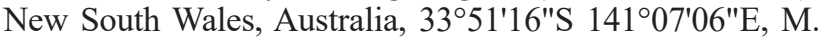
Lebreton, 12-16 October 1998; AMS KS.50784, 10, Simpson Desert (Ethabuka station), Queensland, Australia, $23^{\circ} 45^{\prime} \mathrm{S}$ 138²8'E, H. Wilson, July 1997.

Other material examined. Queensland: QM S35214, 2우, Westmar, 2754'45.98"S 149²'30.56"E, V. Davies, T. Adams \& R. Raven, 10 January 1979. Western Australia:
WAM T130261, 19, $16.5 \mathrm{~km}$ southeast of Pannawonica Fortescue River Valley, $21^{\circ} 41^{\prime} 38^{\prime \prime}$ S $116^{\circ} 28^{\prime} 24^{\prime \prime E}$, F. Bokhari, 10 September 2012; WAM T146672, 1 \% , Goldfields Survey (dune shrubland), 32 $23^{\prime} 15^{\prime \prime} \mathrm{S} 119^{\circ} 45^{\prime} 00^{\prime \prime} \mathrm{E}$.

Diagnosis. Females of S. arenata sp. nov. and S. cambridgei have a predominantly orange body colouration and the external shape of their epigynum is similar, with $\mathrm{CO}$ hidden by the lateral folds of the plate (Fig. 6A, C and D). Still, females of $S$. arenata sp. nov. can be distinguished from $S$. cambridgei by their complete atrium delimited anteriorly by the folds of the epigynal plate, and copulatory ducts sclerotized and not coiled. Males are similar to those of $S$. cambridgei due to their striped legs (Fig. 7A), single and curved RTA (Fig 7C and 7D) and the tibiae and metatarsi I bearing long and thin barbs (Fig 7A); male palp can be also distinguished by the bent/tilted cymbium and shorter 


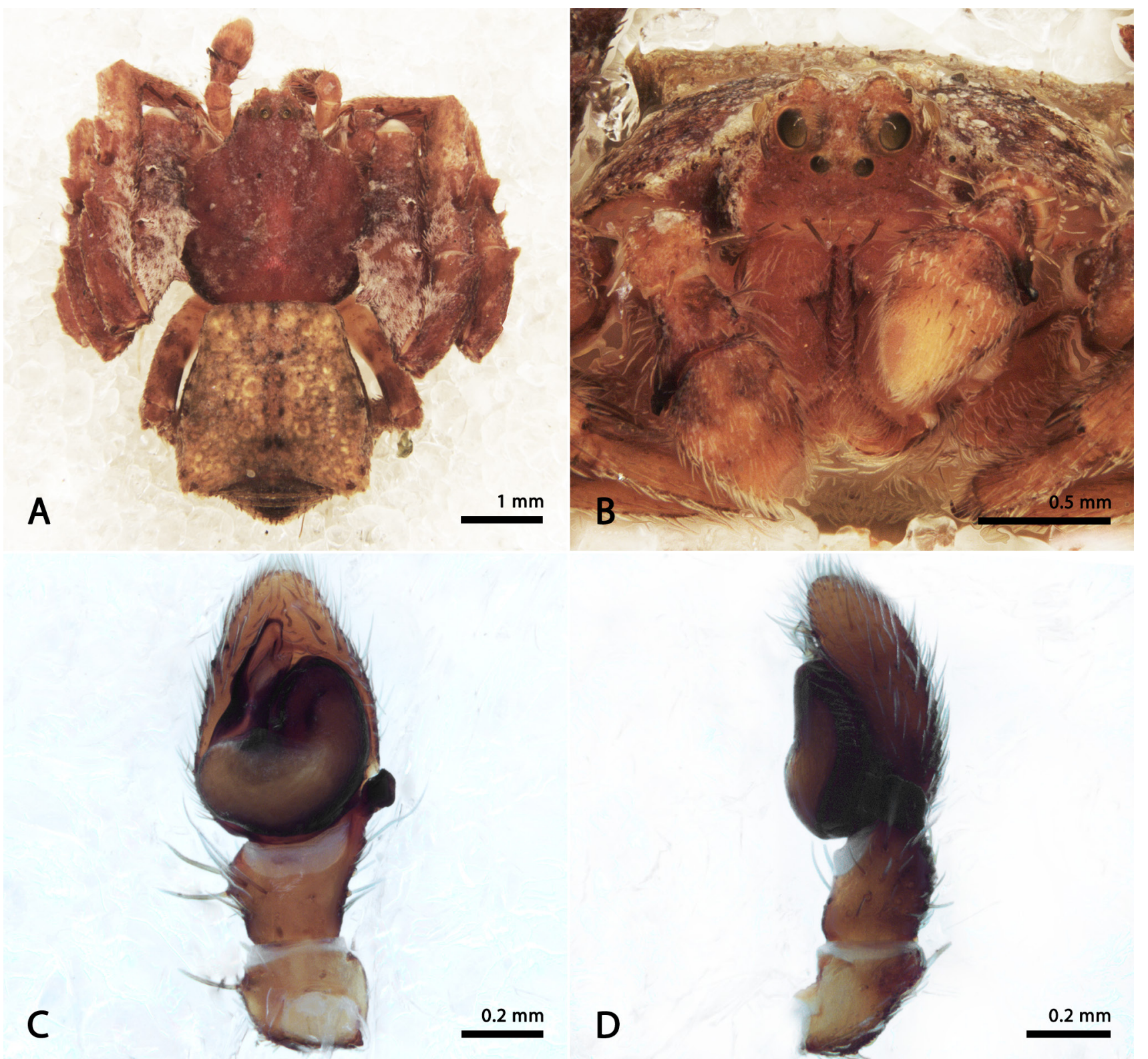

Figure 5. Stephanopis angulata Rainbow, 1899, male (MCZ 133894). (A) dorsal habitus; (B) front; (C) ventral view of the left palp; (D) left palp, retro lateral view.

embolus (Fig. 7C). Moreover, as this species occurs in desertic areas, it can be undoubtedly recognized due to the grains of sand, rock fragments and other soil particles attached to their bodies (Figs 6A and 7A).

Description. Female (AMS KS.128001): Anterior eyes arranged in a strongly recurved row and posterior eyes in straight row; cephalic area narrowed (Fig. 6A and B); body predominantly dark orange and covered in grains of sand and thick bacillar setae. Legs striped; femur I with pair of prolateral macrosetae. Opisthosoma slightly wider than long and copulatory ducts asymmetrically coiled; anterior chamber absent and glandular-heads reduced, dorsally oriented (Fig. 6D).

Measurements: eye diameters and interdistances: AME 0.06, ALE 0.12, PME 0.10, PLE 0.10, AME-AME 0.08, AME-ALE 0.04, PME-PME 0.14, PME-PLE 0.12, MOQ length 0.36 , width 0.28 ; leg formula: 1-2-4-3: leg I-femur 3.39 / patella $1.07 /$ tibia 2.20 / metatarsus 1.26 / tarsus 0.65 / total 8.57 ; II $-1.89 / 0.79 / 1.40 / 1.13 / 0.445 .65$; III-1.23/ $0.55 / 1.64 / 0.61 / 0.52 / 4.55$; IV $-1.75 / 0.62 / 1.14 / 1.11 /$ $0.63 / 5.25$. Total body length 5.97 ; prosoma length 2.59 , width 2.37; opisthosoma length 3.38; clypeus height 0.47 ; sternum length 1.16 , width 1.16 ; gnathocoxae length 0.43 , width 0.24 ; labium length 0.25 , width 0.39 .

Male (AMS KS.66762): Prosoma and opisthosoma lightorange (Fig. 7B), leg segments (except tibiae, metatarsi and tarsi I and II) yellow with dark-brown annuli (Fig. 7A); Pcym reduced, hyaline and placed at same height as tip of the RTA (Fig. 7C). Other somatic features as in female.

Measurements: eye diameters and interdistances: AME 0.07, ALE 0.18, PME 0.09, PLE 0.10, AME-AME 0.11, AME-ALE 0.05, PME-PME 0.16, PME-PLE 0.16, MOQ 


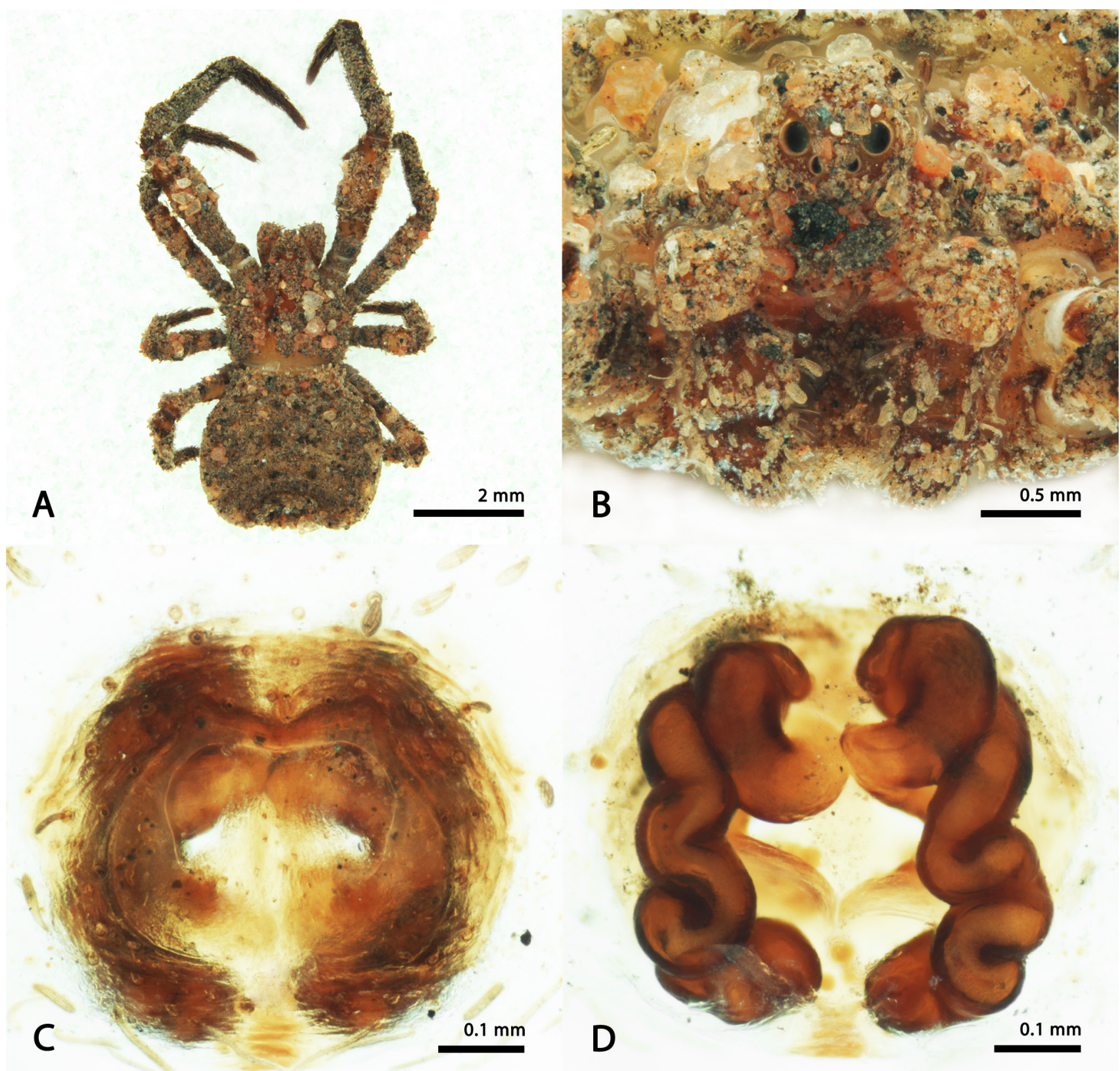

Figure 6. Stephanopis arenata sp. nov., female (KS.128001). (A) dorsal habitus; $(B)$ front; $(C)$ epigynal plate, ventral view; $(D)$ epigynal plate/spermathecae.

length 0.32 , width 0.23 ; leg formula: $1-2-4-3$ : leg I-femur 3.23 / patella 1.11 / tibia 3.26 / metatarsus 1.94 / tarsus 0.73 / total 10.27; II $-2.26 / 0.79 / 1.94 / 1.44 / 0.71 / 7.14$; III-1.45/ $0.60 / 1.05 / 0.86 / 0.57 / 4.53 ; \mathrm{IV}-2.28 / 0.68 / 1.59 / 1.48 /$ $0.67 / 6.70$. Total body length 7.14 ; prosoma length 2.63 , width 2.41; opisthosoma length 2.75; clypeus height 0.44 ; sternum length 1.14 , width 1.16 ; gnathocoxae length 0.48 , width 0.29 ; labium length 0.38 , width 0.40 .

Etymology. The specific epithet derives from the feminine Latin noun "arena", which means sand; the word "arenata" means covered with sand.

Distribution. Western Australia and New South Wales, Australia (Fig. 13).

\section{Stephanopis armata L. Koch, 1874}

Figs 8-9

Stephanopis armata L. Koch, 1874: 503, pl. 38, Fig. 4.

Type material examined. Holotype $\circ, 18^{\circ} 1^{\prime} 36.19^{\prime \prime S}$ $145^{\circ} 37^{\prime} 47.18^{\prime \prime} \mathrm{E}, \mathrm{ZSMH}$.

Other material examined. Queensland: AMS KS.128290, 1 , Brisbane (Lota Creek Park), 27²8'35.2"S 15311'07.4"E, R. Raven, April 2017; QM S110116, 1 \% , Brisbane (Fig Tree Pocket, Roedean Street), 2730'55.43"S 152 57'53.16"E, V. E. Davies, 23 June 1984; QM S62815, 1今', Burbank (Buhot Creek), 27³5'16.188"S $153^{\circ} 10^{\prime} 11.28 " E$, E. S. Volschenk, 30 April 2003; AMS KS.103218, $1 \partial^{\lambda}$, Tingalpa Creek (Buholt Creek Reserve), 27³5'27"S $153^{\circ} 10^{\prime} 19^{\prime \prime E}$, H. Smith \& G. Anderson, 17 February 2008; QM S110115, 1 ㅇ, Mount Glorious, 2742'56.63"S 1535'15.58"E, A. 


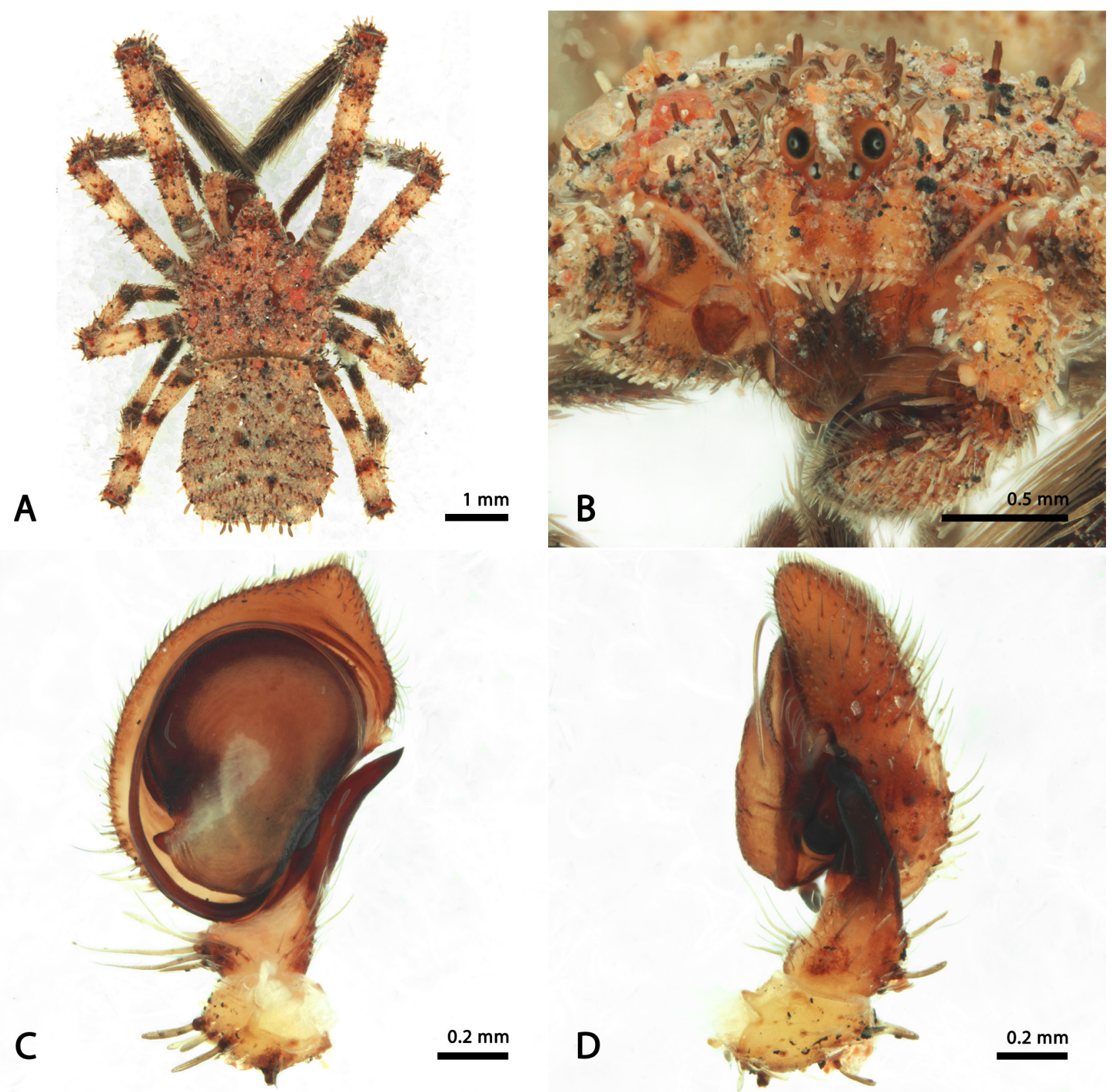

Figure 7. Stephanopis arenata sp. nov., male (KS.66762). (A) dorsal habitus; (B) front; (C) ventral view of the left palp; (D) left palp, retro lateral view.

Hiller, 20 October 1974; AMS KS.352, 1ð, Mount Dryander (north of Proserpine), $20^{\circ} 15^{\prime} \mathrm{S} 148^{\circ} 32^{\prime} \mathrm{E}, \mathrm{M}$. Gray \& C. Horseman; QM

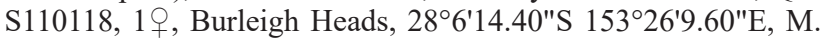
Bishop, 1-7 October 1976. New South Wales: AMS KS.138, $1 \delta^{\lambda}$, Bulburin (northweast of Bundaberg), 24 $31^{\circ} \mathrm{S} 151^{\circ} 29^{\prime} \mathrm{E}, \mathrm{M}$. Gray $\&$ C. Horseman, March 1975; AMS KS.118174, 10, Watagans NP, $33^{\circ} 02^{\prime} 17^{\prime \prime S} 151^{\circ} 22^{\prime} 27^{\prime} \mathrm{E}, \mathrm{G}$. Milledge \& H. Smith, 20 March 2012.

Diagnosis. Females of $S$. armata resemble those of $S$. monulfi by the strong anterior legs bearing robust and acute projections on the dorsal surface of their patellae and tibiae $\mathrm{I}$ and median spire on thoracic portion of prosoma (Fig. 8B). However, they can be distinguished by their reduced body size and wider anterior femora covered by dorsal and prolateral setiferous tubercles (Fig. 8A). Also, the epigynal plate of $S$. armata possesses a pair of C-shaped $\mathrm{CO}$ placed in a flattened atrium (Fig. 8C) instead of the remarkable septum seen in $S$. monulfi. In addition, the anterior chambers are wider than the spermathecae in $S$. armata (Fig. 8D). The males of $S$. armata are similar to those of $S$. bicornis and S. lata by their robust form, rough tegument and trapezoid opisthosoma (Fig. 9A), but unlike S. bicornis, S. armata do not have acute projections above the ALE (Fig. 9B), and different from $S$. lata by the leg projections on the dorsal surface of patellae and tibiae being are discrete. Also, S. armata have strikingly enlarged femora I (Fig. 9A). Males of S. armata have similar palpi to both $S$. bicornis and $S$. lata, with slight differences. The RTA of $S$. armata is curved, pointing ventrally before it becomes laterally oriented (Fig. 9C).

Description. Female (QM S110118): Anterior eye row recurved and posterior slightly recurved, almost straight (Fig. $8 \mathrm{~A}$ and $\mathrm{B}$ ); prosoma and legs brown, covered by whitish plumose setae (which are more clustered in median thoracic portion, sides of cephalic area and proximal tibiae I) (Fig. 

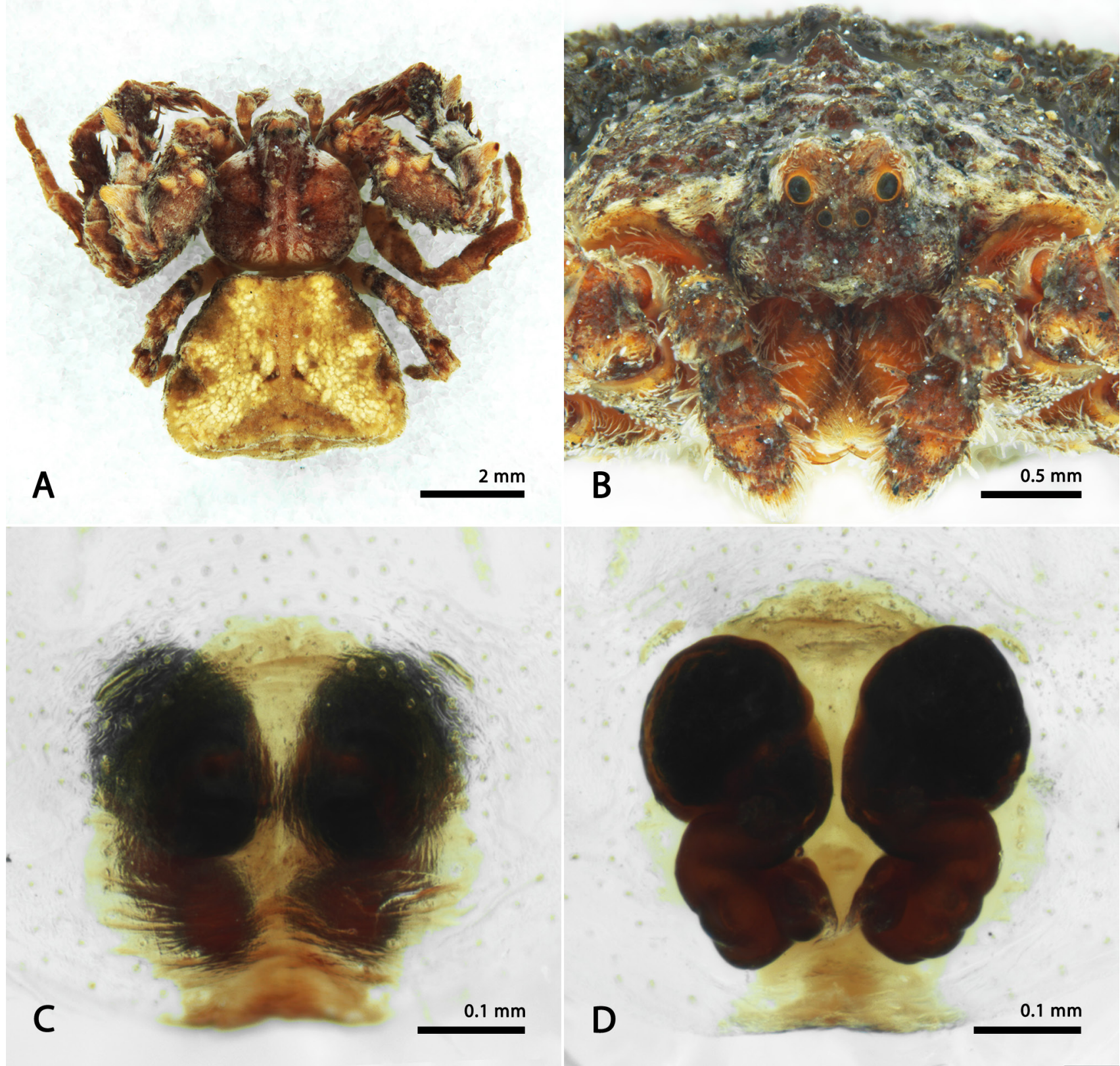

Figure 8. Stephanopis armata L. Koch, 1874, female (QM S110118). (A) dorsal habitus; (B) front; (C) epigynal plate, ventral view; (D) epigynal plate/spermathecae.

8A). Opisthosoma trapezoid and predominantly yellow with brown patches on the sides. Spermathecae small, with few and short curves, preceded by a wide and sclerotized pair of globose chambers (Fig. 8D).

Measurements: eye diameters and interdistances: AME 0.07, ALE 0.15, PME 0.10, PLE 0.09, AME-AME 0.11, AME-ALE 0.07, PME-PME 0.22, PME-PLE 0.09, MOQ length 0.35 , width 0.39 ; leg formula: 1-2-4-3: leg I-femur 3.05 / patella 1.54 / tibia 2.26 / metatarsus 1.55 / tarsus 0.83 / total 9.23; II-2.69/ 1.45/ 1.87/ 1.36/ 0.80 8.17; III-1.86/ $0.98 / 1.35 / 0.99 / 0.69 / 5.87$; IV $-2.11 / 0.90 / 1.29 / 1.07 /$ $0.61 / 5.98$. Total body length 6.93 ; prosoma length 3.23 , width 3.24; opisthosoma length 3.70 ; clypeus height 0.32 ; sternum length 1.40 , width 1.30 ; gnathocoxae length 0.73 , width 0.34 ; labium length 0.51 , width 0.60 .
Male (AMS KS.103218): Eyes position as in female (Fig 9B); prosoma brown with two parallel lines of whitish setae on the median portion going from the posterior slope until the sides of cephalic area and behind the PLE (Fig. 9A). Femora, patellae and tibiae I and II predominantly dark-brown; proximal portion of anterior femora (I and II) and entire metatarsi and tarsi I and II light-yellow; colour pattern of posterior legs (III and IV) as in the anterior ones but lighter. Opisthosoma dark-yellow with a posterior diamond-shaped brown stain (Fig. 9A).

Measurements: eye diameters and interdistances: AME 0.05, ALE 0.12, PME 0.10, PLE 0.11, AME-AME 0.09, AME-ALE 0.05, PME-PME 0.16, PME-PLE 0.08, MOQ length 0.35 , width 0.29 ; leg formula: 1-2-4-3: leg I-femur 2.00 / patella 0.95 / tibia 1.41 / metatarsus 1.09 / tarsus 0.56 / 

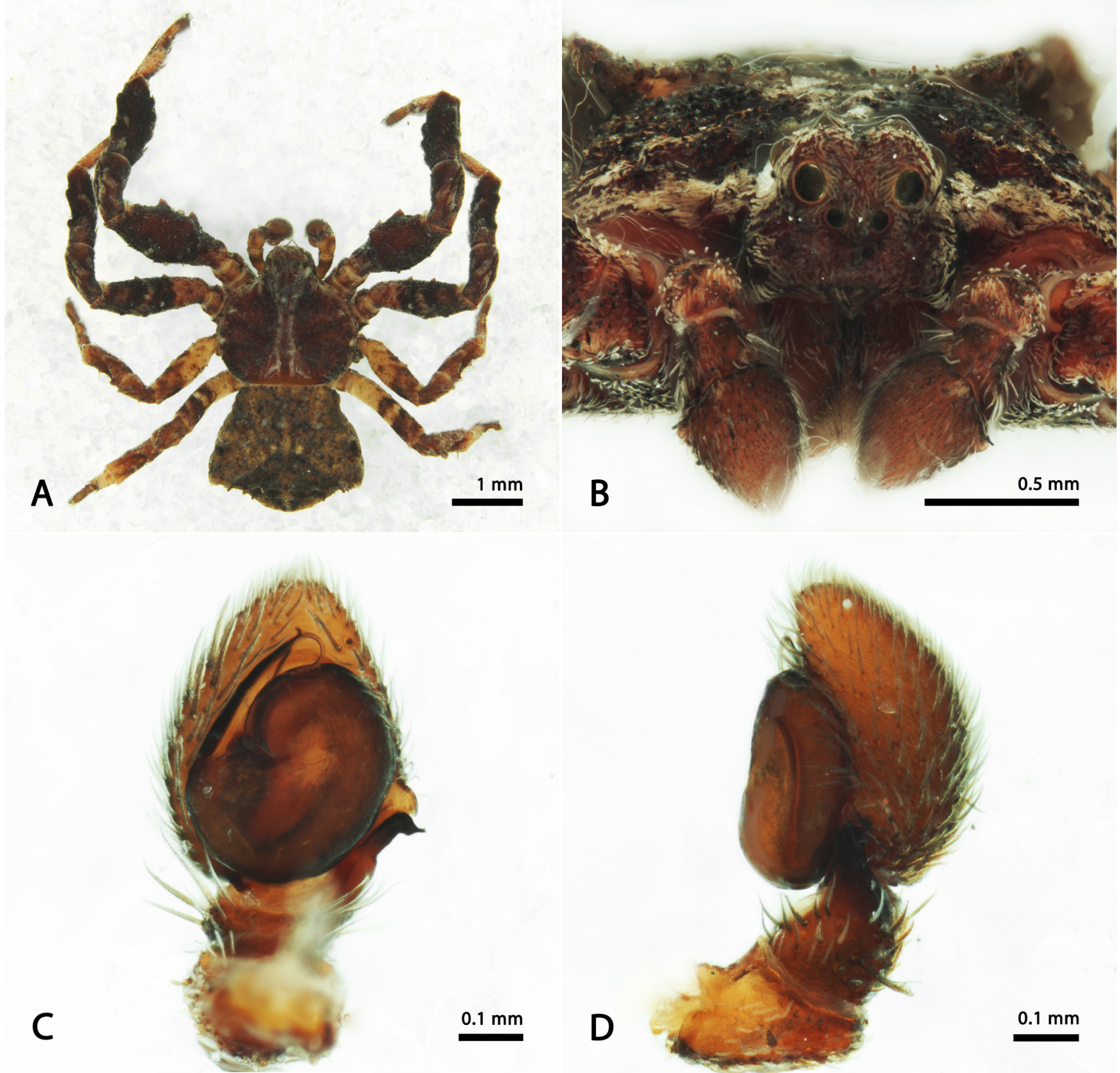

$0.1 \mathrm{~mm}$

Figure 9. Stephanopis armata L. Koch, 1874, male (KS.103218). left palp, retro lateral view.

total 6.01 ; II-1.82/ 0.88/ 1.23/ 0.93/ 0.615 .47 ; III-1.07/ $0.59 / 0.86 / 0.65 / 0.50 / 3.67$; IV $-1.31 / 0.57 / 0.83 / 0.62 /$ $0.44 / 3.77$. Total body length 3.90 ; prosoma length 2.01 , width 1.96; opisthosoma length 1.89 ; clypeus height 0.20 ; sternum length 0.89 , width 0.88 ; gnathocoxae length 0.44 , width 0.22 ; labium length 0.23 , width 0.36 .

Distribution. Queensland and New South Wales, Australia (Fig. 13).

\section{Stephanopis barbipes Keyserling, 1890}

Figs 10-12

Stephanopis barbipes Keyserling, 1890: 254, pl. 23, fig. 6.

Neotype $\widehat{\sigma}$ designated here, QM S110112, Tallebudgera Valley, Queensland, Australia, 28 $11^{\prime} 2.00^{\prime S}$ 15322'1.00"E, D. J. Cook, 1 January 1986.

Holotype $\widehat{\jmath}$, Cape York, Queensland, Australia, originally deposited in Bradley's collection-lost.

According to Keyserling (1890), the holotype of $S$. barbipes was originally deposited in Bradley's collection, which is known to have been transferred and currently curated in the OUMNH. However, after several attempts to locate the type material in this and even other European institutions, the specimen was not found. 

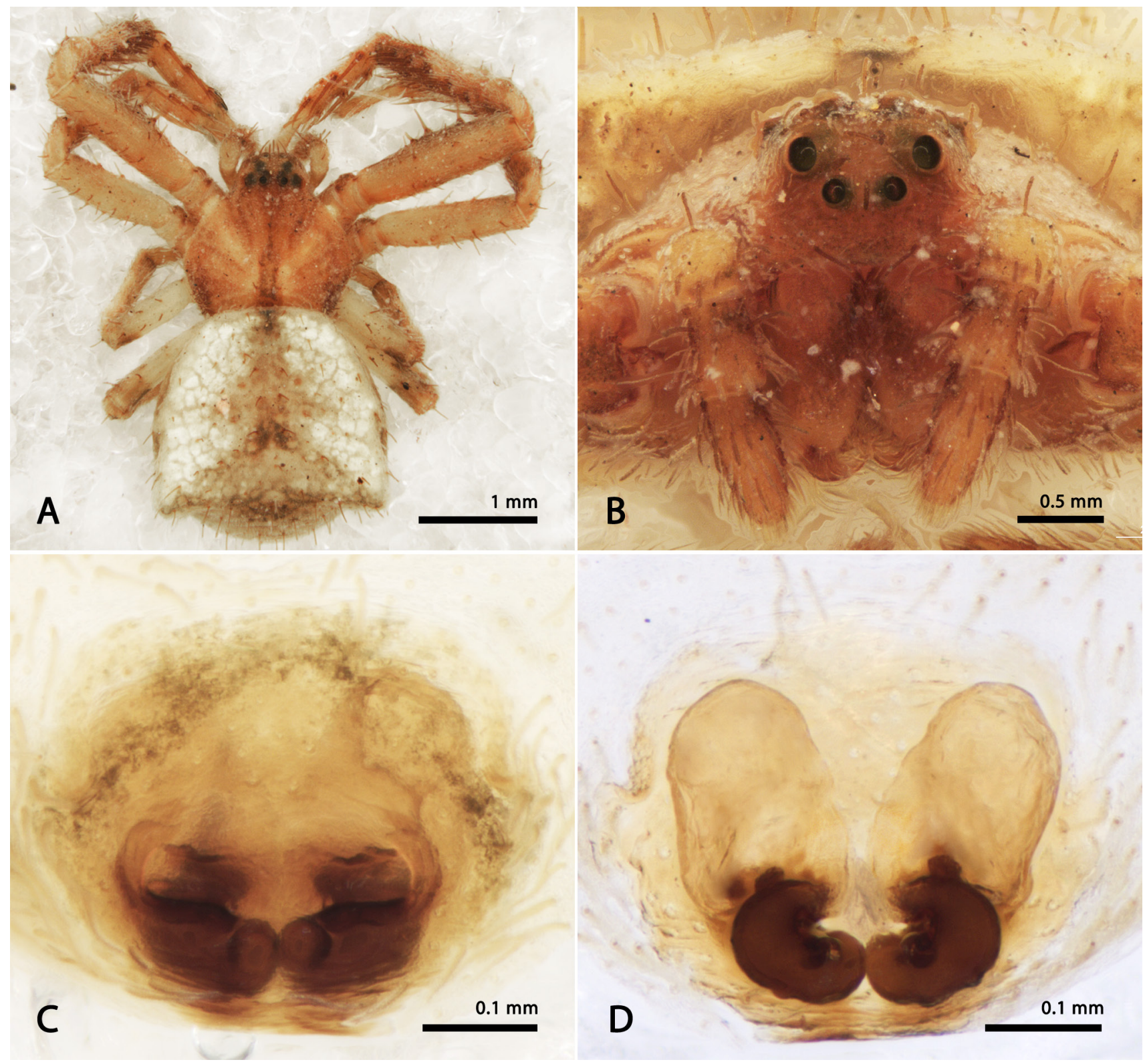

Figure 10. Stephanopis barbipes Keyserling, 1890, female (AMS KS.31359). (A) dorsal habitus; (B) front; (C) epigynal plate, ventral view; (D) epigynal plate/spermathecae.

The original description and illustration of the male of $S$. barbipes shows a remarkable spider with a set of somatic features that is not observed in any other species of this group (e.g., the lamellar setae tufts on the first pair of tibiae), allowing its easy recognition. Nevertheless, we see the need to propose a neotype in order to secure the stability of the species name, providing sufficient data and a clearer description to ensure its recognition. As no paratypes, paralectotypes or syntypic series were found, the specimen elected to be the neotype of S. barbipes is more recent (from 1986) but collected as close as possible to the original type locality (northeastern Australia).

Other material examined. Queensland: AMS KS.108673,2 $\overbrace{}^{\lambda} \sigma^{\text {, }}$ Kuranda, $16^{\circ} 49^{\prime} \mathrm{S} 145^{\circ} 38^{\prime} \mathrm{E}, \mathrm{N}$. Coleman \& R. Mascord, 2 February 1975; QM S110079, 1 ${ }^{\Uparrow}$, Kirrama Range (via Kennedy), 189'13.28"S

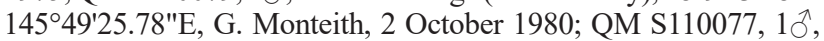
Kroombit Tops NP, 24²7'22.12"S 15052'43.80"E, V. E. Davies \& J. Gallon, 9-19 December 1983; QM S110078, 1今̂, Kroombit Tops NP(Beauty spot 98), 24²7'41.21"S 15053'59.33"E; QM S110082,
1万人, Brisbane (Fig Tree Pocket, Roedean street), 27²3'56.22"S 15258'47.57"E, V. E. Davies, 14 November 1973; QM S110083,

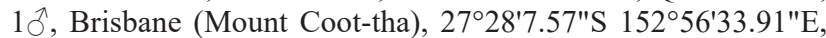
R. R. Jackson \& J. Grimshaw, 14 December 1979; QM S110084, $1{ }^{\lambda}$, Brisbane (Fig Tree Pocket, Jesmond road), 27³1'5.99"S $152^{\circ} 57^{\prime} 53.94 " E$, K. Stodart, December 1983. New South Wales:

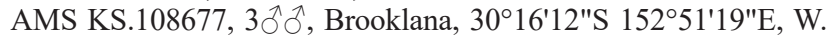
Heron, June 1929; AMS KS.9648, 10 , Wilsons Peak Flora Reserve, $31^{\circ} 18^{\prime} \mathrm{S} 152^{\circ} 29^{\prime} \mathrm{E}$; AMS KS.126523, $2{ }^{\wedge}{ }^{\wedge}$, Copeland Tops State Conservation Area, 31 ${ }^{\circ} 59^{\prime} 16^{\prime \prime S} 151^{\circ} 48^{\prime} 42^{\prime \prime E}$, G. Milledge \& H. Smith, 28 November 2016; AMS KS.126499, 1 ऽ, old Copeland road, $32^{\circ} 00^{\prime} 08^{\prime \prime S} 151^{\circ} 49^{\prime} 56^{\prime E} \mathrm{E}, \mathrm{G}$. Milledge \& H. Smith, 27 November

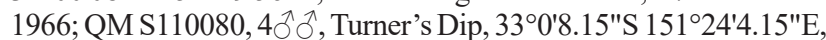
R. Raven, 22-23 November 1978; QM S110081, $2 \precsim \hat{\jmath}$, R. Raven et al.; AMS KS. $61764,1{ }^{\lambda}, 3 \mathrm{~km}$ southwest of Mangrove, $33^{\circ} 22^{\prime} 28^{\prime \prime S}$ $151^{\circ} 15^{\prime} 39^{\prime}$ E, M. Gray, G. Milledge \& H. Smith, 15 November

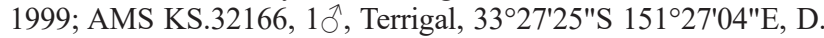
J. Bickel, 23 June 1986; AMS KS.108675, 1ð̊, Pittwater, 33³8'S $151^{\circ} 18^{\prime} \mathrm{E}, \mathrm{R}$. Mascord, 17 April 1966; AMS KS.108711, 1 , , Mona Vale (Pittwater), $33^{\circ} 38^{\prime} \mathrm{S} 151^{\circ} 18^{\prime} \mathrm{E}, \mathrm{R}$. E. Mascord, 12 March 1966;

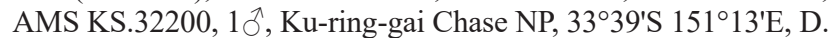




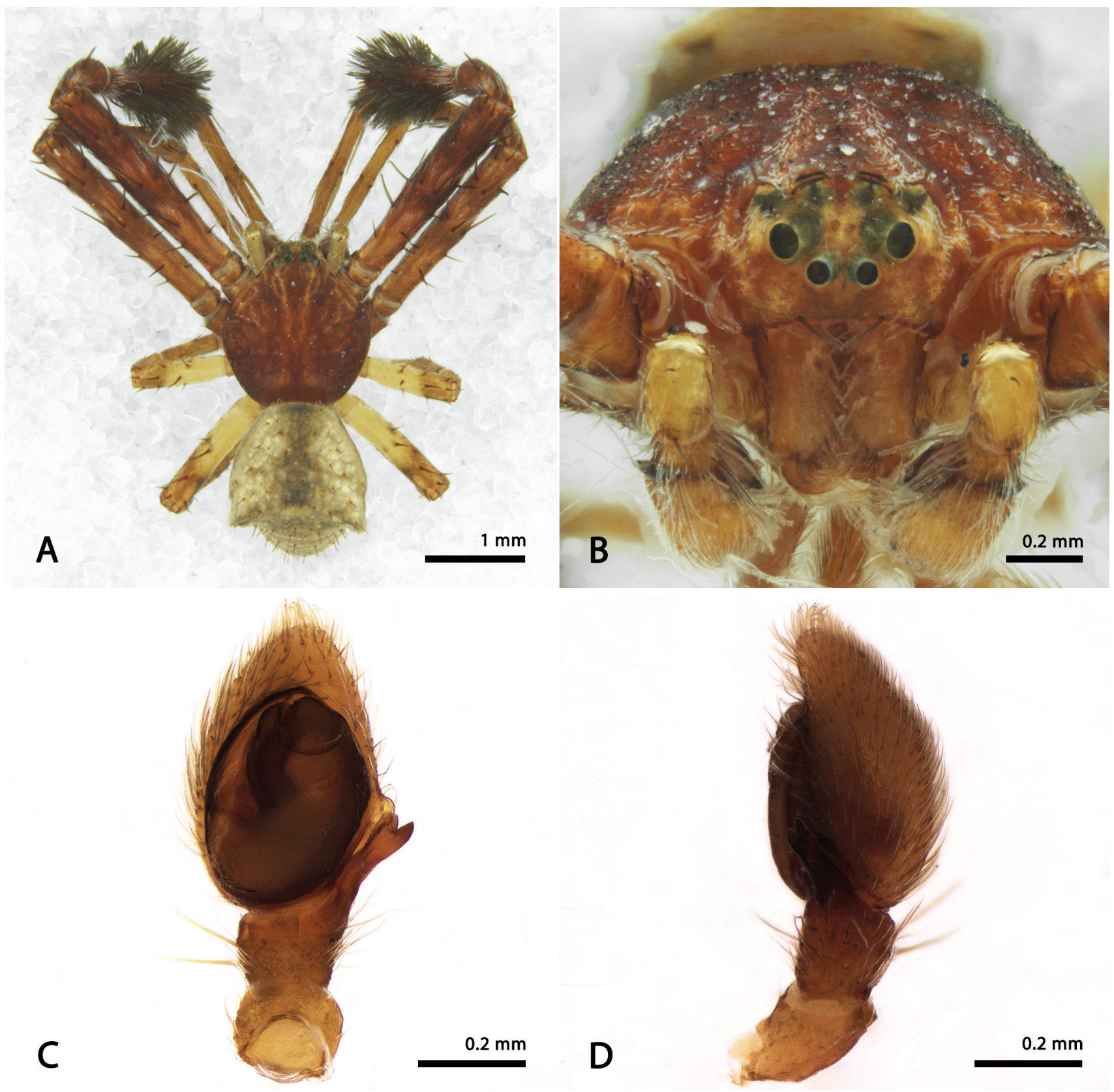

Figure 11. Stephanopis barbipes Keyserling, 1890, male (QM S110112). (A) dorsal habitus; (B) front; (C) ventral view of the left palp; (D) left palp, retro lateral view.

Bickel, 28 November 1985; AMS KS.111692, 1ð̂, Ku-ring-gai Chase

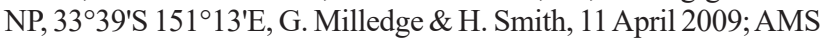
KS.76757, $1{ }^{\dagger}$, Beecroft, $33^{\circ} 45^{\prime} \mathrm{S} 151^{\circ} 04^{\prime} \mathrm{E}$, J. Noble, 3 December 2001; AMS KS.10484, $1{ }^{\prime}$, Gordon, $33^{\circ} 45^{\prime} \mathrm{S} 151^{\circ} 10^{\prime} \mathrm{E}$, C. Horseman \& D. Jones, 8 December 1982; AMS KS.108678, 1今, Eastwood, $33^{\circ} 47^{\prime} \mathrm{S} 151^{\circ} 06^{\prime} \mathrm{E}, \mathrm{H}$. Rowe, December 1955; AMS KS.51190, $1{ }^{\lambda}$,

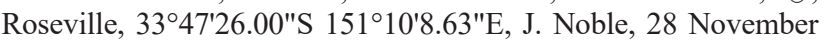

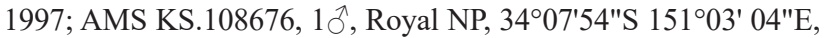
R. E. Mascord, 10 December 1966; AMS KS.45293, 1§, Mount Ousley (near Wollongong), 34 $24^{\circ} \mathrm{S}$ 150 $50^{\circ} \mathrm{E}$, F. Anderson, 15 March 1996; AMS KS.81361, $1{ }^{\top}$, Foxground (near Gerrigong), 34²4'S $150^{\circ} 46^{\prime} \mathrm{E}, \mathrm{M}$. Zabka \& M. Gray, 29 October 2002; AMS KS.119721, $1{ }^{\top}$, Bournda NP, 36 44'17"S 149 58'52"E, G. Milledge \& H. Smith, 25 December 2012. Western Australia: WAM T111251, $1 \hat{\jmath}$, Glenbourne Farm (south of Gracetown), 33 ${ }^{\circ} 54^{\prime} 32^{\prime \prime S} 115^{\circ} 00^{\prime} 24^{\prime \prime E}$, J. M. Waldock, 26 October 2003; WAM T111192, 1의, Glenbourne Farm (south of Gracetown), 33⒌'35"S $115^{\circ} 00^{\prime} 15^{\prime \prime E}$, L. Marsh et al., 29-31 October 2005; WAM T111251, 1ठิ, J. M. Waldock,

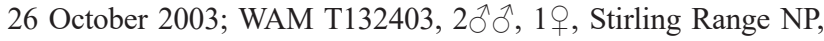
$34^{\circ} 22^{\prime} 52^{\prime \prime S} 118^{\circ} 17^{\prime} 21^{\prime \prime E}$, M.L. Moir \& K. Brennan. Victoria: AMS KS.36783, 1 q, Melbourne (Belgrave), $37^{\circ} 55^{\prime} \mathrm{S} 145^{\circ} 21^{\prime} \mathrm{E}$, C. Oke, January 1944. Tasmania: MACN-Ar 12008, 1어, Weldborough Pass, $41^{\circ} 13^{\prime} 0.00^{\prime \prime S} 147^{\circ} 56^{\prime} 18.50 " \mathrm{E}, \mathrm{M}$. Ramírez et al., 6-7 March 2006; MACN-Ar 11224, 1 ㅇ, St. Helens, $41^{\circ} 13^{\prime} 4.20^{\prime \prime}$ S $147^{\circ} 59^{\prime} 6.60^{\prime \prime E}, \mathrm{M}$. Ramírez et al., 7 March 2003; AMS KS.31359, 19, Punch Bowl, $41^{\circ} 27^{\prime} \mathrm{S} 147^{\circ} 10^{\prime} \mathrm{E}, \mathrm{V}$. V. Hickman, 17 May 1928; AMS KS.31356, 3 우, Tarraleah, $42^{\circ} 18^{\prime} \mathrm{S} 146^{\circ} 26^{\prime} \mathrm{E}, \mathrm{V}$. V. Hickman, May 1952; MACN-Ar 11149, 1, Queenstown (Kelly Basin), 42 18'37.10"S 145³6'58.30"E, M. Ramírez et al., 10 March 2006; AMS KS.31357, 1 으. Risdon, $42^{\circ} 49^{\prime} \mathrm{S} 147^{\circ} 21^{\prime} \mathrm{E}, \mathrm{V}$. V. Hickman, 10 September 1963; AMS KS.31409, 10, Lenah Valley, 4252'S $147^{\circ} 17^{\prime} \mathrm{E}, \mathrm{V}$. V. Hickman, 9 February 1934; AMS KS.31514, 1ð, 25 April 1933; AMS KS.31512, $10^{\lambda}$, New Town, 42॰ $53^{\prime}$ S $147^{\circ} 19^{\prime} \mathrm{E}, \mathrm{V}$. V. Hickman, 2 January 1945; AMS KS.31408, $1{ }^{\lambda}$, New Town, $42^{\circ} 53^{\prime}$ 'S $147^{\circ} 19^{\prime} \mathrm{E}$, V. V. Hickman, 25 December 1933; AMS KS31360, 1ㅇ, Ridgeway, $42^{\circ} 56^{\prime} \mathrm{S} 147^{\circ} 17^{\prime} \mathrm{E}, \mathrm{V}$. V. Hickman, 14 May 1948. 


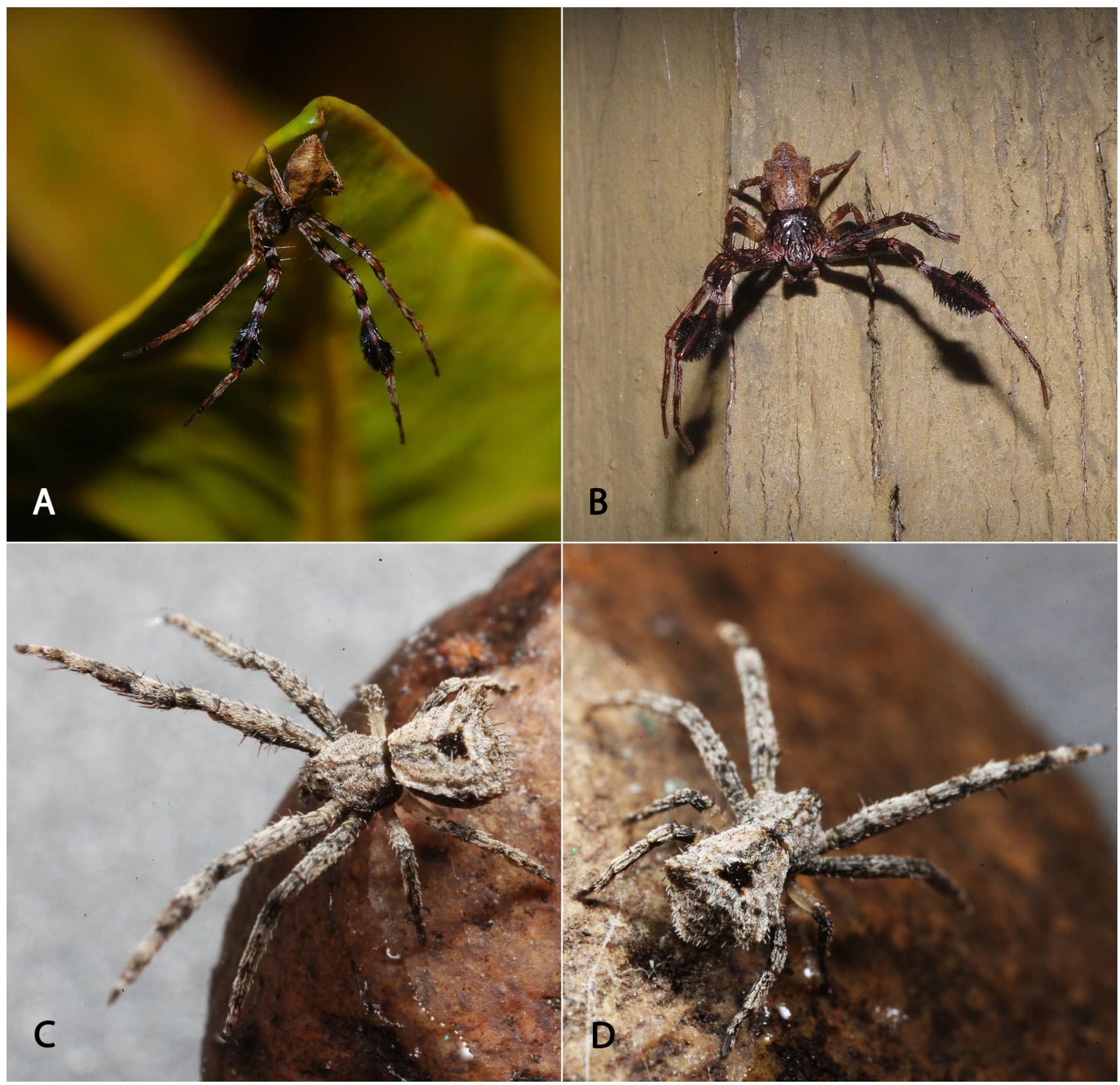

Figure 12. Stephanopis barbipes $(A-B)$ males and $(C-D)$ female. Photos by Nicholas Fisher.

Diagnosis. Females of $S$. barbipes are easily distinguished from their congeneric species by their reduced body size (it is the smallest species of the genus) and opisthosoma being trapezoid with a pair of acute posterior-lateral projections (Figs 10A, 12C and D). They can be also recognized by the triad of spiny macrosetae on the ventral surface of their femur I and hook-shaped CO obliquely positioned, forming a V-shaped atrium on the epigynal plate (Fig. 10C). The males of $S$. barbipes, like those of $S$. arenata sp. nov., $S$. cambridgei, $S$. longimana, $S$. similis sp. nov. and $S$. spiralis sp. nov., possess modified setae on their first pair of legs (Fig. 11A). However, unlike these species, in S. barbipes the setae are confined to tibiae I, are not filiform but lamellar, thicker and more aggregated, giving a tufted, a "bearded" appearance to their first pair of legs (Fig. 12A and B), hence the specific epithet. Also, in contrast to the above-mentioned species, the male palp of $S$. barbipes bears a bifid RTA and an embolus shape and resting position (apical) that is more similar to that observed in S. altifrons and S. nigra (Fig. 11C).

Description. Female (AMS KS.31359): Eyes arranged in two recurved rows (posterior one slightly recurved, almost straight) (Fig. 10A and B), prosoma and anterior legs predominantly dark-yellow with no significant markings except for the brown areas on the sides and the median area of the posterior slope of the thoracic region. Posterior legs dark-yellow, lighter on the femora; opisthosoma whitish, darker around the heart fovea (Fig. 10A). Spermathecae peanut-shaped, with no pseudo-segmentation and preceded by a pair of hyaline chambers (Fig. 10D).

Measurements: eye diameters and interdistances: AME 0.06, ALE 0.11, PME 0.06, PLE 0.08, AME-AME 0.09, AME-ALE 0.04, PME-PME 0.09, PME-PLE 0.11, MOQ length 0.21 , width 0.20 ; leg formula: $1-2-4-3$ : leg I-femur 1.53 / patella 0.74 / tibia 1.33 / metatarsus 0.84 / tarsus 0.44 / 


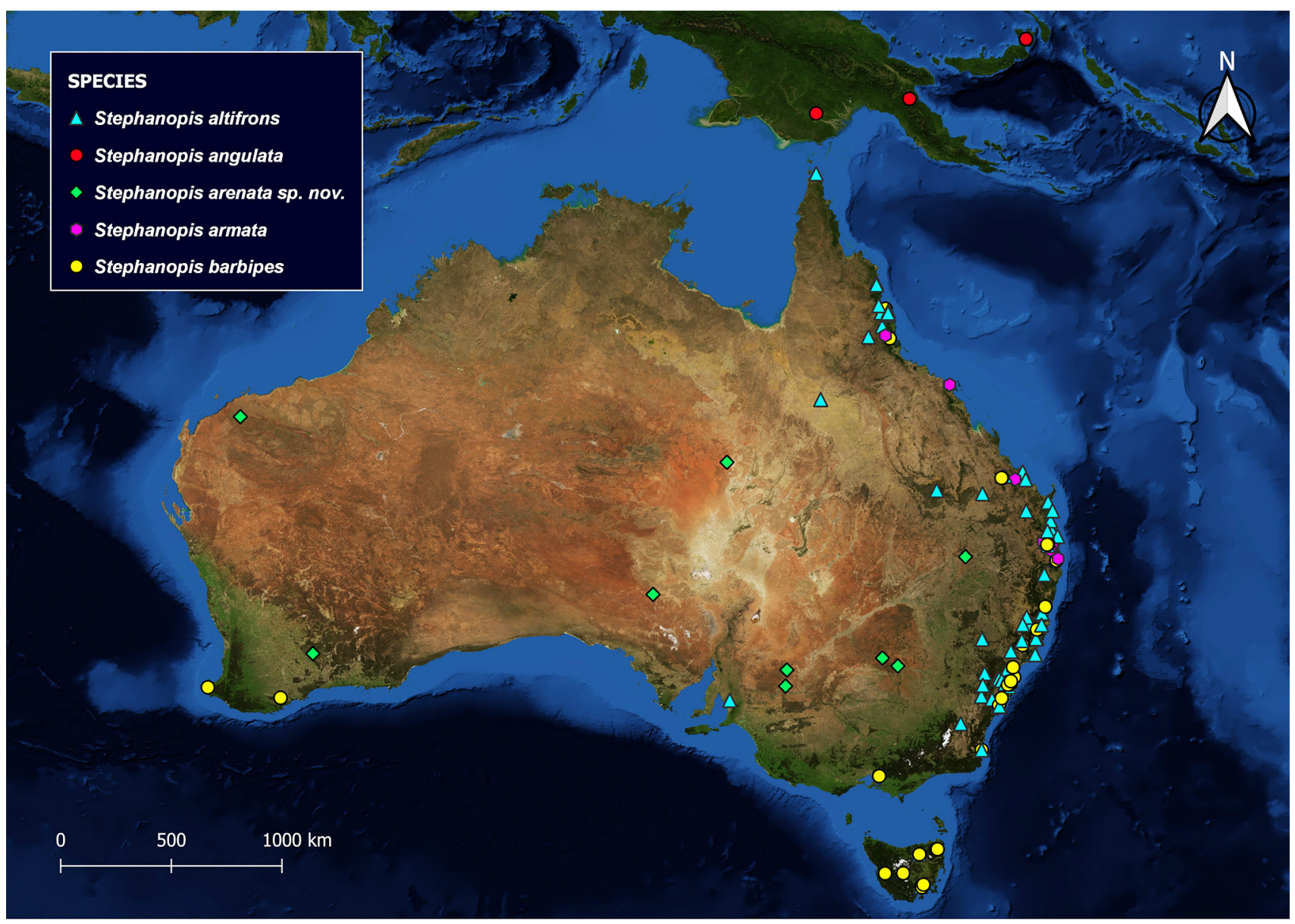

Figure 13. Distribution records of Stephanopis altifrons, S. angulata, S. arenata sp. nov., S. armata and S. barbipes.

total 4.88; II-1.37/ 0.61/ $1.06 / 0.68 / 0.394 .11 ; \mathrm{III}-0.65 /$ $0.44 / 0.62 / 0.38 / 0.33 / 2.42 ; \mathrm{IV}-1.05 / 0.43 / 0.68 / 0.38 /$ $0.31 / 2.85$. Total body length 3.82 ; prosoma length 1.56 , width 1.42; opisthosoma length 2.26; clypeus height 0.15 ; sternum length 0.70 , width 0.67 ; gnathocoxae length 0.33 , width 0.19 ; labium length 0.17 , width 0.24 .

Male (QM S110112): Prosoma and anterior legs (I and II) entirely brown, darker than the female; eye arrangement as in female (Fig. 11A and B). Posterior femora (III and IV) are yellow on their proximal half. Opisthosoma whitish-yellow with a brown median taint, covered by sparse needle-shaped setae; trapezoid and with anal region projected backwards (Fig. 11A). Tegular ridge apical, helicoidal and nesting the flexible and thin tip of the embolus (Fig. 11C); Pcym stout and rounded such as both branches of the RTA (Fig 11D).

Measurements: eye diameters and interdistances: AME 0.06, ALE 0.09, PME 0.08, PLE 0.07, AME-AME 0.06, AME-ALE 0.04, PME-PME 0.10, PME-PLE 0.11, MOQ length 0.25 , width 0.17 ; leg formula: $1-2-4-3$ : leg I-femur 1.45 / patella $0.57 /$ tibia $1.31 /$ metatarsus $0.94 /$ tarsus 0.59 / total 4.86; II-1.30/ 0.55/ 1.09/ 0.79/ 0.55/4.28; III-0.72/ $0.37 / 0.50 / 0.39 / 0.32 / 2.30$; IV $-1.05 / 0.39 / 0.63 / 0.40 /$ $0.32 / 2.79$. Total body length 2.77 ; prosoma length 1.35 , width 1.23; opisthosoma length 1.42 ; clypeus height 0.14 ; sternum length 0.60 , width 0.62 ; gnathocoxae length 0.29 , width 0.18 ; labium length 0.17 , width 0.20 .

Distribution. Queensland, New South Wales, Western Australia and Tasmania, Australia (Fig. 13).

\section{Stephanopis bicornis L. Koch, 1874}

Figs 14-15

Stephanopis bicornis L. Koch, 1874: 501, pl. 38, fig. 3.-L. Koch, 1876: 751, pl. 66, fig. 1.

Stephanopis aruana Thorell, 1881: 317 (holotype, female, Wokam [547'16.66"S 134³0'45.05"E], Aru Island, Indonesia, deposited in the MSNG, examined). New synonym.

Stephanopis yulensis Thorell, 1881: 319 (syntype, female, Yule Island [8 $\left.8^{\circ} 49^{\prime} S 146^{\circ} 32^{\prime} E\right]$, Papua New Guinea, deposited in the MSNG, examined). New synonym.

Type material examined. Syntypes, $3 \circ \circ$, ZMB 3415, Sydney, New South Wales, Australia, 33⒌' $151^{\circ} 12^{\prime} \mathrm{E}$; ZSMH, 1 + , Sydney.

Other material examined. Queensland: AMS KS.66438, $1 \hat{0}$, Cape Tribulation Rd, c. $100 \mathrm{~m}$ N of Cape Kimberley Rd turnoff., $16^{\circ} 15^{\prime} 35^{\prime \prime S ~} 145^{\circ} 26^{\prime} 11^{\prime \prime E}$, G. Milledge \& H. Smith, 20 May 2000; QM S15957, 1 9 , Mount Moffatt NP (Kenniff Cave), 25¹'0.012"S $147^{\circ} 57^{\prime} \mathrm{E}, \mathrm{M}$. Bennie, 27 September 1987; AMS KS.33565, 1을 Condamine, 26 $6^{\circ} 6^{\prime} \mathrm{S} 150^{\circ} 08^{\prime} \mathrm{E}, \mathrm{N}$. Geary, 10 March 1937. New South Wales: AMS KS.52155, 1 , , Swansea area, $23^{\circ} 05^{\prime} \mathrm{S}$ $151^{\circ} 38^{\prime} \mathrm{E}, \mathrm{M}$. R. Gray, 2 April 1990; QM S104662, 10ิ, Byron Bay, $28^{\circ} 38^{\prime} 50.52^{\prime \prime S} 153^{\circ} 36^{\prime} 7.12^{\prime \prime E}$, R. Monroe, 25 November

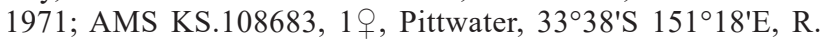
E. Mascord, 2 October 1966; AMS KS.18778, 1우 Ku-ring-gai Chase NP, 3339'S $151^{\circ} 08^{\prime} \mathrm{E}, \mathrm{M}$. R. Gray, January 1988; AMS

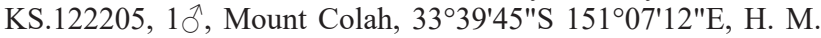
Smith, 15 April 2013; AMS KS.70139, 1ㅇ, Hornsby (Waitara

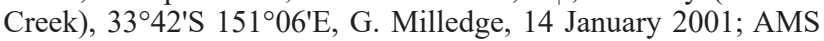



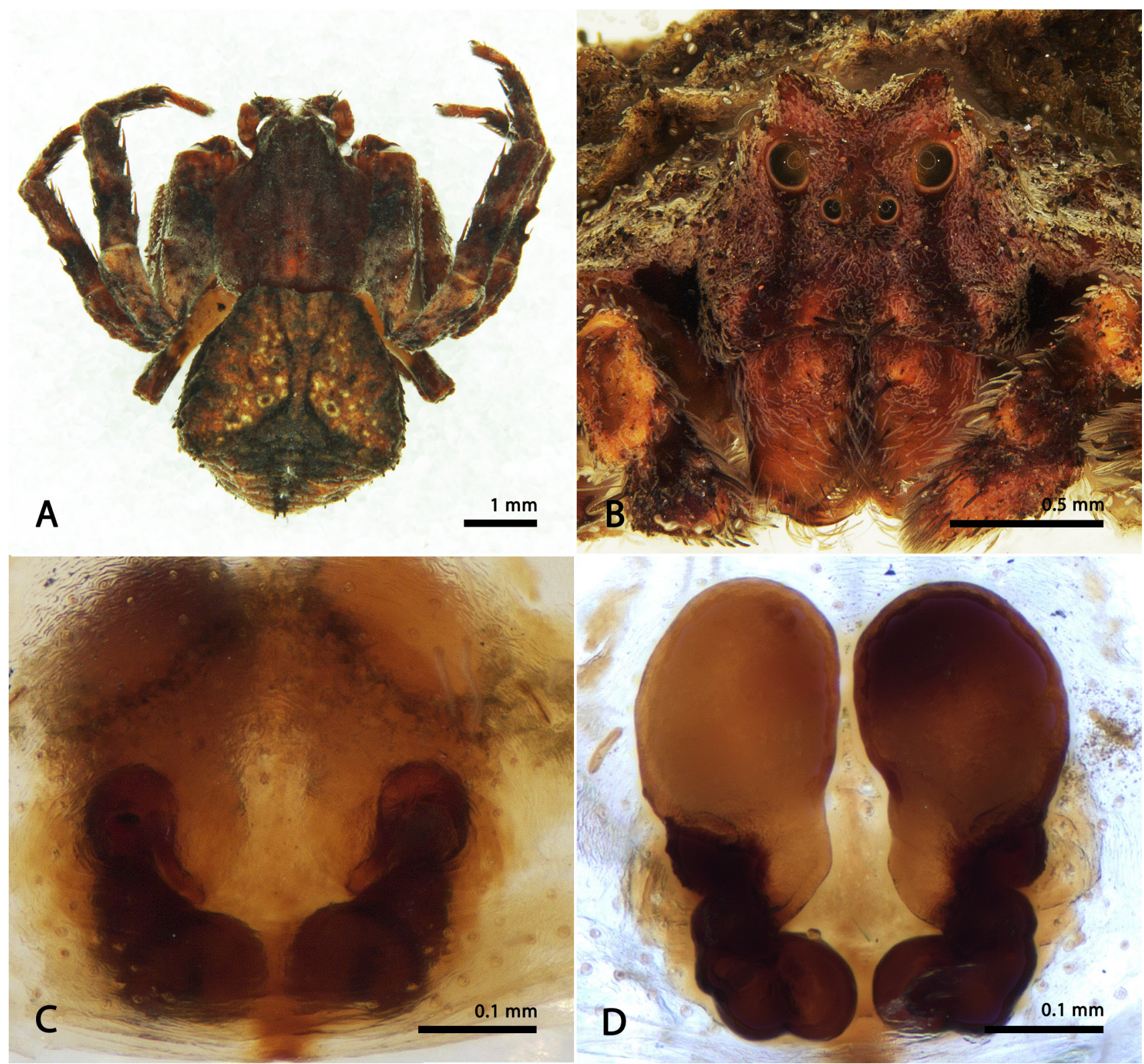

Figure 14. Stephanopis bicornis L. Koch, 1874, female (AMS KS.70139). (A) dorsal habitus; (B) front; (C) epigynal plate, ventral view; (D) epigynal plate/spermathecae.

KS.108685, 2 우, Gladesville, $33^{\circ} 50^{\prime} \mathrm{S} 151^{\circ} 08^{\prime} \mathrm{E}, \mathrm{R}$. E. Mascord, 4 December 1965; AMS KS.108659, 1 ㅇ, Sydney, $33^{\circ} 53^{\prime} \mathrm{S} 151^{\circ} 13^{\prime} \mathrm{E}$, J. Hild; AMS KS.108681, $1 \delta^{\top}$, Kurnell (Sydney), $34^{\circ} 00^{\prime} \mathrm{S} 151^{\circ} 13^{\prime} \mathrm{E}$, C. E. Chadwick, 4 April 1970; AMS KS.101228, 2 우, Livingstone $\mathrm{NP}\left(30 \mathrm{~km}\right.$ South of Wagga Wagga), $35^{\circ} 22^{\prime} \mathrm{S} 147^{\circ} 22^{\prime} \mathrm{E}, \mathrm{C}$. Car, 19 September 2001; AMS KS.101259, 1§, same data except 22 June 2001; AMS KS.101226, 19, same data except 18 October 2001; AMS KS.101278, 3우, same data except 24 May 2001; AMS KS.101284, 19, same data except 21 July 2001; AMS KS.107253,

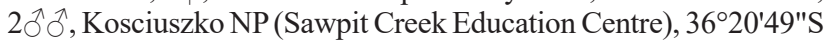
$148^{\circ} 33^{\prime} 54^{\prime \prime E}$, D. R. Britton \& A. D. Hegedus, 5 March 2008. South Australia: AMS KS.76382, 1 ${ }^{\lambda}$, Cleland Conservation Park, 3458'40"S 13841'59"E, G. Milledge \& H. Smith, 18 March 2002. Tasmania: AMS KS.31412, 1 을, Trevallyn, $41^{\circ} 27^{\prime} \mathrm{S} 147^{\circ} 10^{\prime} \mathrm{E}$, V. V. Hickman, 1 December 1928; AMS KS.52166, 3 우, Mount Nelson, 42 $56^{\circ} \mathrm{S} 147^{\circ} 20^{\prime} \mathrm{E}, 15$ September 1971.

Diagnosis. Both males and females of S. bicornis are similar to those of $S$. angulata, $S$. lata and $S$. monulfi in possessing a trapezoidal opisthosoma and having the triad of projections arranged in a dorsal row along the anterior patellae and tibiae (I and II) (Figs 14A and 15A). However, S. bicornis can be easily distinguished by the high and acute projections above the ALE (Fig. 14B and 15B). Females are also diagnosed by their slit-shaped $\mathrm{CO}$ located laterally at the edges of the epigynal plate, with its folds forming round entrances (Fig. 14C); males have a characteristic palp with a prolateral tuft of short serrated setae on the dorsal surface of the cymbium and a hook-shaped RTA with squared and discrete RTAvbr (Fig. 15C and D).

Description. Female (AMS KS.70139): Anterior eye row strongly recurved and posterior row straight (Fig. 14A and B); prosoma and anterior legs predominantly dark-brown with some yellowish spots; femora I and II bear stout setiferous tubercles and femora III and IV are smooth and almost entirely yellow; tibiae I and II ventrally armed with four pairs of macrosetae. Opisthosoma trapezoid, covered by sparse claviate setae, with spinneret area projected backwards 


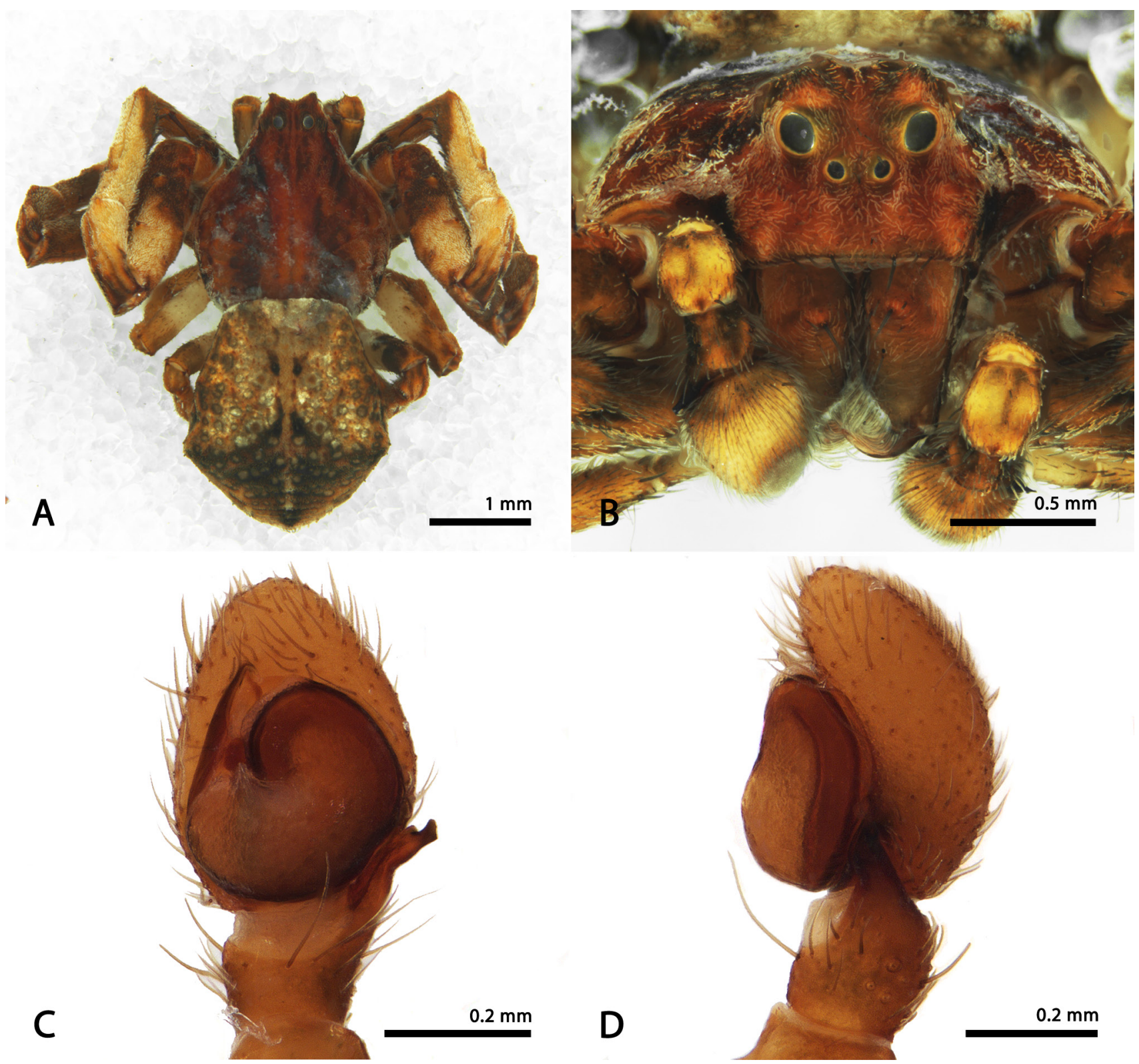

Figure 15. Stephanopis bicornis L. Koch, 1874, male (AMS KS.122205). (A) dorsal habitus; (B) front; (C) ventral view of the left palp; (D) left palp, retro lateral view.

and anterior border slightly concave; dark-yellow on dorsum, darker on median posterior area (Fig 14A). Spermathecae stomach-shaped, preceded by glandular-heads directed laterally and oval wide anterior chambers (Fig. 14D).

Measurements: eye diameters and interdistances: AME 0.10, ALE 0.15, PME 0.11, PLE 0.12, AME-AME 0.14, AME-ALE 0.10, PME-PME 0.23, PME-PLE 0.17, MOQ length 0.42 , width 0.24 ; leg formula: 1-2-4-3: leg I-femur 2.97 / patella 1.43 / tibia 2.15 / metatarsus 1.25 / tarsus 0.84 / total 8.64; II-2.55/ 1.26/ 1.81/ 1.07/ 0.80/ 7.49; III-1.75/ $0.76 / 1.09 / 0.69 / 0.47 / 4.76$; IV $-1.73 / 0.74 / 1.14 / 0.77 /$ $0.54 / 4,92$. Total body length 5.93 ; prosoma length 2.56 , width 2.37; opisthosoma length 3.37 ; clypeus height 0.26 ; sternum length 1.19 , width 1.07 ; gnathocoxae length 0.69 , width 0.38 ; labium length 0.37 , width 0.52 .

Male (AMS KS.122205): Eye arrangement as in female; prosoma reddish-brown with some darker spots; legs predominantly yellow, with some distal or proximal brown spots (except for leg II, which is mostly brown with just the tarsi and metatarsi yellow) (Fig. 15A). Opisthosoma darkyellow with small whitish spots and darker on the posterior slope, near the anal region. Embolus short and curved, and cymbium thick (Fig. 15C and D).

Measurements: eye diameters and interdistances: AME 0.07, ALE 0.19, PME 0.08, PLE 0.12, AME-AME 0.11, AME-ALE 0.09, PME-PME 0.20, PME-PLE 0.12, MOQ length 0.42 , width 0.49 ; leg formula: 1-2-4-3: leg I-femur 2.69 / patella 1.29 / tibia 2.10 / metatarsus 1.24 / tarsus $0.67 /$ total 7.99; II-2.27/ 1.05/ 1.72/ 1.04/ 0.61/ 6.69; III-0.87/ $0.46 / 0.71 / 0.53 / 0.39 / 2.96$; IV $-1.19 / 0.47 / 0.78 / 0.59 /$ $0.41 / 3.44$. Total body length 4.65 ; prosoma length 2.31 , width 2.00; opisthosoma length 2.34; clypeus height 0.29 ; sternum length 0.88 , width 0.81 ; gnathocoxae length 0.39 , width 0.25 ; labium length 0.24 , width 0.28 .

Distribution. Queensland, New South Wales, South Australia and Tasmania, Australia (Fig. 24). 


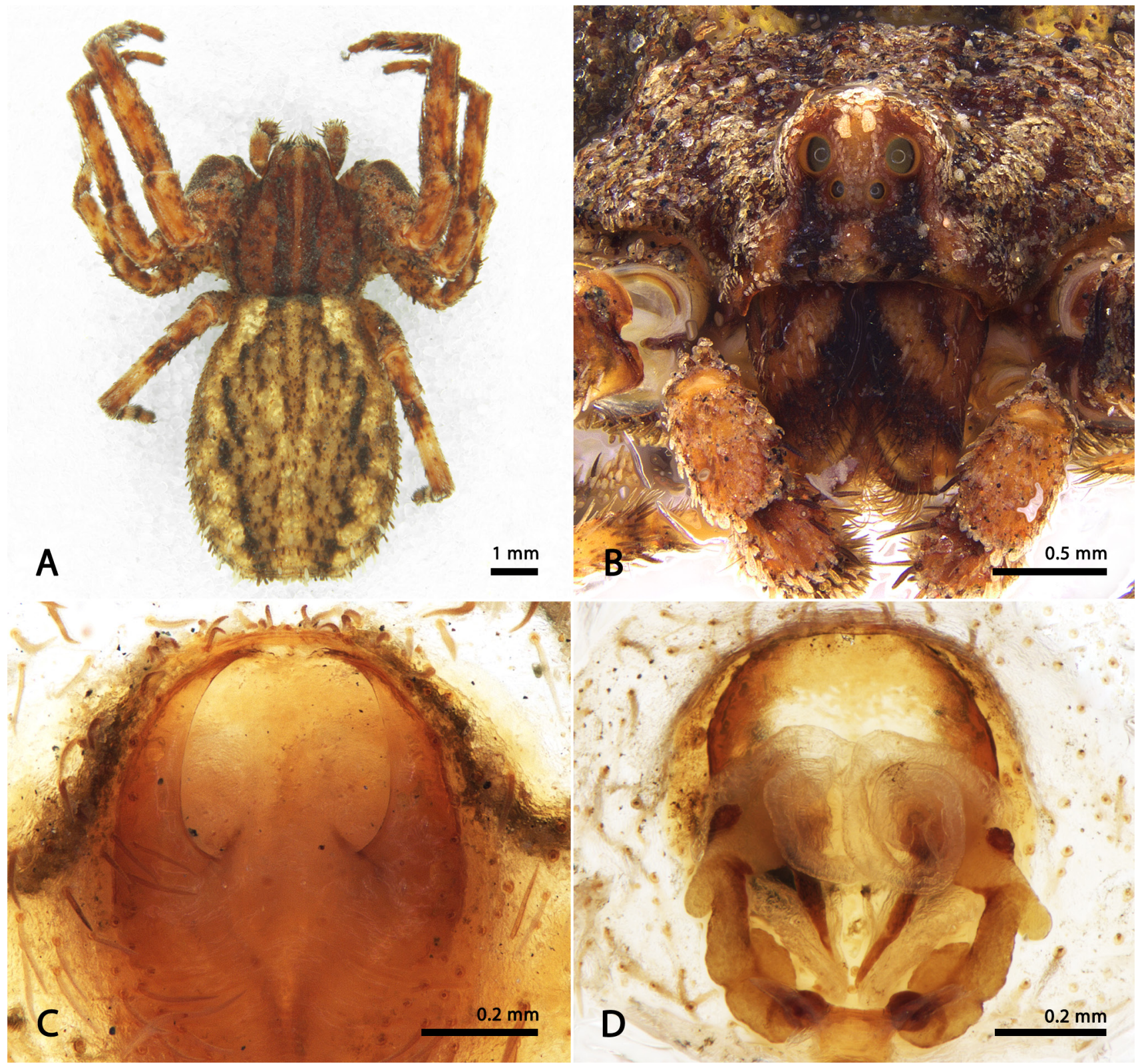

Figure 16. Stephanopis cambridgei Thorell, 1870, female (AMS KS.10530). (A) dorsal habitus; (B) front; (C) epigynal plate, ventral view; (D) epigynal plate/spermathecae.

\section{Stephanopis cambridgei Thorell, 1870}

Figs $16-18$

Stephanopis cambridgei Thorell, 1870: 378.-L. Koch, 1874: 510, pl. 38, fig. 7.-L. Koch, 1876: 744, pl. 65, fig. 3.-Hickman, 1967: 105, figs 175-176.-Benjamin, 2011: 19, figs 5D,G, 66A-G, 67A-F.

Stephanopis macleayi Bradley, 1871: 238. (holotype, female, Goulburn, New South Wales, Australia, OUMNH 297, examined). New synonym.

Stephanopis obtusifrons Rainbow, 1902: 491, pl. 18, fig. 3 (holotype female, Jervis Bay, New South Wales, Australia, deposited in AMS KS.49746, examined). New synonym.

Type material examined. Holotype $\circ$, SMNH 1163, Australia, (photos examined).

Other material examined. Queensland: AMS KS.108661, 1 을, Yungaburra, $17^{\circ} 16^{\prime} \mathrm{S} 145^{\circ} 35^{\prime} \mathrm{E}$, R. Mascord, 20 September 1976; AMS KS.7363, 19, Mount Dryander (North of Proserpine), $20^{\circ} 15^{\prime} \mathrm{S} 148^{\circ} 32^{\prime} \mathrm{E}, \mathrm{M}$. Gray \& C. Horseman, April 1975; AMS KS.53387, 2 우, Eungella area (road to Eungella Dam), $21^{\circ} 12^{\prime} \mathrm{S}$ $148^{\circ} 29^{\prime}$ E, G. Milledge, 21 April 1998; AMS KS.53388, 1 q, Eungella area (1.4 km west of Freegards Road), $21^{\circ} 12^{\prime} 56^{\prime \prime} \mathrm{S} 148^{\circ} 29^{\prime} 07^{\prime \prime} \mathrm{E}$, G. Milledge, 21 April, 1998; AMS KS.66407, 19, 6,2 km west of Yeppoon beachfront, $23^{\circ} 09^{\prime} 36^{\prime \prime S} 150^{\circ} 42^{\prime} 30 " \mathrm{E}$, G. Milledge \& H. Smith, 27 May 2000; AMS KS.66506, 1요 Blackdown Tableland NP, $23^{\circ} 47^{\prime} 49^{\prime \prime S} 149^{\circ} 04^{\prime} 14 " \mathrm{H}, \mathrm{G}$. Milledge \& H. Smith, 8 May 2000; QM S33395, 1 \%, Gympie (Cooloola Cove), 26²'S $153^{\circ} 3^{\prime} \mathrm{E}, \mathrm{K}$. Sadler, 7 April 1987; QM S110045, 1옹, Dalby (Lake Broadwater Cottage), $27^{\circ} 21^{\prime} \mathrm{S} 151^{\circ} 6^{\prime} \mathrm{E}, \mathrm{J}$. Gallon, 9 December 1987; QM S110044, 19, Brisbane (Albion), 27²5'55"S 1532'46"E, 2 July 1896; AMS KS.108686, 1 \%, Gatton, $27^{\circ} 34^{\prime} \mathrm{S} 152^{\circ} 17^{\prime} \mathrm{E}$, August 1903; AMS KS.128377, 1ठ, Beechmont (Binna Burra Road), $28^{\circ} 09^{\prime} 42.4^{\prime \prime S} 153^{\circ} 11^{\prime} 47.9^{\prime \prime} \mathrm{E}, \mathrm{A}$. Grabolle, March 2017; QM S110046, 1ㅇ, Stanthorpe, 2839'35.90"S 15156'15.22"E, W. McKenzie, 15 August 1987. New South Wales: AMS KS.30868, 1 ․ Washpool NP, $29^{\circ} 16^{\prime} \mathrm{S} 152^{\circ} 22^{\prime} \mathrm{E}, \mathrm{M}$. R. Gray, 9 February 1992; AMS KS.101147, 2 우, Sturt NP, 29²9'06"S 142¹4'24"E, C. Car, 5 July 2002; AMS KS.119874, 1 \%, Yarrawonga Weir, 3000'25"S 

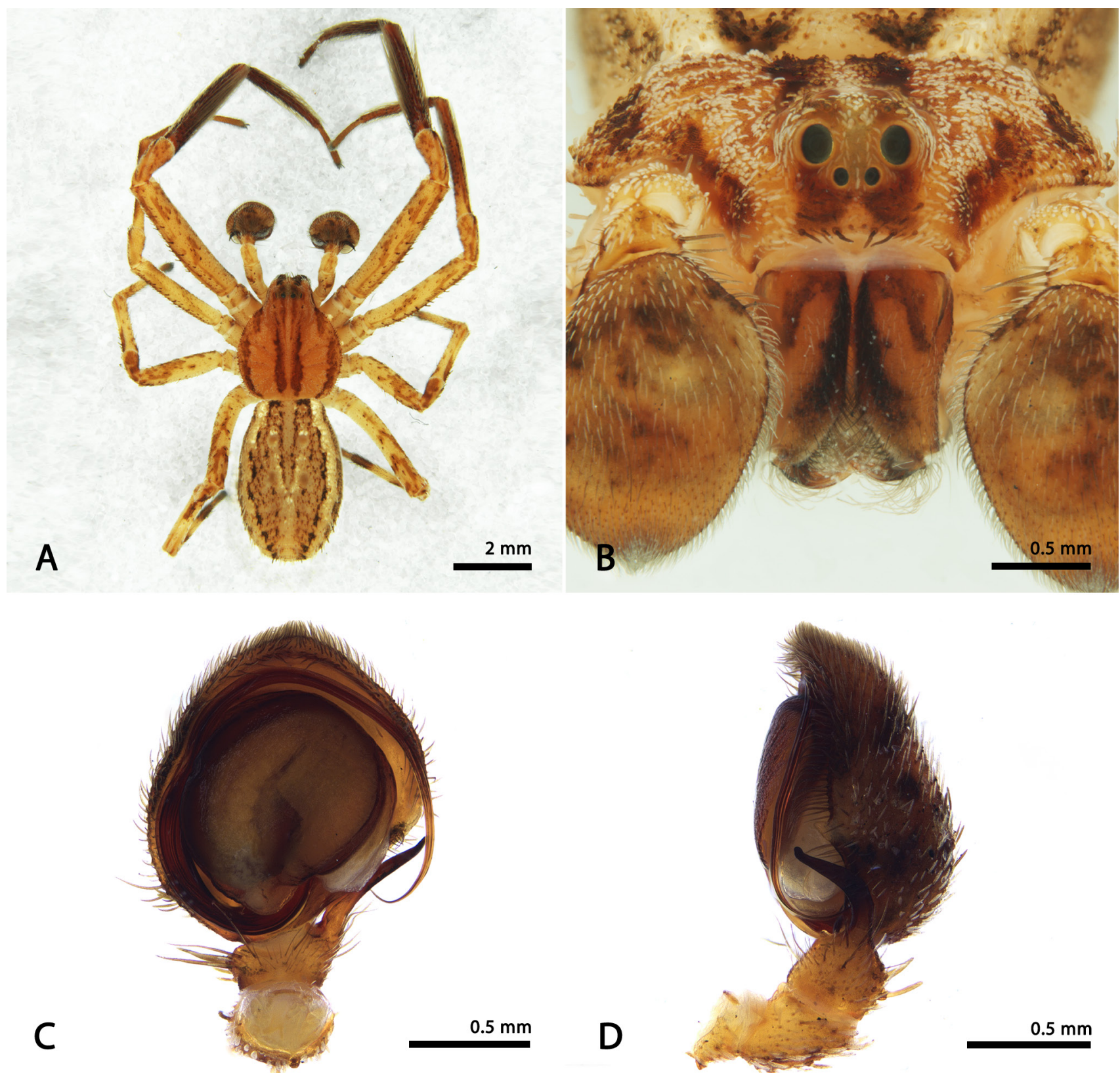

Figure 17. Stephanopis cambridgei Thorell, 1870, male (AMS KS.128377). (A) dorsal habitus; (B) front; (C) ventral view of the left palp; (D) left palp, retro lateral view.

1455'ㄴ'4"E, M. Aobison, 29 November 2007; AMS KS.105712, 1 ㅇ, Bourke, $30^{\circ} 04^{\prime} \mathrm{S} 145^{\circ} 57^{\prime} \mathrm{E}$, 5 June 1890; AMS KS.105690, $2 \hat{\partial} \hat{\jmath}$, Mount Kaputar NP, 30¹1'S 15009'E, 18-19 September 1968, M. Gray; AMS KS.106401, 1q, Kamilaroy Highway (south of Narrabri at Gun Club Road Junction), 30²1'58.3"S 14946'10"E, G. Milledge \& H. Smith, 24 November 2008; AMS KS.108698, 1 , Kempsey, $30^{\circ} 44^{\prime} \mathrm{S} 152^{\circ} 25^{\prime} \mathrm{E}$, C. Chadwick, 17 March 1972; AMS

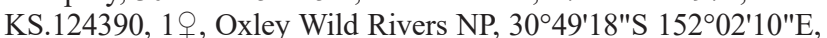
H. Smith, 7 November 2015; AMS KS.128966, 10, Warrumbungle NP, 31 ${ }^{\circ} 16^{\prime} 36^{\prime \prime S} 148^{\circ} 58^{\prime} 56^{\prime \prime E}$, G. Milledge \& H. Smith, 27 September 2018; AMS KS.23383, 10, 1ㅇ, Marthaguy (12 km west of Gilgandra), $31^{\circ} 40^{\prime} \mathrm{S} 148^{\circ} 32^{\prime} \mathrm{E}$, C. Horseman \& J. Thompson, 27 August 1990; AMS KS.101559, $2 \hat{\AA}$. Watchimbark Nature Reserve, $31^{\circ} 42$ '27"S 151³7'52"E, H. Smith, 31 May 2007; AMS KS.23395, 1 을, Collie, $31^{\circ} 52^{\prime} \mathrm{S} 148^{\circ} 20^{\prime} \mathrm{E}$; AMS KS.98557, 1 옹, Barrington Tops NP, G. Milledge \& H. Smith, 5 December 2006; AMS KS.108680, 1 , , Barrington Tops NP, $31^{\circ} 58^{\prime} \mathrm{S} 151^{\circ} 28^{\prime} \mathrm{E}$, A. Musgrave, 15 January 1947; AMS KS.115156, 10, Round Hill (near to Euabalong), $32^{\circ} 58^{\prime} \mathrm{S} 146^{\circ} 09^{\prime} \mathrm{E}, \mathrm{M}$. Gray, 20 March 1970; AMS KS.118229,

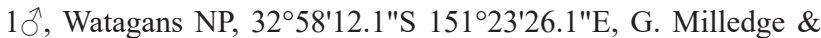
H. Smith, 21 March 2012; AMS KS.118310, 19, Watagans NP, $33^{\circ} 02^{\prime} 42^{\prime \prime S ~} 151^{\circ} 21^{\prime} 55.9^{\prime \prime E}$, G. Milledge \& H. Smith, 22 March

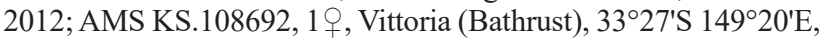
C. Chadwick, 1 October 1967; KS AMS 122246, 19 , Mount Irvine, $33^{\circ} 29^{\prime} \mathrm{S} 150^{\circ} 28^{\prime} \mathrm{E}$, October 1941; AMS KS.73346, $1 \delta^{\lambda}$, Maroota State Forest, $33^{\circ} 31^{\prime S} 150^{\circ} 59^{\prime} \mathrm{E}$, G.A. Webb, 2 November 1979; AMS KS.108694, 3 우오, Hartley (Blue Mountains), 333'ㄴ $150^{\circ} 11^{\prime} \mathrm{E}$, C. Chadwick, 28 April 1968; AMS KS.108693, 1옹, Mount York

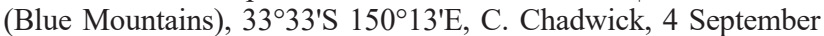
1966; AMS KS.122539, $10^{\lambda}$, Berowra Valley NP, 3338'04"S $151^{\circ} 06^{\prime} 13^{\prime \prime E}, \mathrm{G}$. Milledge \& H. Smith, 24 February 2014; AMS

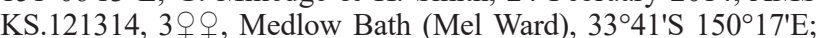
AMS KS.121460, 1ㅇ, same data; AMS KS.121799, 1옹 same

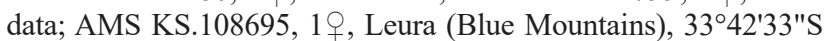
$150^{\circ} 20^{\prime} 07^{\prime \prime E}$; AMS KS.86839, $1 \mathrm{O}^{\lambda}$, Beecroft, $33^{\circ} 45^{\prime} \mathrm{S} 151^{\circ} 04^{\prime} \mathrm{E}$, J. Noble, 20 March 2003; AMS KS.64188, 19, same data except 29

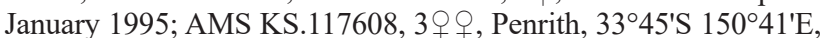
Dr Ramsay, 11 December 1869; AMS KS.108689, 1q, Jenolan 


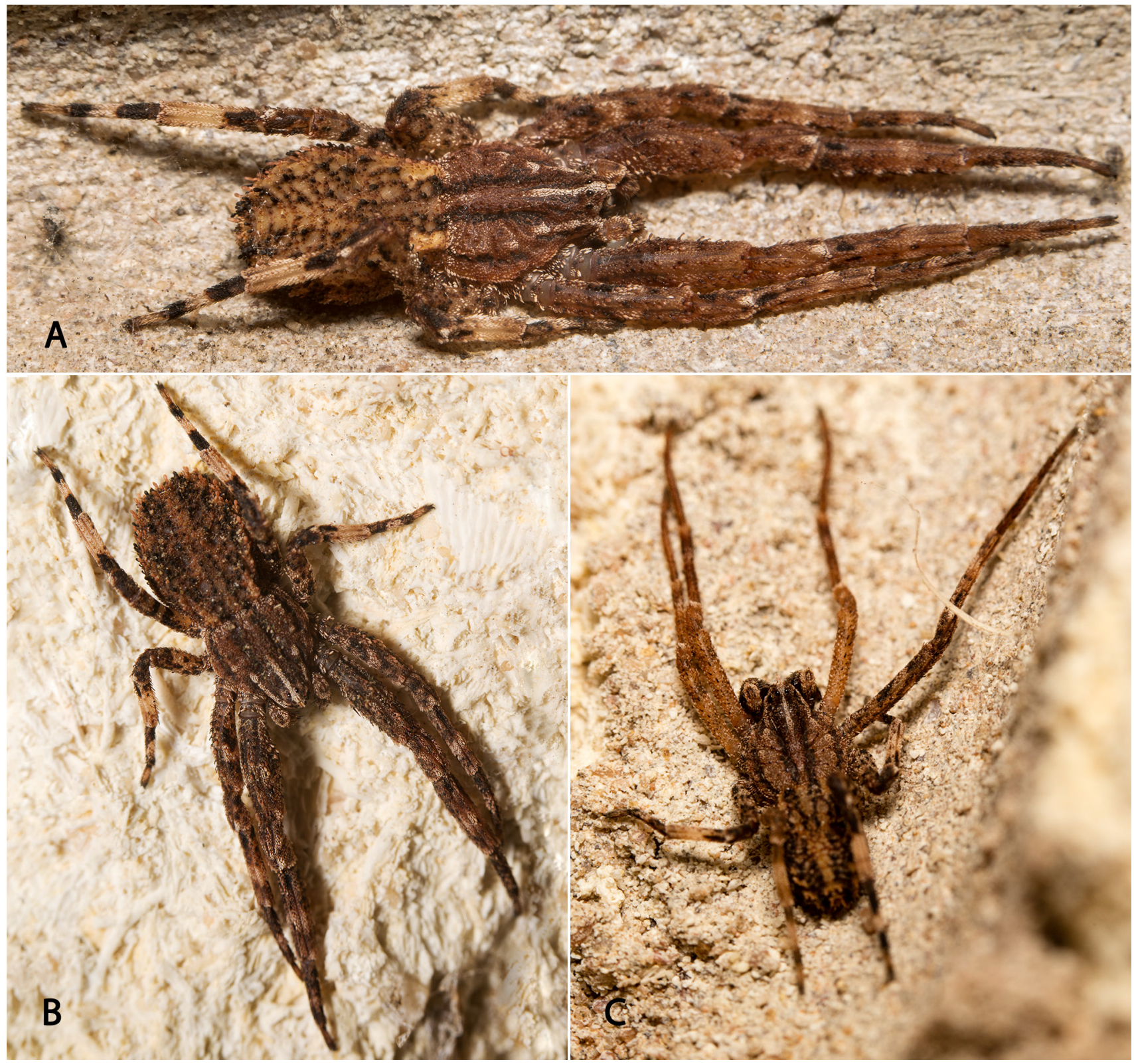

Figure 18. Stephanopis cambridgei $(A$ and $B$ ) females and a $(C)$ male. Photos by Allan Lance.

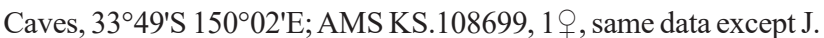
Child, 12 September 1965; AMS KS.108702, 1 , , Mulgoa (Penrith), $33^{\circ} 50^{\prime} \mathrm{S} 150^{\circ} 38^{\prime} \mathrm{E}, \mathrm{R}$. Mascord, 7 August 1966; AMS KS.108700, $1{ }^{\top}$, Royal NP, $34^{\circ} 08^{\prime} \mathrm{S} 151^{\circ} 02^{\prime} \mathrm{E}, \mathrm{A}$. Speechley, 9 January 1966 ; AMS KS.108697, 1 을 Helensburgh, $34^{\circ} 11^{\prime} \mathrm{S} 151^{\circ} \mathrm{E}, \mathrm{R}$. Mulder, 15 September 1966; AMS KS.108701, 1우, Figtree (Wollongong), $34^{\circ} 26^{\prime} \mathrm{S} 150^{\circ} 51^{\prime} \mathrm{E}, \mathrm{C}$. Chadwick, 12 June 1965; AMS KS.49694, $10^{\lambda}$, Barren Grounds, $34^{\circ} 42^{\prime} \mathrm{S} 150^{\circ} 43^{\prime} \mathrm{E}, 3$ September 1996; AMS KS.111105, 10̄, Bowning, 3446'16"S 14849'29"E, J.R. Gollan \& M.A. Ashcroft, 14-16 October 2008; AMS KS.108690, 2우, Brindabella NP, $35^{\circ} 23^{\prime} \mathrm{S} 148^{\circ} 46^{\prime} \mathrm{E}$, J. Child, 1965; AMS KS.125161,

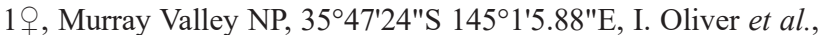
10-14 February 2015; AMS KS.84459, $1 \delta^{\lambda}, 14.5 \mathrm{~km}$ northwest of Corowa, 35 54'33"S 146 $16^{\circ} 11 "$ E, D. Freudenberger, November 2000. South Australia: AMS KS.10530, 1 , $5 \mathrm{~km}$ south of Mylor, $35^{\circ} 03^{\prime}$ S $138^{\circ} 46^{\prime} \mathrm{E}$, A.D. Austin, 8 June 1980. Victoria: AMS KS.19790, 1ㅇ, Blackwood (Loam Creek), 37²9'S 144¹9'E; AMS KS.108687, 1 오, Gisborne, $37^{\circ} 30^{\prime} \mathrm{S} 144^{\circ} 35^{\prime} \mathrm{E}$; WAM T146683, 3 오오, Airey's Inlet, $38^{\circ} 28^{\prime}$ S $144^{\circ} 06^{\prime}$ E, M.S. Harvey \& M.E. Blosfelds, 13-14 April 1992; QM S104676, 1․, Wilsons Promontory (Lilly Pilly upper track), 39¹'19.24"S 146²19'16.45"E, B. Humphries, 15
July 1976. Tasmania: AMS KS.31401, 2 우, Cascades, $41^{\circ} 10^{\prime} \mathrm{S}$ $147^{\circ} 49^{\prime} \mathrm{E}, \mathrm{V}$. V. Hickman, 26 May 1923; AMS KS.31403, 1수, 1 우, same data except 28 May 1929; AMS KS.31404, 1 त, same data except 25 August 1947; AMS KS.31451, 19, same data except 26 June 1963; AMS KS.31452, 1 ㅇ, same data except 14 June 1948; AMS KS.31402, $10^{\lambda}, 1$, , Forth Falls, $41^{\circ} 23^{\prime} \mathrm{S} 146^{\circ} 13^{\prime} \mathrm{E}$, V. V. Hickman, January 1928; AMS KS.31489, 1 9 , Punch Bowl, 41 ${ }^{\circ} 27$ 'S $147^{\circ} 10^{\prime}$ E, C. Oke, 17 May 1948; AMS KS.52160, 1웅. Maggs Mountain, $41^{\circ} 45^{\prime}$ S $146^{\circ} 12^{\prime}$ E, R.H. Green, 19 September 1979; MACN 11163, 1 , , Derwent Bridge, $42^{\circ} 8^{\prime} 15.60^{\prime \prime S} 146^{\circ} 13^{\prime} 48.93^{\prime \prime E}$, M. Ramírez, C. Griswold, D. Silva, G. Hormiga, L. Lopardo, N. Scharff \& T. Szuts, 11 March 2006; AMS KS.111841, 19, Old Man's Head (near Interlaken), $42^{\circ} 12^{\prime}$ S $147^{\circ} 13^{\prime} E$, R.B. Mawbey, 29 May 1974; AMS KS.31485, 1 \% , Tarraleah, $42^{\circ} 18^{\prime} \mathrm{S} 146^{\circ} 26^{\prime} \mathrm{E}$, V. V. Hickman, 29 December 1960; AMS KS.31486, 10, same data except 26 December 1956; AMS KS.118867, 19, Elderslie, 4234'23.63"S 147³'7.67"E, G.A. Davis, 2-29 November 2010; AMS KS.31432, $10^{\top}, 1$, , Queens Domain, 42 $52^{\prime}$ 'S $147^{\circ} 19^{\prime} \mathrm{E}$, J.L. Hickman, 19 January 1962; AMS KS.31453, $1 \hat{\jmath}$, same data except V. V. Hickman, 13 February 1967; AMS KS.31395, $1{ }^{\lambda}$, same data except 14 February 1969. 
Diagnosis. Females of $S$. cambridgei are similar to those of S. rufiventris, in having an elongated body (Fig. 18A-C), predominant orange coloration and obovate opisthosoma. However, they can be distinguished by the prosoma being longer than wide, with two pairs of longitudinal lines (a median pair that runs from the carapace slope until the posterior eye row and a lateral one placed close to the border of the prosoma and limited to the thoracic portion), epigynal plate flattened with depressed atrium, $\mathrm{CO}$ hidden by the lateral folds (like a pair of lateral pockets) (Fig. 16C), and long, coiled and membranous copulatory ducts (Fig. 16D). Males are easily recognized by their set of modified (long, thin and filiform) barbs on tibiae and metatarsi I (Fig. 17A) and by the remarkably rounded and big palpi with a single curved RTA (Fig. 17C and D).

Description. Female (AMS KS.10530): Cephalic area slightly elevated with a pair of whitish setae on the MOQ (Fig. 16B); anterior eyes arranged in a strongly recurved row and posterior ones in a straight row; PLE preceded by a pair of clavate setae. Clypeal area and chelicerae striped; prosoma and legs orange with reddish-brown stripes and sparse spots; tibiae I bear five pairs of ventral macrosetae (Fig. 16A). Opisthosoma obovate, with anterior border slightly concave, yellowish with median light-brown bands weakly delimited by darker ones on both sides (Fig. 16A). Spermathecae elongated, with glandular-heads directed laterally (Fig. 16D).

Measurements: eye diameters and interdistances: AME 0.08, ALE 0.18, PME 0.10, PLE 0.12, AME-AME 0.18, AME-ALE 0.18, PME-PME 0.20, PME-PLE 0.22, MOQ length 0.41 , width 0.50 ; leg formula: 1-2-4-3: leg I-femur 3.34 / patella 1.72 / tibia 3.21 / metatarsus 2.31 / tarsus 0.94 / total 11.52 ; II-3.00/ 1.37/2.69/2.18/0.92/ 10.16; III-2.11/ $1.02 / 1.68 / 1.37 / 0.75 / 6.93$; IV—2.77/ 1.10/ $2.27 / 1.90 /$ $0.87 / 8.91$. Total body length 9.61 ; prosoma length 3.37 , width 3.25; opisthosoma length 6.24; clypeus height 0.32 ; sternum length 1.69 , width 1.73; gnathocoxae length 0.75 , width 0.42 ; labium length 0.50 , width 0.53 .

Male (AMS KS.128377): Eye pattern and cephalic area as in female; prosoma light-orange with darker stripes on its median portion and sides (Fig. 17A and B); opisthosoma and legs predominantly yellow and covered by claviate setae, except by the tibiae, metatarsi and tarsi of the leg I, which are dark-orange and bear long filiform barbs (Fig. 17A). Palpi with rounded tegulum, long and flattened embolus resting on a retro lateral membranous region of the tegular ridge; Pcym discrete and hyaline (Fig. 17C). Other somatic features as in female.

Measurements: eye diameters and interdistances: AME 0.09, ALE 0.20, PME 0.15, PLE 0.15, AME-AME 0.09, AME-ALE 0.08, PME-PME 0.12, PME-PLE 0.12, MOQ length 0.44, width 0.34; leg formula: 1-2-4-3: leg I-femur 3.94/ patella 1.61 / tibia $4.41 /$ metatarsus $3.67 /$ tarsus 1.21 / total 14.84; II-3.67/ 1.39/3.82/3.11/0.86/12.85; III-2.31/ $0.95 / 2.04 / 1.64 / 0.82 / 7.76$; IV-3.00/ 1.08/ 2.78/ 2.36/ $0.89 / 10.11$. Total body length 7.79 ; prosoma length 3.45 , width 2.74; opisthosoma length 4.34; clypeus height 0.26 ; sternum length 1.56 , width 1.54 ; gnathocoxae length 0.76 , width 0.39 ; labium length 0.48 , width 0.54 .

Distribution. Queensland, New South Wales, South Australia, Victoria and Tasmania, Australia (Fig. 24).

\section{Stephanopis carcinoides Machado sp. nov.}

http://zoobank.org/NomenclaturalActs/8F14CAF8-F536-4ADA-840F-C0A331D7EF8E

Figs 19-21

Holotype 9 AMS KS.108724, from Minnamurra Rainforest

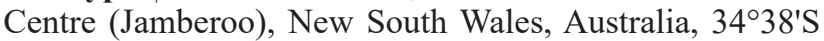
$150^{\circ} 44^{\prime} \mathrm{E}, \mathrm{R}$. Mascord, 1 February 1965 . Paratypes: AMS KS.81287, 1ㅇ, Mulgrave River, New South Wales, Australia, $17^{\circ} 07^{\prime} \mathrm{S} 145^{\circ} 47^{\prime} \mathrm{E}, \mathrm{R}$. Mascord, 13 July 1978; AMS KS.81293, $1{ }^{\Uparrow}, 1$ female from Minnamurra Rainforest Centre (Jamberoo), New South Wales, Australia, $34^{\circ} 38^{\prime} \mathrm{S} 150^{\circ} 44^{\prime} \mathrm{E}$, R. Mascord, 01 November 1966; QM S104677, 2ðð, 1q, Bunya Mountains (Dandabah Camping Area), Queensland, Australia, 26 $52^{\prime} 50.31 " \mathrm{~S} 151^{\circ} 35^{\prime} 50.58^{\prime \prime} \mathrm{E}$, Queensland Museum staff, 17 March 1976.

Other material examined. Papua New Guinea, Morobe: MCZ 134023, 10, Wau, 648'4.94"S 146³3'41.93"E, H. Levi, 25 March 1979; MCZ 134021, 1ㅇ, 7²0'13.69"S 146²42'57.37"E, M. Robinson, 20 November 1979; MCZ 134022, 1ð, M. Robinson \& H. Levi. Australia, Queensland: QM S104673, 1 , , Shiptons Flat, $15^{\circ} 44^{\prime} 20.14$ "S 145 13 '32.81"E, Queensland Museum party, 17-21 November 1975; AMS KS.106795, 1ㅇ, Kuranda, 16²48'35.6"S $145^{\circ} 39^{\prime} 14.29^{\prime \prime E}$, G. Milledge \& H. Smith, 8 December 2008; AMS KS.103078, 1 ,, $16^{\circ} 49^{\prime} 50^{\prime \prime S} 145^{\circ} 38^{\prime} 36^{\prime \prime}$, G. Milledge \& H. Smith, 27 February-7 March 2008; AMS KS.108713, 1․ Lake Euramoo, $17^{\circ} 10^{\prime}$ S $145^{\circ} 38^{\prime} \mathrm{E}, \mathrm{R}$. E. Mascord, 23 July 1978; QM S9925, $1 \jmath^{\lambda}$, Nerimberah, $23^{\circ} 23^{\prime} 58.74^{\prime \prime S ~} 150^{\circ} 35^{\prime} 12.17^{\prime \prime E}$, R. Raven \& J. Gallon, 17 February 1986; QM S14675, 10, Kroombit Tops NP, $24^{\circ} 22^{\prime} 40.14^{\prime \prime} \mathrm{S} 150^{\circ} 55^{\prime} 42.55^{\prime \prime E}$, Davies \& Gallon, 9-19 December 1983; AMS KS.69488, 1 ㅇ, Brisbane Forest Park, 27²5'04"S $152^{\circ} 49^{\prime} 48^{\prime \prime E}$, N. Power, 1-6 March 1998; AMS KS.69547, 1 ㅇ, 12-17 April 1998; QM S104653, 10, Cooloola, 27²8'11.18"S $153^{\circ} 1$ '30.45"E, R. Raven \& V. E. Davies, 3-8 February 1976; QM

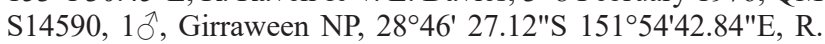
Raven, 22 February 1973. New South Wales: AMS KS.2830, $1 \hat{\jmath}$, Mount Wilson, 3330'S 150²3'E, C. Horseman, 28 March 1979.

Diagnosis. Males and females of $S$. carcinoides sp. nov. are similar to those S. nigra and S. altifrons in having a high cephalic prominence, high clypeus (Figs 19B and 20B) and cryptic habitus (Fig. 21A-D), however, it is distinguished from these species by its prosoma slightly wider than long, opisthosoma pentagonal and femur I with a pair of prolateral setiferous tubercles instead of just one (Figs 19A and 20A). The epigynal plate of females resemble those of $S$. nigra but the atrium is wider and shorter, and the $\mathrm{CO}$ are smaller (Fig. 19C, D). As in S. altifrons, the male palpi present equal-sized and pointed RTA and RTAvbr, however, in S. carcinoides sp. nov. the RTA is curved, points ventrally, parallel to the tegulum (Fig. 20D), and both RTA and RTAvbr are shorter and flattened (compressed laterally) (Fig. 20C).

Description. Female (AMS KS.108724): Anterior eye row strongly recurved and posterior procurved, prosoma darkyellow with brown stains on the thoracic portion and sides of the cephalic prominence (Fig. 19A and B). Legs darkyellow with brown patches on the median portion of anterior femora (I and II); patellae, tibiae and metatarsi with brown patches sparsely distributed; anterior tibiae ventrally armed with four pairs of macrosetae (Fig. 19A). Opisthosoma with concave anterior border, whitish-yellow with a brown spot on the heart-sigilla and a pair of darker transverse patches on the posterior region. 


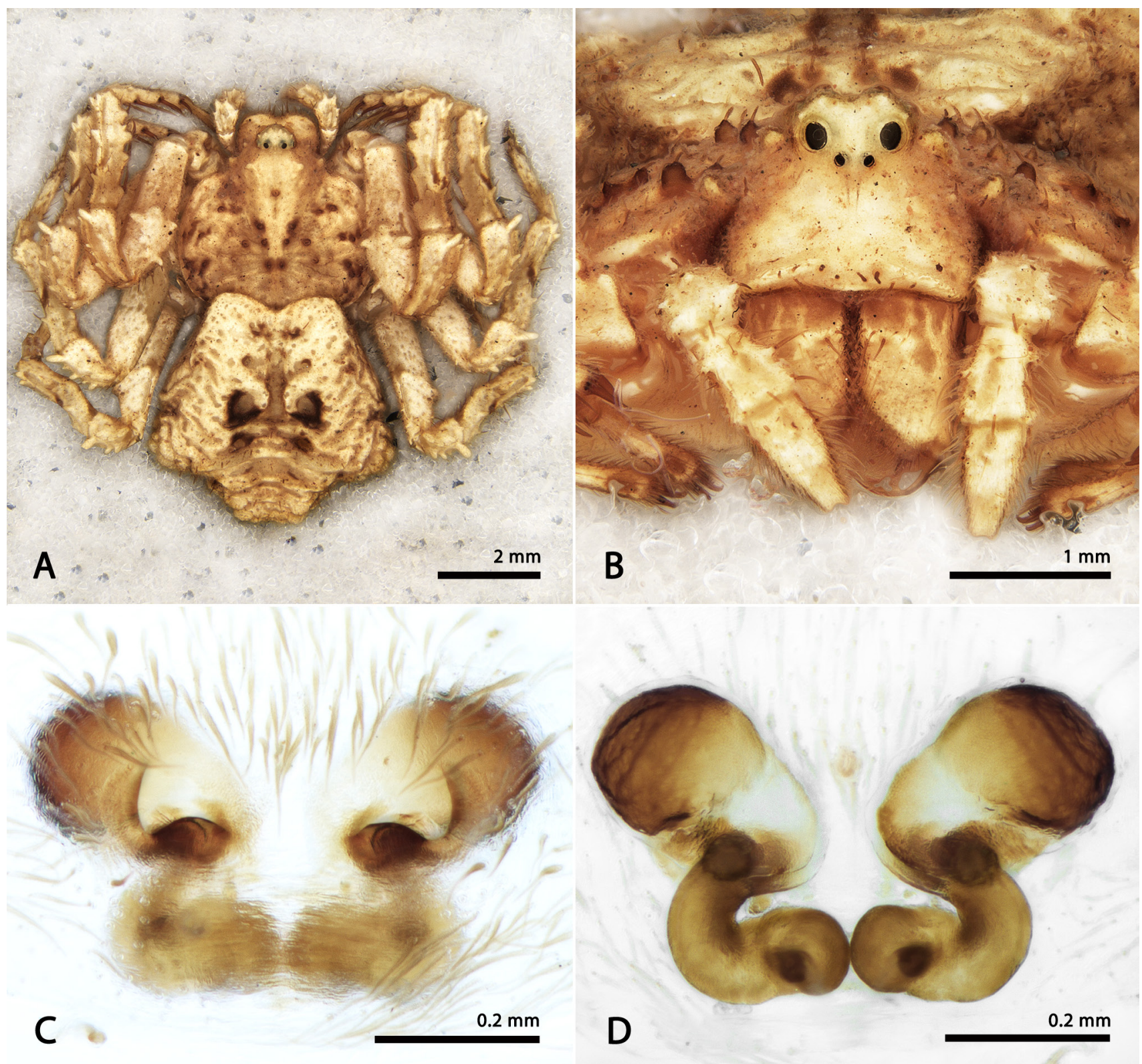

Figure 19. Stephanopis carcinoides sp. nov., female (AMS KS.108724). (A) dorsal habitus; (B) front; (C) epigynal plate, ventral view; (D) epigynal plate/spermathecae.

Measurements: eye diameters and interdistances: AME 0.07, ALE 0.17, PME 0.15, PLE 0.11, AME-AME 0.10, AME-ALE 0.07, PME-PME 0.18, PME-PLE 0.11, MOQ length 0.44, width 0.35; leg formula: 1-2-4-3: leg I-femur 2.74 / patella 1.54 / tibia 2.19 / metatarsus $1.57 /$ tarsus $0.97 /$ total 9.01; II-2.85/ 1.49/2.08/ 1.65/ 0.949 .01 ; III-2.45/ $1.13 / 2.06 / 1.88 / 0.95 / 8.47$; IV $-2.64 / 0.91 / 1.97 / 1.95 /$ $1.06 / 8.53$. Total body length 9.31 ; prosoma length 3.69 , width 3.80 ; opisthosoma length 5.62; clypeus height 0.71 ; sternum length 1.71 , width 1.53 ; gnathocoxae length 0.95 , width 0.47 ; labium length 0.61 , width 0.66 .

Male (QM S104677). Eye arrangement and colour pattern as in female, predominantly whitish-yellow with brown patches
(Fig. 20A and B). Embolus sclerotized at is basis, flexible at is terminal portion and resting on the apical tegular ridge (Fig. 20C). Other somatic characters as in female.

Measurements: eye diameters and interdistances: AME 0.06, ALE 0.15, PME 0.10, PLE 0.10, AME-AME 0.10, AME-ALE 0.06, PME-PME 0.15, PME-PLE 0.08, MOQ length 0.37 , width 0.28; leg formula: 1-2-3-4: leg I-femur 2.26 / patella 1.16 / tibia 1.75 / metatarsus 1.56 / tarsus 0.83 / total 7.56; II-2.05/ 0.98/ 1.50/ 1.35/ 0.876 .75 ; III-1.74/ $0.72 / 1.44 / 1.46 / 0.73 / 6.09$; IV $-1.77 / 0.62 / 1.35 / 1.44 /$ $0.75 / 5.93$. Total body length 5.18 ; prosoma length 2.51 , width 2.44; opisthosoma length 2.67; clypeus height 0.54 ; sternum length 1.21 , width 1.18; gnathocoxae length 0.54 , width 0.34 ; labium length 0.65 , width 0.35 . 


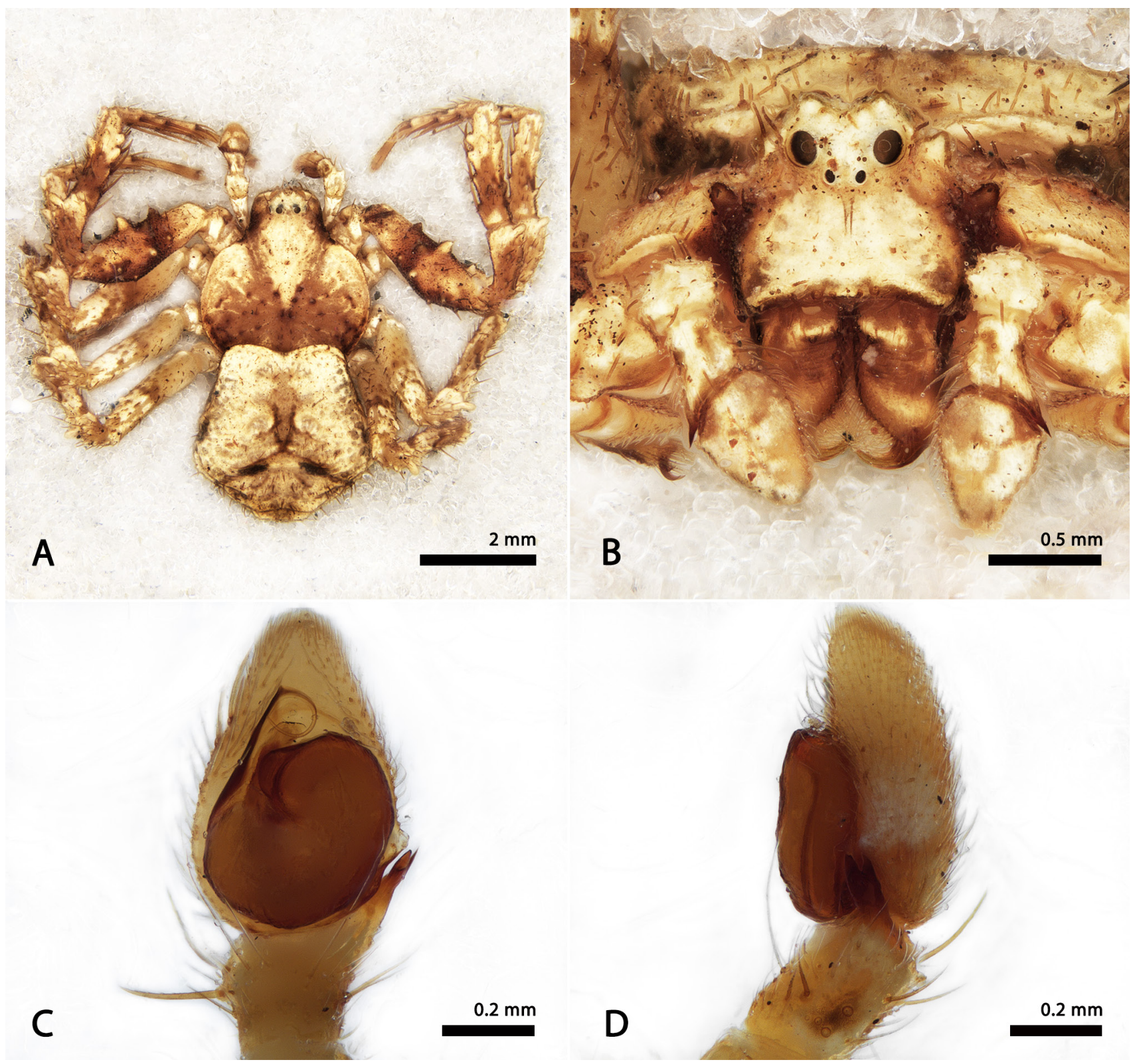

Figure 20. Stephanopis carcinoides sp. nov., male (QM S104677). (A) dorsal habitus; (B) front; (C) ventral view of the left palp; (D) left palp, retro lateral view.

Etymology. The specific epithet is the combination of the Greek noun "carcino", meaning crab, and the suffix "oides", meaning resembling, used here to describe a spider that looks like a crab due to its laterigrade legs and flattened dorsal habitus.

Distribution. Morobe, Papua New Guinea; Queensland and New South Wales, Australia (Fig. 24).

Variation. All examined specimens present pale-yellow cuticle (preserved in ethanol), however, live specimens may be greenish due to the accumulation of debris such as lichen or moss. 


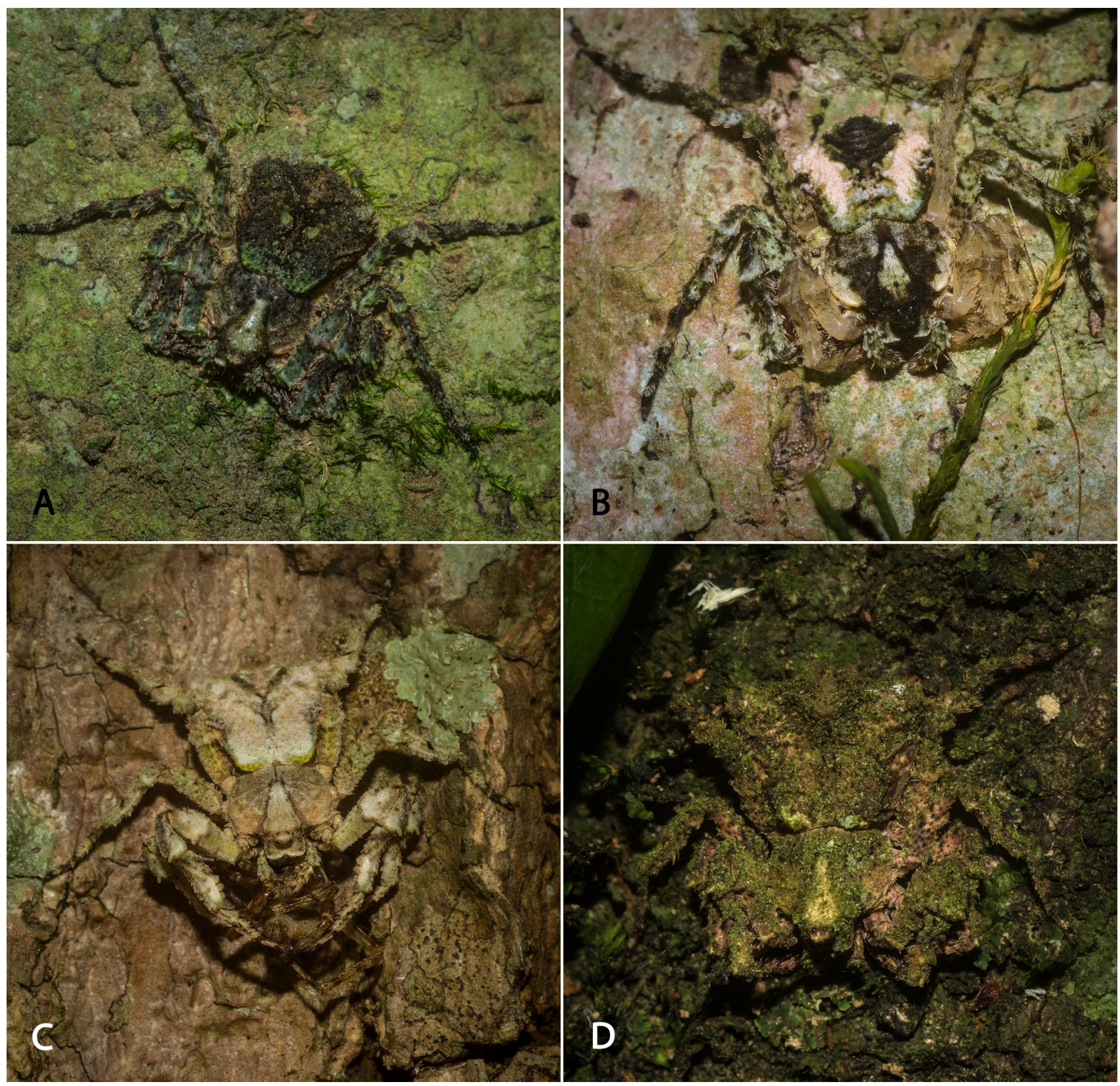

Figure 21. (A-D) Stephanopis carcinoides sp. nov. colour variations of females. Photos by Nicholas Fisher. 

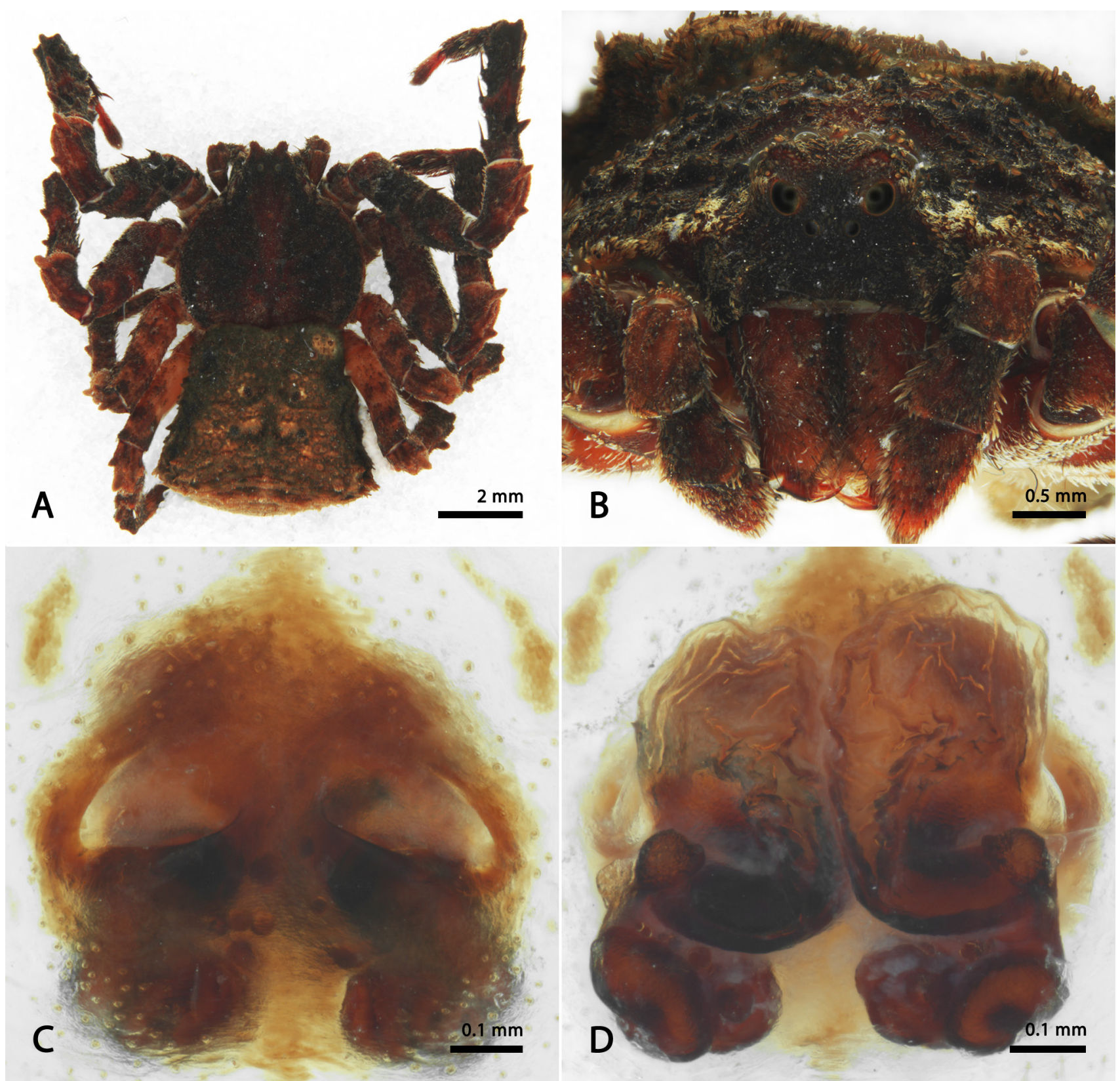

Figure 22. Stephanopis corticalis L. Koch, 1876, female (AMS KS.108671). (A) dorsal habitus; (B) front; (C) epigynal plate, ventral view; (D) epigynal plate/spermathecae.

\section{Stephanopis corticalis L. Koch, 1876}

Fig. 22

Stephanopis corticalis L. Koch, 1876: 748, pl. 65, Fig. 5.

Type material examined. Holotype $\circ, \mathrm{ZSMH}$, Gayndah, Queensland, Australia, [253'ㅇ $\left.151^{\circ} 36^{\prime} \mathrm{E}\right]$.

Other material examined. Northern Territory: AMS KS.109399, 1 을, Yirrkala, $12^{\circ} 15^{\prime} \mathrm{S} 136^{\circ} 53^{\prime} \mathrm{E}, \mathrm{C}$. Chaseling. Queensland,: AMS KS.108717, 1 \%, Mareeba, $17^{\circ} \mathrm{S} 145^{\circ} 26^{\prime} \mathrm{E}$, N.C. Coleman, 11 May 1975. Western Australia: WAM T142491,

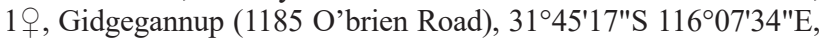
3 August 2012; WAM T146671, 1 \%, Greenmount, 31 ${ }^{\circ} 54^{\prime 2} 2.30 " \mathrm{~S}$ $116^{\circ} 3^{\prime} 0.92 " E$, G.H. Lowe, June 1979; WAM 1517, 1 ㅇ, 20 Km south of Ravensthorpe, 3337'6.97"S 120³'20.71"E, G. Harold, 2 January 1994. New South Wales: AMS KS.108671, 1 , , Dubbo (Minore Village), 32¹5'49.27"S 148²7'18.53"E, H. Levi, 29 January 1957.
Diagnosis. The females of $S$. corticalis resemble those of $S$. lata in the predominantly reddish-brown body colouration, shape of their opisthosoma and size and proportion of their legs (Fig. 22A), however, they can be distinguished by the presence of a pair of acute and forward oriented cephalic projections above the ALE (Fig. 22B). S. corticalis can be also recognized by the wide and exposed copulatory $\mathrm{CO}$ (Fig. 22C) and internal ducts oriented sideways with glandularheads on top (Fig. 22D).

Description. Female (AMS KS.108671): Anterior eye row recurved and posterior straight (Fig. 22B); anterior legs and prosoma reddish-brown while the posterior legs and the median part of the opisthosoma are lighter (Fig. 22A). All legs bear a remarkable dorsal row of acute projections (a pair on the patellae and a triad on the tibiae). Spermathecae tubular, curling on itself and preceded by hyaline rounded pair of anterior chambers (Fig. 22D). 

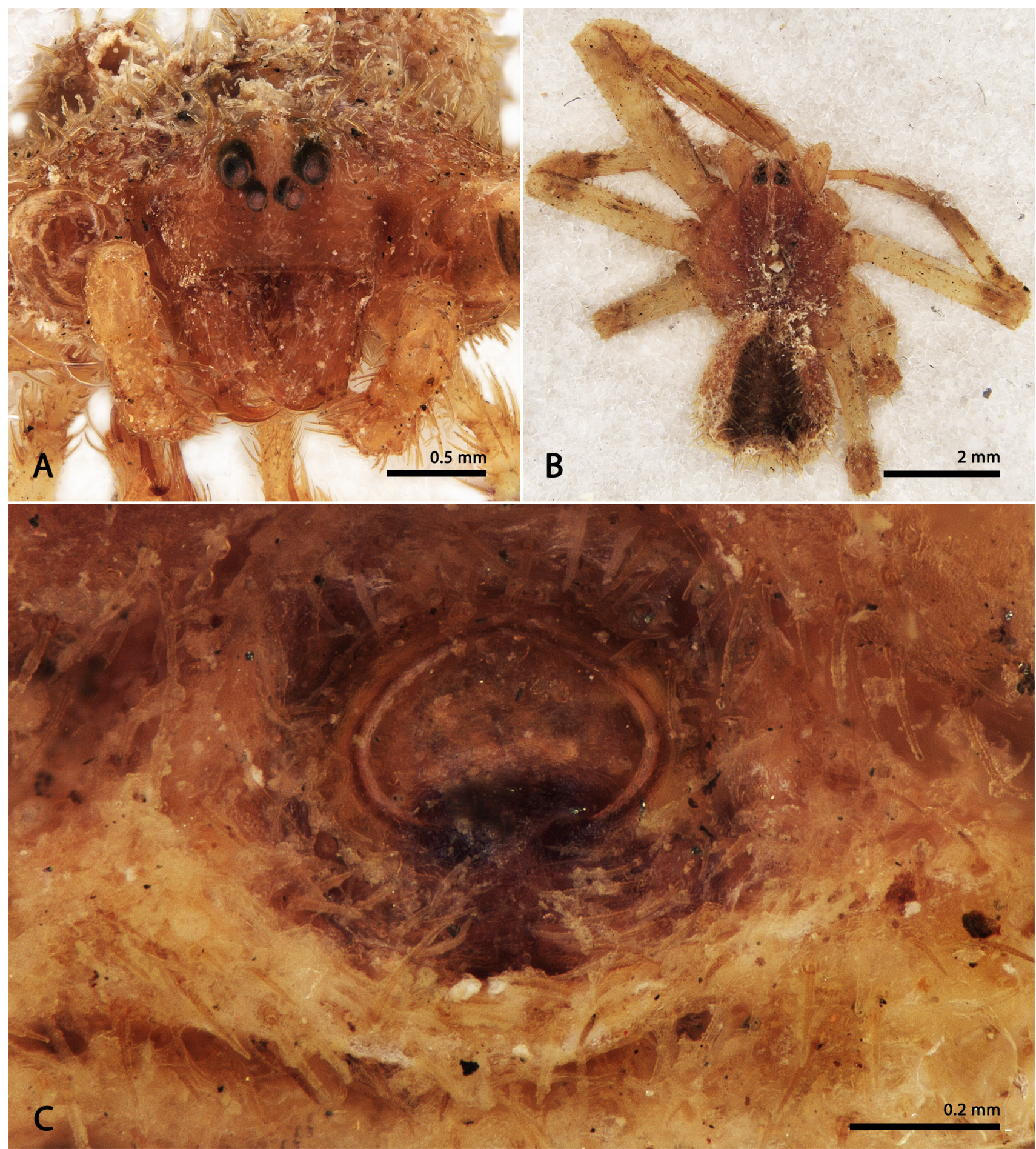

Figure 23. Stephanopis erinacea Karsch, 1878, female (ZMB). (A) front; (B) dorsal habitus; (C) epigynal plate, ventral view.

Measurements: eye diameters and interdistances: AME 0.13, ALE 0.25, PME 0.19, PLE 0.20, AME-AME 0.18, AME-ALE 0.10, PME-PME 0.26, PME-PLE 0.21, MOQ length 0.65 , width 0.45 ; leg formula: 1-2-4-3: leg I-femur 4.52 / patella 2.21 / tibia 3.76 / metatarsus 2.11 / tarsus 1.13 / total 13.73; II-3.89/1.84/3.10/1.86/1.06 11.75; III-3.24/ $1.43 / 2.62 / 1.54 / 1.05 / 9.88 ; \mathrm{IV}-3.35 / 1.29 / 2.33 / 1.36 /$ 0.93 / 9.26. Total body length 9.01; prosoma length 4.35 , width 4.55; opisthosoma length 4.66; clypeus height 0.45 ; sternum length 2.03 , width 1.76; gnathocoxae length 1.11 , width 0.52 ; labium length 0.70 , width 0.85 .

Male: Unknown.

\section{Stephanopis erinacea Karsch, 1878}

Fig. 23

Stephanopis erinacea Karsch, 1878: 810.

Type material material. Holotype $\odot$, ZMB, Fiji, $\left[17^{\circ} 42^{\prime} \mathrm{S}\right.$ $\left.178^{\circ} 03^{\prime} \mathrm{E}\right]$, pinned in the dry collection. No other material examined.

Diagnosis. The female of $S$. erinacea resembles that of $S$. fissifrons in the shape of its epigynal plate with depressed atrium (Fig. 23C), and by its trapezoid opisthosoma. However, females of $S$. erinacea can be distinguished by 


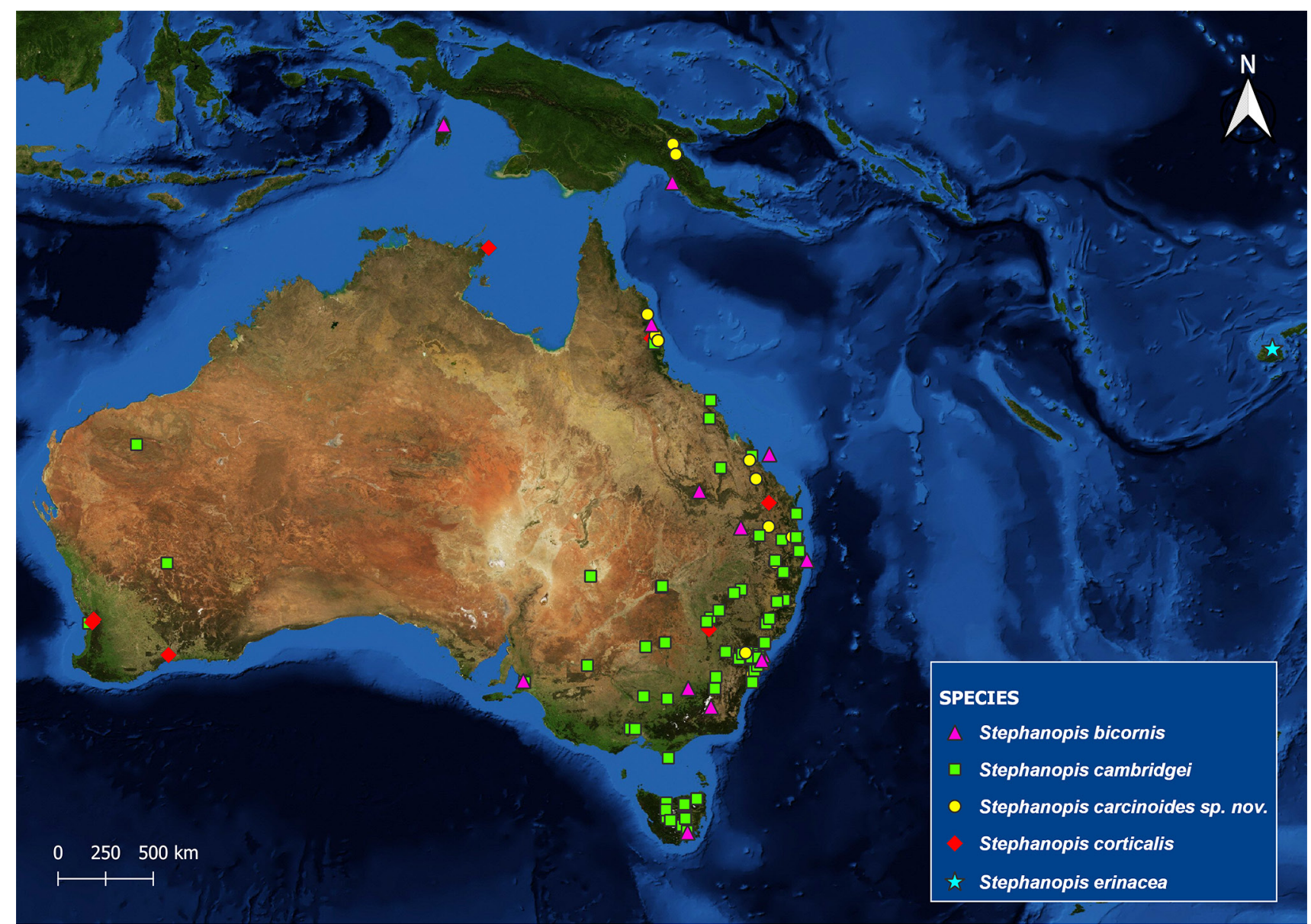

Figure 24. Distribution records of Stephanopis bicornis, S. cambridgei, S. carcinoides sp. nov., S. corticalis and S. erinacea.

the long and spiniform setae covering their entire body (Fig. $23 \mathrm{~A}$ and $\mathrm{B}$ ) and the $\mathrm{CO}$ hidden by the lateral folds of the epigynal plate (Fig. 23C).

Description. Female (ZMB 1878): Both anterior and posterior eye rows recurved, with the anterior eyes arranged in a strong curved line and the posterior ones almost in a straight row (Fig. 23A and B). Prosoma orange and legs predominantly yellow, with just the extremities of each segment being brownish; tibiae I ventrally armed with five pairs of macrosetae (Fig. 23B). Opisthosoma trapezoid, dark-yellow on the sides and venter but entirely dark-brown on the dorsum.

Measurements: eye diameters and interdistances: AME 0.10, ALE 0.15, PME 0.10, PLE 0.12, AME-AME 0.10, AME-ALE 0.07, PME-PME 0.13, PME-PLE 0.11, MOQ length 0.37 , width 0.20 ; leg formula: $1-2-4-3$ : leg I-femur 3.32 / patella 0.93 / tibia 2.78 / metatarsus 1.32 / tarsus $0.87 /$ total 9.22; II-2.71/ 0.82/2.27/ 1.25/ 0.81/ 7.86; III-1.93/ $0.82 / 1.21 / 1.11 / 0.77 / 5.84$; IV $-2.53 / 1.02 / 1.29 / 0.97 /$ $0.63 / 6.44$. Total body length 5.63 ; prosoma length 3.00 , width 2.72; opisthosoma length 2.63; clypeus height 0.31 ; sternum length 1.26 , width 1.12 ; gnathocoxae length 0.71 , width 0.40 ; labium length 0.38 , width 0.52 .

Male: Unknown.

Distribution. Fiji (Fig. 24).

\section{Stephanopis fissifrons Rainbow, 1920}

Figs 25-26

Stephanopis fissifrons Rainbow, 1920: 253, pl. 29, figs 67-68.

Type material examined. Syntypes: Lord Howe Island, New South Wales, Australia, AMS KS.6682, 10, 1 \% $31^{\circ} 33^{\prime} \mathrm{S} 159^{\circ} 05^{\prime} \mathrm{E}, \mathrm{A}$. M. Lea, December 1915 to January 1916; SAM NN262, 13 juveniles, $31^{\circ} 30^{\prime} \mathrm{S} 159^{\circ} 4^{\prime} \mathrm{E}$, December 1915 to January 1916; SAM NN26, 1 ㅇ, 31 $31^{\circ} 30^{\prime}$ S $159^{\circ} 4^{\prime} \mathrm{E}$, December 1915 to January 1916.

Other material examined. Lord Howe Island, New South Wales, Australia: AMS KS.86884, 1ㅇ, 3131'49"S 15904'38"E, T. Kingston \& B. Miller, 19 September 1978; AMS KS.86886, 1 ,

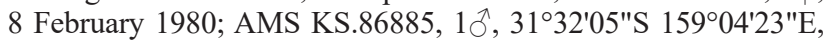

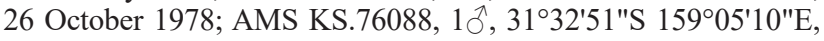
AMS staff, 26 November-3 December 2000; AMS KS.83210, 1 , $31^{\circ} 33^{\prime} \mathrm{S} 159^{\circ} 05^{\prime} \mathrm{E}, \mathrm{M}$. Gray, February 1971; AMS KS.90928, $1{ }^{\prime}$, H. M. Smith, 3 December 2000; AMS KS.84026, 1, 31 ${ }^{\circ} 33^{\prime} 15^{\prime \prime S}$ $159^{\circ} 04^{\prime}$ 50"E, J. Tarnawski, 20 February 2001; AMS KS.8403, 2 우, $31^{\circ} 33^{\prime} 19.19^{\prime \prime S} 159^{\circ} 4^{\prime} 55.63 " \mathrm{E}, \mathrm{M}$. Gray, February 1971; AMS

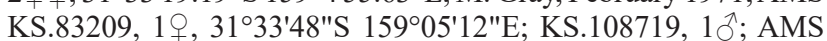
KS.86883, 1, 3134'47"S 15904'34"E, T. Kingston, 26 April 1979;

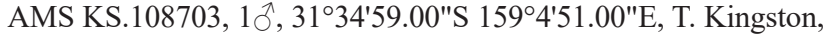
29 March 1979; AMS KS.84023, 1 ㅇ, Ball's Pyramid, 3145'8.03"S $159^{\circ} 14^{\prime} 58.38^{\prime \prime E}, \mathrm{~T}$. Kingston, 21 January 1980; AMS KS.51686, 1ð, Jamberoo Mountain, 34³9'S 15046'E, J. Noble, 20 April 1995.

Diagnosis. Females of $S$. fissifrons resemble those of $S$. lata in having a trapezoid opisthosoma, prosoma as long 

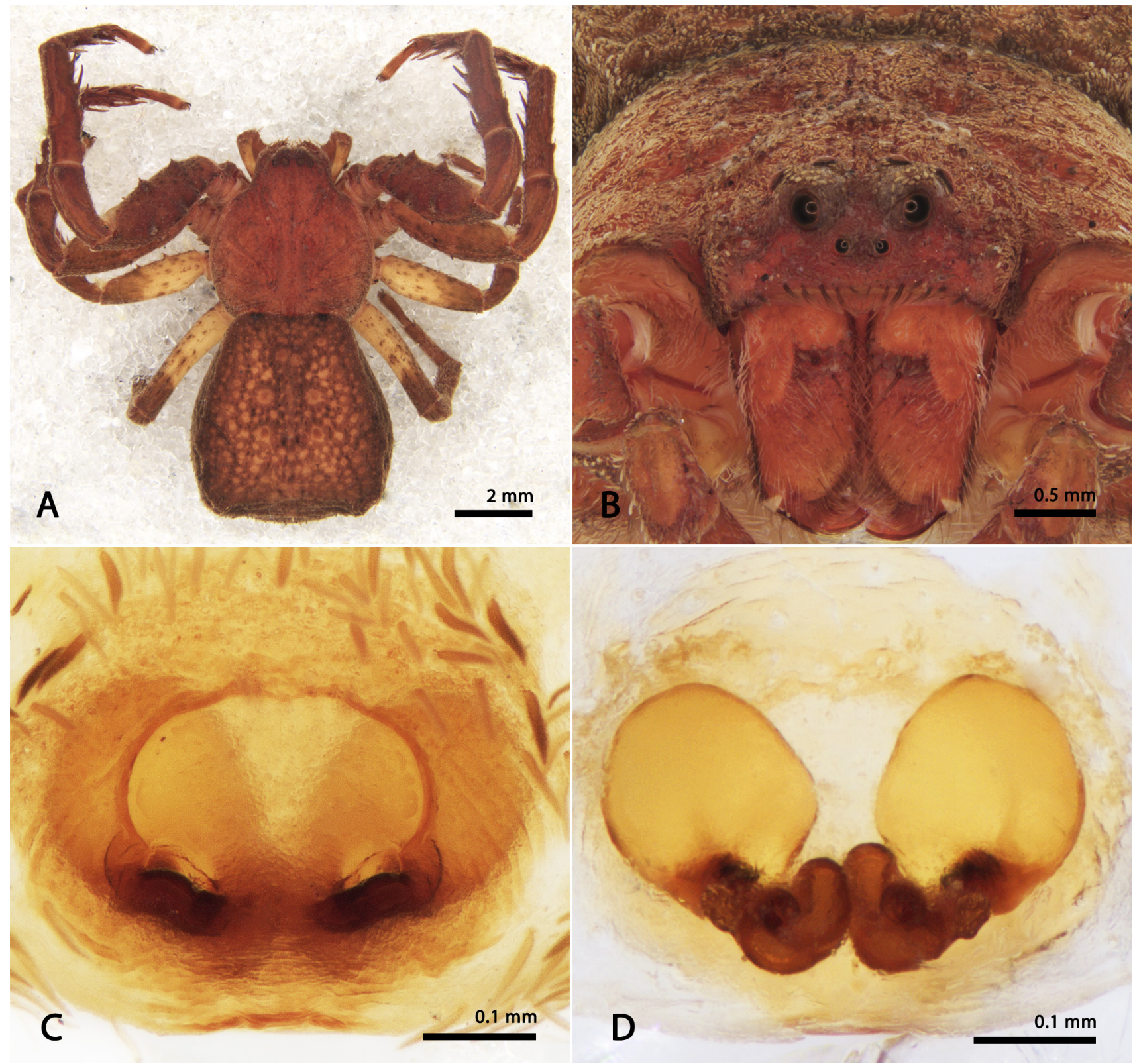

Figure 25. Stephanopis fissifrons Rainbow, 1920, female (AMS KS.84037). (A) dorsal habitus; (B) front; (C) epigynal plate, ventral view; (D) epigynal plate/spermathecae.

as wide and triad of projections on the dorsal surface of their anterior patellae and tibiae (I and II). However, they can be distinguished by their smoother and more flattened habitus (Fig. 25A), absence of cephalic prominence (Fig. 25B), discrete dorsal leg projections and $\mathrm{CO}$ positioned on the posterior border of the epigynal plate (Fig. 25C). Male palpi are similar to those of $S$. lata, however they differ by the discrete Pcym and trapezoid RTA instead of an acute one (Fig. 26C), rounded tegulum and thick cymbium (Fig. 26D). Moreover, males of $S$. fissifrons have long, thin and smooth femora and tibiae (Fig. 26A) instead of the armed and robust legs of $S$. lata males.

Description. Female (AMS KS.84037): Eyes arranged in a recurved anterior row (Fig 25A) and a straight posterior one (Fig. 25B). Prosoma and legs predominantly reddish-brown except by the proximal part of the posterior femora, which are yellow (Fig. 25A); tibiae I and II ventrally armed with four pairs of macrosetae. Opisthosoma brown with many lighter circular maculae on its dorsum; trapezoid. Epigynum in dorsal view presents a pair of globose anterior chambers, glandular-heads disposed sideways and spermathecae beanshaped (Fig. 25D).

Measurements: eye diameters and interdistances: AME 0.09, ALE 0.20, PME 0.14, PLE 0.14, AME-AME 0.14, AME-ALE 0.18, PME-PME 0.25, PME-PLE 0.15, MOQ length 0.46 , width 0.31 ; leg formula: $1-2-4-3$ : leg I-femur 3.70 / patella 1.89 / tibia 2.76 / metatarsus 1.84 / tarsus 0.95 / total 11.14; II-3.51/ 1.70/2.49/1.67/0.95/ 10.32; III-2.26/ 1.10/ 1.80/ 1.19/ 0.55/ 6.90; IV-2.64/ 1.02/ 1.86/ 1.30/ $0.71 / 7.53$. Total body length 7.59 ; prosoma length 3.93 , width 3.58; opisthosoma length 3.66; clypeus height 0.25 ; sternum length 1.78 , width 1.41 ; gnathocoxae length 0.98 , width 0.47 ; labium length 0.55 , width 0.63 .

Male (AMS KS.86882): Eye arrangement as in female (Fig. 


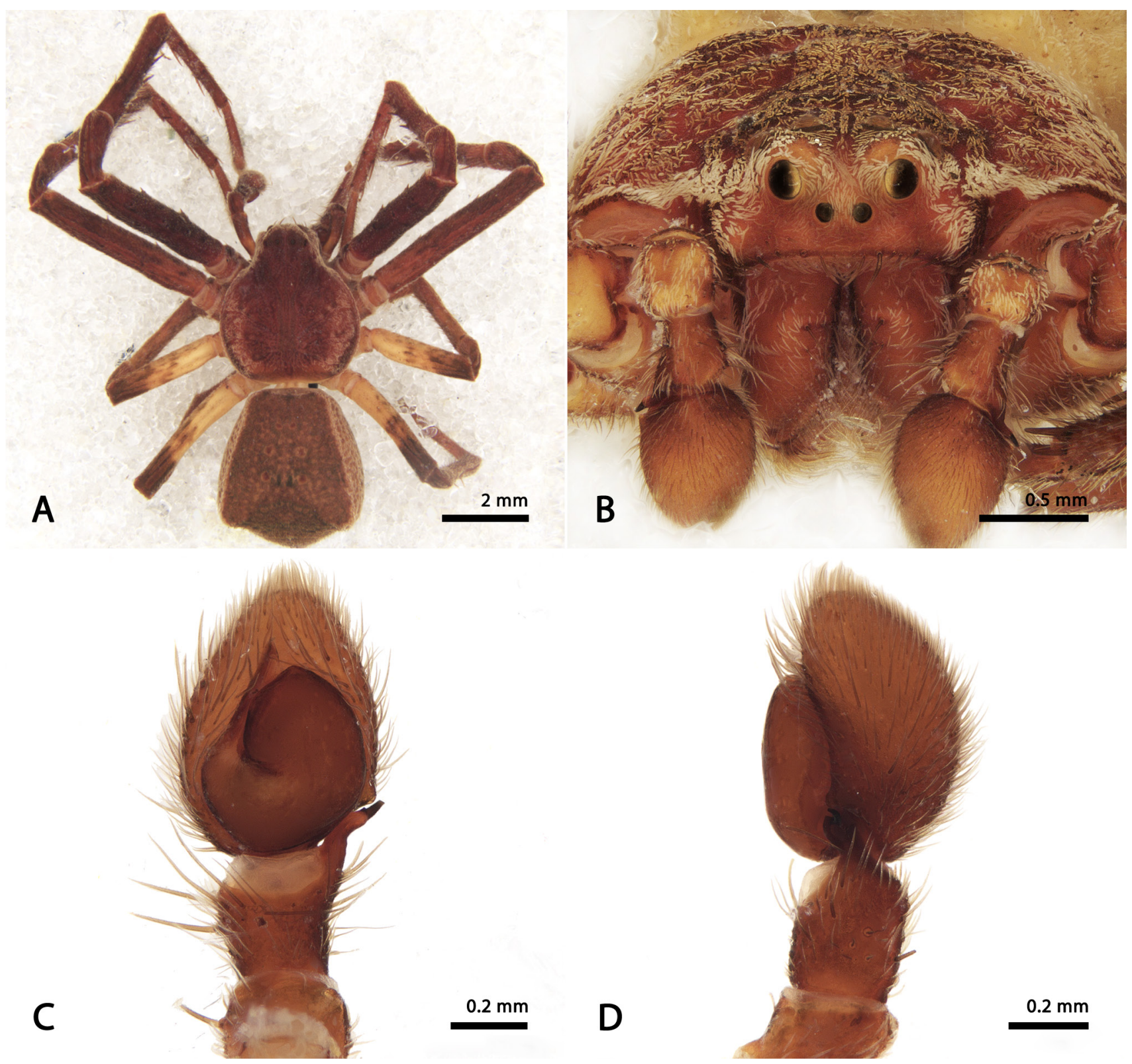

Figure 26. Stephanopis fissifrons Rainbow, 1920, male (AMS KS.86882). (A) dorsal habitus; (B) front; (C) ventral view of the left palp; (D) left palp, retro lateral view.

26B). Prosoma covered by hyaline setae, entirely brown with darker marks on the sides of the cephalic portion (Fig. 26A). Anterior legs (I and II) entirely brown and posterior ones (III and III) yellow only on the proximal half of the femora (Fig. 26A). Embolus short, curved on itself (Fig. 26C).

Measurements: eye diameters and interdistances: AME 0.10, ALE 0.15, PME 0.13, PLE 0.13, AME-AME 0.10, AME-ALE 0.08, PME-PME 0.16, PME-PLE 0.11, MOQ length 0.37, width 0.29; leg formula: 1-2-4-3: leg I-femur 2.33 / patella 1.12 / tibia 1.70 / metatarsus 1.14 / tarsus 0.68 / total 6.97; II-2.06/ 1.06/ 1.51/ 1.01/0.61/ 6.25; III-1.20/ $0.62 / 0.88 / 0.56 / 0.47 / 3.73$; IV $-1.43 / 0.58 / 0.91 / 0.66 /$ $0.44 / 4.02$. Total body length 4.57 ; prosoma length 2.22 , width 2.10; opisthosoma length 2.35; clypeus height 0.21 ; sternum length 0.92 , width 0.87 ; gnathocoxae length 0.49 , width 0.28 ; labium length 0.26 , width 0.39 .

Distribution. Lord Howe Island, New South Wales, Australia (Fig. 35).

\section{Stephanopis flagellata Machado sp. nov.}

http://zoobank.org/NomenclaturalActs/6E325F04-D3B9-482D-845A-6253062C7066

Fig. 27

Holotype $\widehat{A}$ AMS KS.77129, from Mungindi, 2849'46"S 149 $18^{\prime} 55^{\prime \prime E}$, Queensland, Australia, L. Wilkie, R. Harris and T. Moulds, 18 December 1999. Paratypes: AMS KS.120712, $1{ }^{\lambda}$, Scotia Sanctuary, $33^{\circ} 09^{\prime} 23^{\prime \prime S ~} 141^{\circ} 07^{\prime} 46^{\prime \prime E}$, New South Wales, C. Silvey, 1 February 2011; AMS KS.128002, $1 \overbrace{}^{\Uparrow}$,

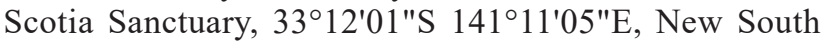
Wales, H. Gibb, February 2010.

Other material examined. Only the type material.

Diagnosis. Males of $S$. flagellata sp. nov. are almost indistinguishable from those of $S$. altifrons and $S$. nigra somatically. All three species possess a high cephalic prominence (Fig. 27B), flattened prosoma and obovate opisthosoma with stout setiferous tubercles on the rear 

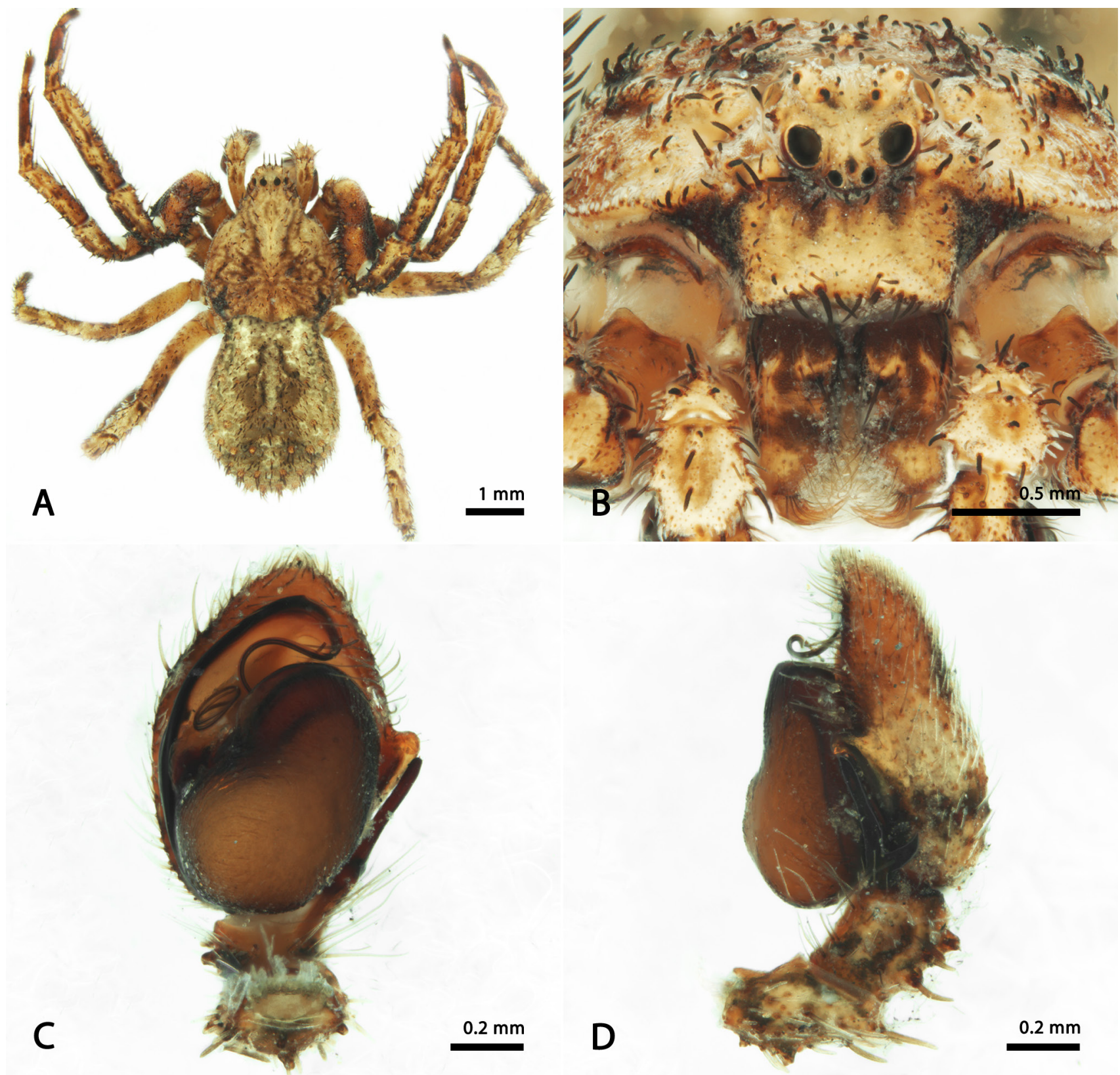

$0.2 \mathrm{~mm}$

Figure 27. Stephanopis flagellata sp. nov., male (AMS KS.128001). (A) dorsal habitus; (B) front; (C) ventral view of the left palp; (D) left palp, retro lateral view.

(Fig. 27A). However, S. flagellata sp. nov. can be easily distinguished from these species by its remarkable palpi: a larger PrsP, long whip-like embolus (coiled at its terminal portion and resting behind the tegulum) and a RTAvbr acute and long, having thrice the size of the RTA (Fig. 27C and D).

Description. Male (AMS KS.128001): Anterior eye row strongly recurved (Fig. 27A) and posterior row slightly procurved (Fig. 27B); prosoma predominantly dark-yellow with brown tinges on the sides of cephalic portion (Fig. 27A). Posterior legs (III and IV) predominantly yellowish as in the prosoma; anterior legs (I and II) entirely brown on the femora and gradually fading into yellow along the tibiae and metatarsi, with sparse dark spots. Opisthosoma dark-yellow, with concave anterior border and clusters of 3 to 5 long setae on the posterior setiferous tubercles (Fig. 27A).

Measurements: eye diameters and interdistances: AME
0.06, ALE 0.18, PME 0.18, PLE 0.18, AME-AME 0.08, AME-ALE 0.06, PME-PME 0.11, PME-PLE 0.07, MOQ length 0.35 , width 0.32 ; leg formula: $1-2-3-4$ : leg I-femur 2.50 / patella 1.45 / tibia 2.23 / metatarsus 1.71 / tarsus $0.97 /$ total 8.86; II-2.13/ 1.16/ 1.74/ 1.50/ 0.88 7.41; III-1.85/ $0.79 / 1.48 / 1.45 / 0.74 / 6.31$; IV-1.82/ 0.68/ 1.44/ 1.49/ $0.68 / 6.11$. Total body length 6.13 ; prosoma length 2.88 , width 2.36; opisthosoma length 3.25 ; clypeus height 0.46 ; sternum length 1.20 , width 1.15 ; gnathocoxae length 0.57 , width 0.33 ; labium length 0.31 , width 0.44 .

Female: Unknown.

Etymology. The specific name is a Latin feminine adjective meaning whipped or scourged, due to the shape of the long, filiform and whip-like embolus on the male palp.

Distribution. New South Wales, Australia (Fig. 35). 

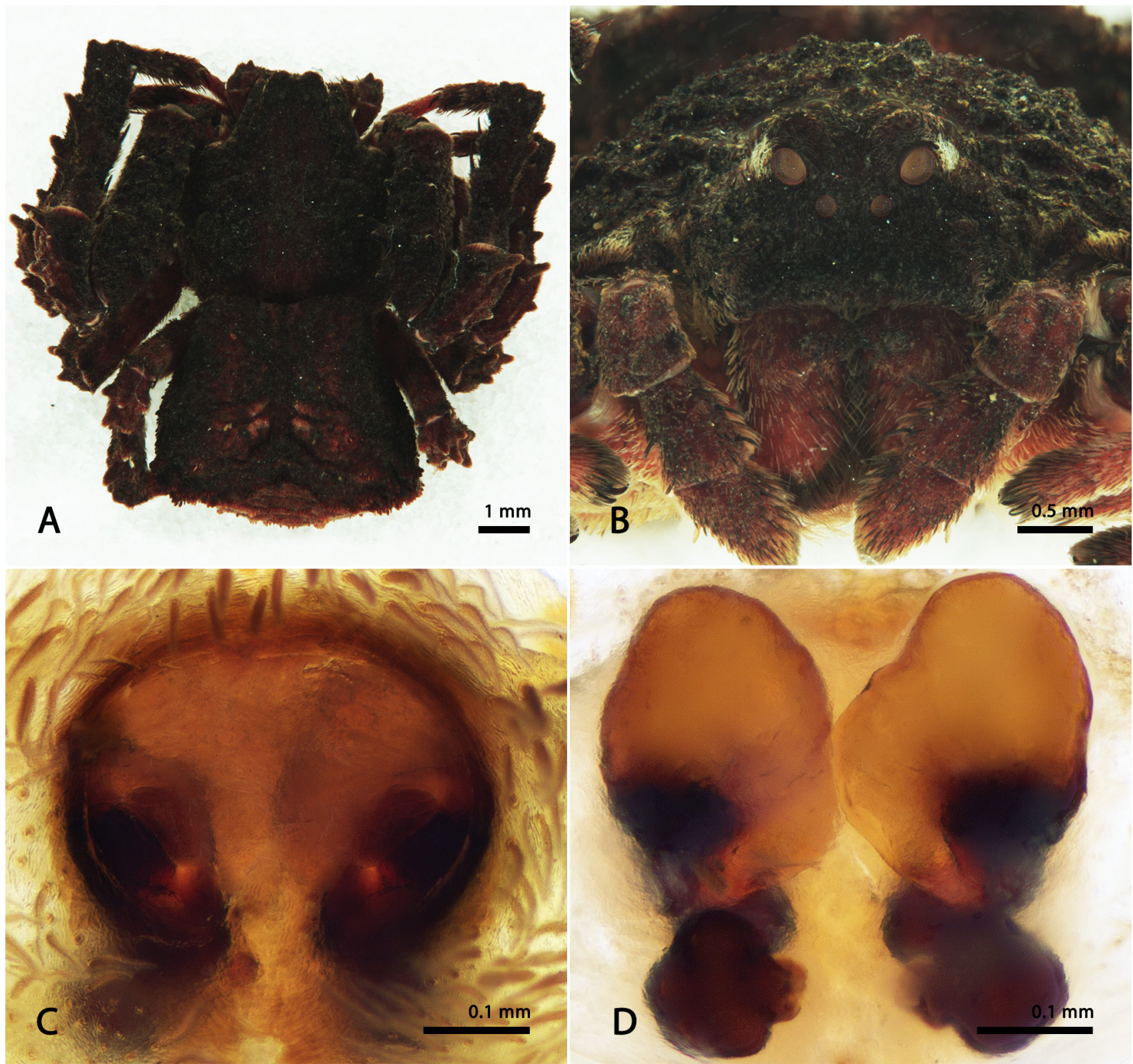

Figure 28. Stephanopis lata O. Pickard-Cambridge, 1869, female (AMS KS.121449). (A) dorsal habitus; (B) front; (C) epigynal plate, ventral view; $(D)$ epigynal plate/spermathecae.

\section{Stephanopis lata \\ O. Pickard-Cambridge, 1869}

Figs 28-29

Stephanopis lata O. Pickard-Cambridge, 1869: 63, pl. 5, figs 42-43.-L. Koch, 1874: 498, pl. 38, fig. 2.-Hickman, 1967: 106, figs 177-179.

Type material examined. Holotype $\circ$, NHMUK 1844.40 (ex British Museum), Tasmania [41 ${ }^{\circ} 27^{\prime} \mathrm{S} 145^{\circ} 58^{\prime} \mathrm{E}$ ], Australia, deposited in the dry collection.

Other material examined. Australia, Queensland: AMS KS.110434, $1{ }^{\lambda}$, Eurimbula (southeast of Gladstone), $24^{\circ} 11^{\prime} \mathrm{S} 151^{\circ} 50^{\prime} \mathrm{E}, \mathrm{M}$. R. Gray \& C. Horseman, March 1975; QM S25632, 2 우, Curra, 264'0.012"S $152^{\circ} 34^{\prime} 59.88^{\prime \prime}$, P. Frater, 4 September 1993. New South Wales: AMS KS.108705, 1 \% , Sydney (Pittwater), $33^{\circ} 38^{\prime} \mathrm{S} 151^{\circ} 18^{\prime} \mathrm{E}$, J. Child, 13 June

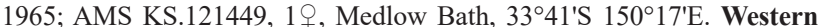
Australia: AMS KS.108672, 1 , , Busselton, $33^{\circ} 39^{\prime} \mathrm{S} 115^{\circ} 20^{\prime} \mathrm{E}$. Tasmania: AMS KS.31442, 3 우, , Cascades, $41^{\circ} 10^{\prime} \mathrm{S} 147^{\circ} 49^{\prime} \mathrm{E}$, V. V. Hickman, 26 May 1923; AMS KS.31443, 2 우, same data except 14 June 1948; AMS KS.10426,
1 , Launceston, $41^{\circ} 27^{\prime} \mathrm{S} 147^{\circ} 10^{\prime} \mathrm{E}$, F. Calverley, 1 February 1982; AMS KS.31391, 1 \%, Domain, $42^{\circ} 52^{\prime} \mathrm{S} 147^{\circ} 19^{\prime} \mathrm{E}$, V. V. Hickman, 9 February 1970; AMS KS.31444, 1 옹 same data except 2 December 1963; AMS KS.31449, $1 \hat{\jmath}, 1$, , same data except September 1958.

Diagnosis. The trapezoid opisthosoma and set of dorsal projections on the anterior patellae and tibiae found in by both males and females of S. lata are also found in S. angulata and S. fissifrons, however, these features are more prominent in $S$. lata. Females of $S$. lata are similar to those of $S$. corticalis in having darker body colouration (Fig. 28A), rough tegument with many irregular sized setiferous tubercles, dorsal leg projections occurring also on legs III and IV, and more robust aspect. However, females of $S$. lata can be distinguished by their extremely flattened epigynal plate with weakly developed lateral folds and slit-shaped CO perpendicularly positioned (Fig. 28C). Males are diagnosed by their straight and acute RTA with truncated RTAvbr (Fig. 29C).

Description. Female (AMS KS.121449): Prosoma and legs entirely reddish dark-brown and bearing many stout and 

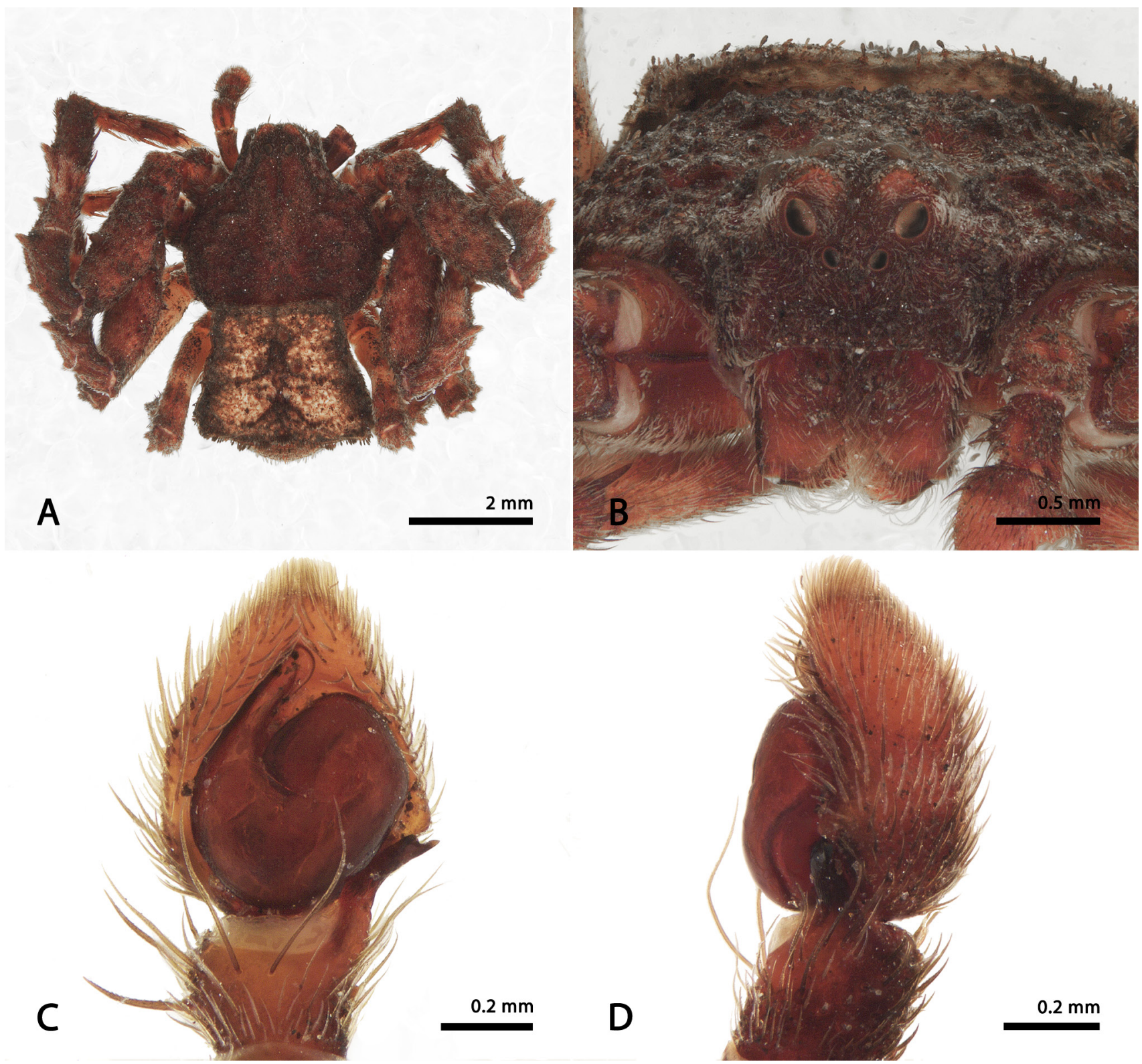

Figure 29. Stephanopis lata O. Pickard-Cambridge, 1869, male (AMS KS.31449). (A) dorsal habitus; (B) front; (C) ventral view of the left palp; (D) left palp, retro lateral view.

acute tubercles and projections (Fig. 28A). Anterior eye row strongly recurved and posterior straight; cephalic prominence absent. Opisthosoma reddish-brown with clavated setae on its posterior region (Fig. 28A). Spermathecae pear-shaped and glandular-heads fused to the pair of lobed anterior chambers (Fig. 28D).

Measurements: eye diameters and interdistances: AME 0.14, ALE 0.26, PME 0.19, PLE 0.20, AME-AME 0.20, AME-ALE 0.17, PME-PME 0.36, PME-PLE 0.23, MOQ length 0.62 , width 0.55 ; leg formula: $1-2-4-3$ : leg I-femur 4.90 / patella 2.39 / tibia 3.79 / metatarsus 2.15 / tarsus 1.24 / total 14.47; II-3.85/ 1.95/3.02/ 1.85/ 1.19/ 11.86; III-3.20/ $1.52 / 2.45 / 1.39 / 0.98 / 9.54$; IV-3.54/ $1.50 / 2.39 / 1.28 /$ $0.92 / 9.63$. Total body length 9.62 ; prosoma length 4.75 , width 4.56; opisthosoma length 4.87; clypeus height 0.58 ; sternum length 2.12, width 1.97; gnathocoxae length 1.15 , width 0.62 ; labium length 0.70 , width 0.97 .

Male (AMS KS.31449): Eye arrangement and disposition as in female (Fig. 29B); prosoma and anterior legs predominantly reddish dark-brown (Fig. 29A); tarsi I and femora III and IV partially dark-yellow. Opisthosoma squared, dark-yellow with borders, sides, heart sigilla and setae dark-brown (Fig. 29A). Palpi bears a wide and short Pcym, well-developed PrsP and flexible embolus resting on an apically positioned tegular ridge (Fig. 29A and B).

Measurements: eye diameters and interdistances: AME 0.09, ALE 0.22, PME 0.18, PLE 0.22, AME-AME 0.12, AME-ALE 0.08, PME-PME 0.18, PME-PLE 0.22, MOQ length 0.36 , width 0.30 ; leg formula: 1-2-4-3: leg I-femur 3.85 / patella 1.47 / tibia 3.08 / metatarsus 1.65 / tarsus $1.06 /$ total 11.11; II-3.68/1.33/2.85/1.63/ 1.06/ 10.55; III-2.31/ $0.79 / 1.93 / 1.20 / 0.84 / 7.07$; IV $-2.40 / 0.80 / 1.88 / 1.18 /$ $0.82 / 7.08$. Total body length 7.11 ; prosoma length 3.70 , width 3.40 ; opisthosoma length 3.41 ; clypeus height 0.41 ; sternum length 1.45 , width 1.39 ; gnathocoxae length 0.78 , width 0.41 ; labium length 0.49 , width 0.69 .

Distribution. Queensland, New South Wales, Western Australia and Tasmania, Australia (Fig. 35). 

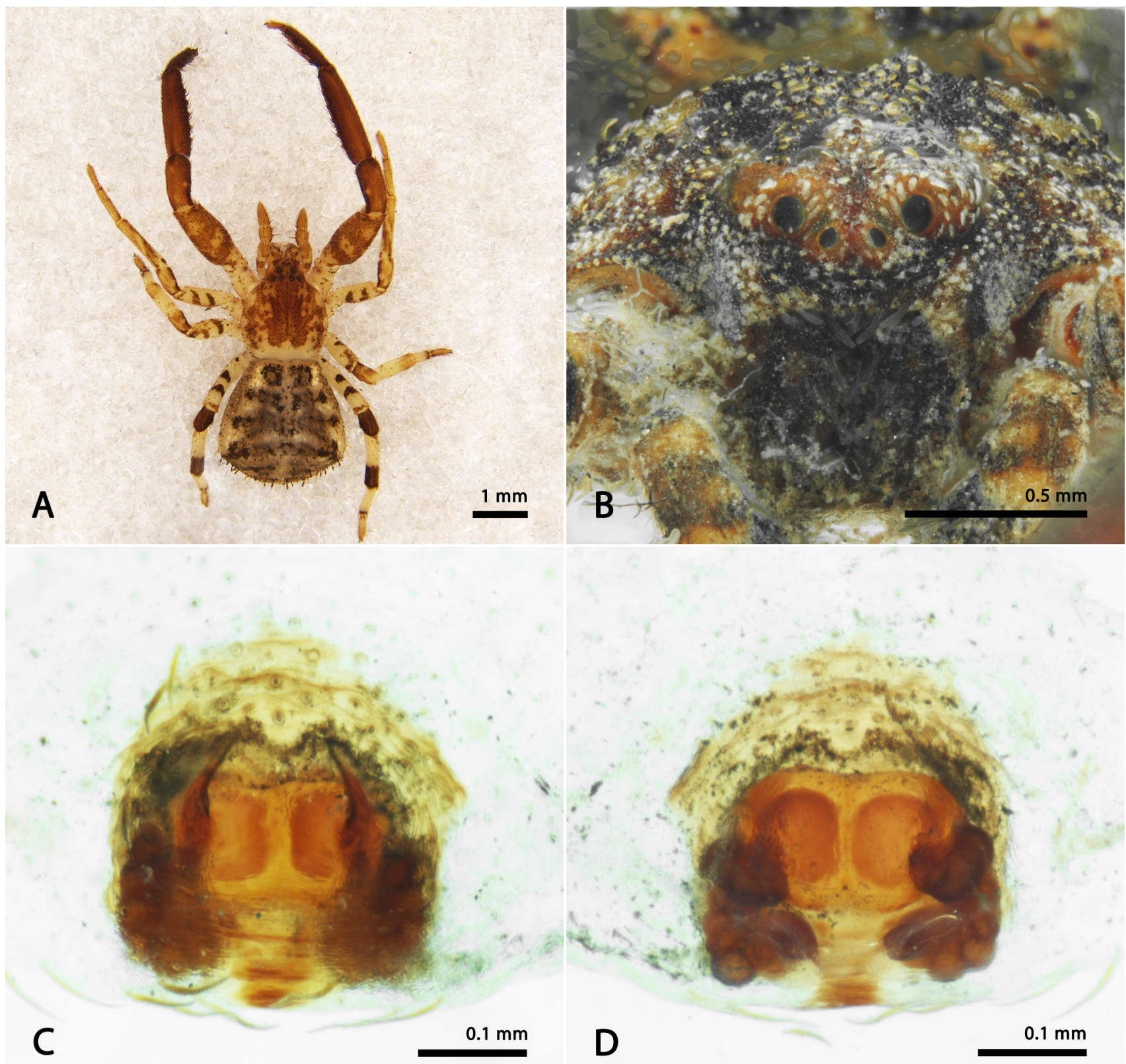

Figure 30. Stephanopis longimana Thorell, 1881, female: (A) ZMB 48561, dorsal habitus; (B-D) AMS KS.122288 (B) front; (C) epigynal plate, ventral view; (D) epigynal plate/spermathecae.

\section{Stephanopis longimana Thorell, 1881}

Figs $30-31$

Stephanopis longimana Thorell, 1881: 322.

Type material examined. Holotype $\odot$, MSNG, Cape York, Queensland $\left[10^{\circ} 42^{\prime} \mathrm{S} 142^{\circ} 31^{\prime} \mathrm{E}\right]$, Australia.

Other material examined. Australia, Queensland: ZMB

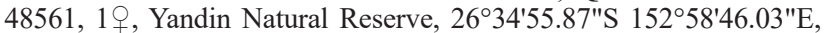
D. Harms, 9 July 2006; QM S19432, 10, Beerwah Forestry Reserve, $26^{\circ} 51^{\prime} \mathrm{S} 152^{\circ} 57^{\prime} \mathrm{E}, \mathrm{M}$. Glover, 10 October 1990; OM S67517, 2 오오,

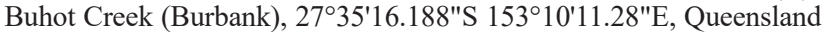
Museum Party, 6 September 2003; QM S67518, 1 Jे, 31 October 2003; QM S62563, 1 , 28 July-2 September 2003. New South Wales: AMS

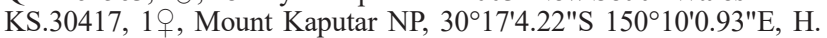
Smith, 20 October 1991; AMS KS.77855, 19, Bulls Ground State Forest, $31^{\circ} 35^{\prime} \mathrm{S} 152^{\circ} 41^{\prime} \mathrm{E}, \mathrm{A}$. York, February 2001; AMS KS.117018, 1 , , same data except November 2002; AMS KS.21662, 10, Jenolan Caves area, 3349'16.04"S 150¹'10.76"E, G. Hunt, 6 July 1989; AMS
KS.22517, $3 ð ð$, same data except 14 August 1989; AMS KS.22542, $1 \hat{\jmath}^{\lambda}$, same data except 14 August 1989; AMS KS.30030, 1 으, Kanangra Boyd NP, 3359'18.74"S 1505'18.11"E, M. Gray, 1971; AMS KS.44650, $1 \jmath^{\lambda}$, Brindabella Rules Point, $35^{\circ} 23^{\prime} 36.82^{\prime \prime S} 148^{\circ} 44^{\prime} 54.43 " \mathrm{E}, \mathrm{M}$. Zabka \& G. Hunt, 1 September 1988; AMS KS.11613, 10, Rockton (Bondi State Forest), 37 $08^{\prime}$ S $149^{\circ} 09^{\prime}$ E, G. Gowing et al., 14 November 1980. Tasmania: AMS KS.31447, 19, Domain, 42 52'6.98"S 147'19'49.31"E, V. V. Hickman, 23 March 1968.

Diagnosis. The females of S. longimana can be easily distinguished by their first pair of legs being remarkably stouter and longer than the rest, resembling the general appearance of a palpimanid spider (Fig. 30A). The epigynal plate possesses $\mathrm{CO}$ hidden by a parallel pair of pockets arranged vertically (Fig. 30C), similar to that seen in $S$. cambridgei but more discrete. Males resemble those of $S$. arenata sp. nov., S. cambridgei, $S$. similis sp. nov. and $S$. spiralis sp. nov. by having the single-tipped and curved RTA and by the tegulum and cymbium retro-ventrally inclined, but these two latter copulatory structures are more elongated than 

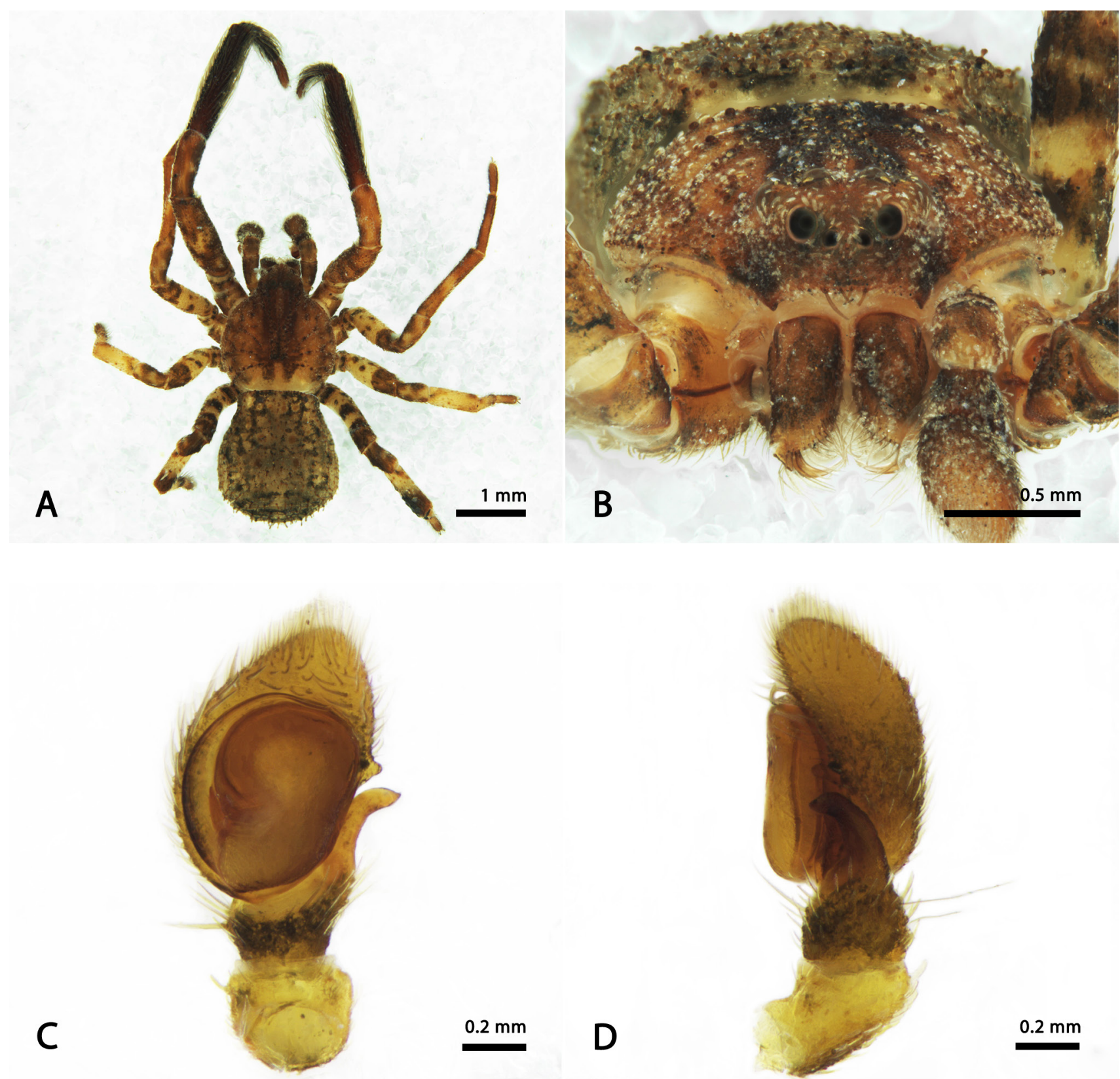

Figure 31. Stephanopis longimana Thorell, 1881, male (AMS KS.22517). (A) dorsal habitus; (B) front; (C) ventral view of the left palp; (D) left palp, retro lateral view.

rounded in S. longimana (Fig. 31C) The males of all these species also share the long thin and filiform barbs on tibiae and metatarsi I (Fig. 31A), but S. longimana is easily distinguished by the reduced body size compared to the other species.

Description. Female (ZMB 48561): Anterior eyes arranged in a recurved row (Fig. 30B) and posterior ones in a straight line; prosoma yellow with large brown or black patches, covered by many hyaline short setae (Fig. 30A). Leg I predominantly brown, with few yellow spots on femora, while the legs II, III and IV are yellow with marked brown patches (Fig. 30A). Opisthosoma obovate and wider on its posterior-lateral portion, covered by clavate setae; yellowish on the sides and with black circular spots delimiting a trapezoid greyish-brown area on the dorsum (Fig. 30A). Spermathecae granulose, preceded by copulatory ducts directed sideways and a pair of globose anterior chambers (Fig. 30D).
Measurements: eye diameters and interdistances: AME 0.06, ALE 0.11, PME 0.09, PLE 0.11, AME-AME 0.10, AME-ALE 0.06, PME-PME 0.14, PME-PLE 0.19, MOQ length 0.30 , width 0.27 ; leg formula: 1-2-4-3: leg I-femur 1.79 / patella 1.00 / tibia 1.61 / metatarsus 1.01 / tarsus 0.38 / total 5.79; II-1.41/ 0.77/ 1.22/ 0.86/0.48/4.74; III-1.02/ $0.57 / 0.73 / 0.55 / 0.36 / 3.23$; IV-1.38/ 0.56/ 0.98/ 0.73/ $0.47 / 4.12$. Total body length 9.62 ; prosoma length 2.06 , width 1.93; opisthosoma length 2.12; clypeus height 0.19 ; sternum length 0.90 , width 0.96 ; gnathocoxae length 0.49 , width 0.27 ; labium length 0.25 , width 0.32 .

Male (AMS KS.22517): Eye arrangement as in female; clypeus possessing a set of median macrosetae (Fig. 31B), prosoma light-brown with a longitudinal darker marking on the median area (Fig. 31A). Leg I becoming gradually darker from the proximal part of the tibia to the tarsus; metatarsus 

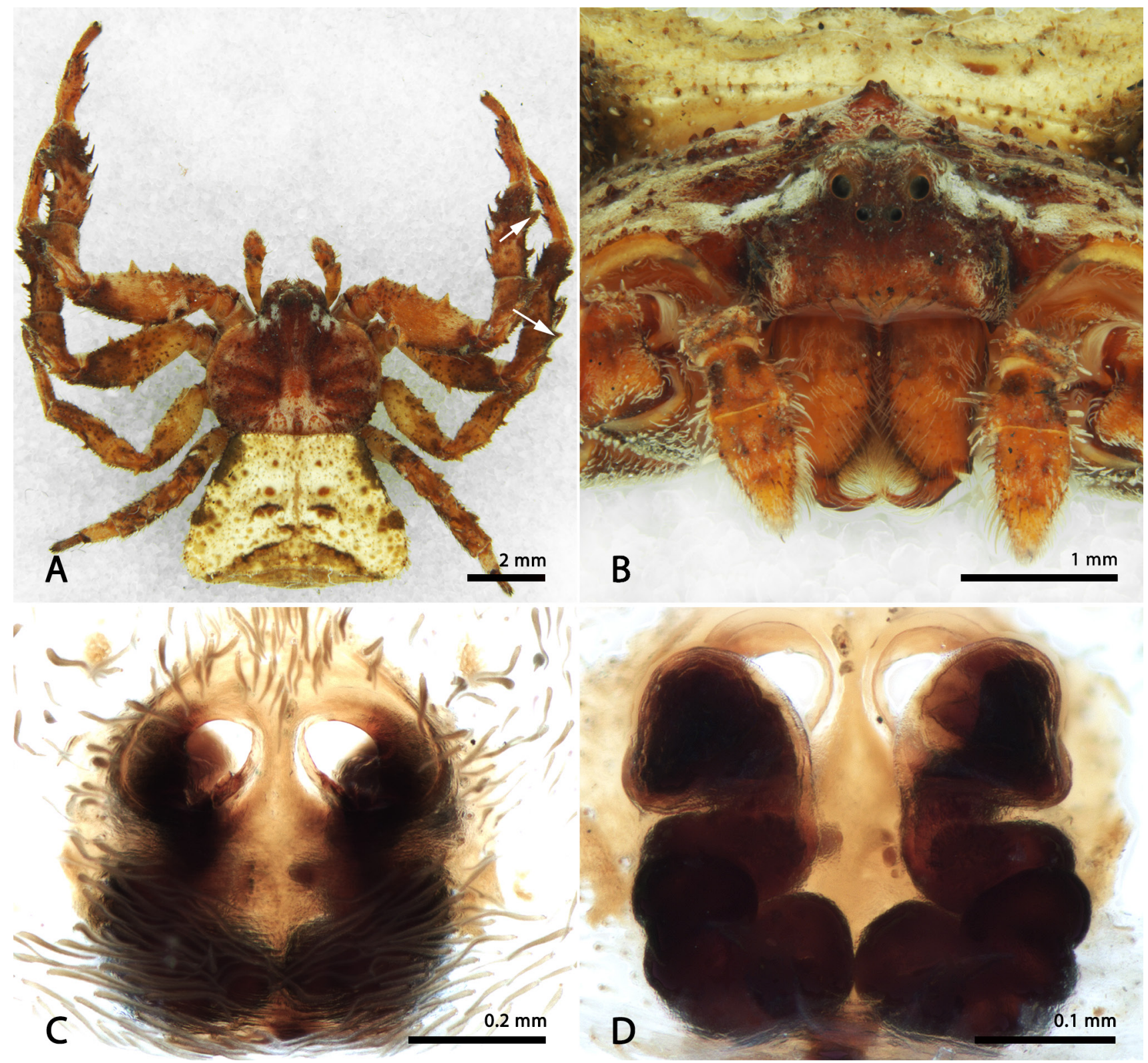

Figure 32. Stephanopis monulfi Chrysanthus, 1964, female (A-B, AMS KS.108712): (A) dorsal habitus; $(B)$ front; $(C-D$, QM S104679): (C) epigynal plate, ventral view; (D) epigynal plate/spermathecae. Arrows $(A)$ indicate dorsal projections on tibiae I and patellae II.

I slightly curved (Fig. 31A). Other leg characteristics as in female. Palp with oval tegulum and embolus running along the prolateral side of the cymbium, laminar with a welldeveloped pars pendula (Fig. 31C); RTA curved retro-laterally and pointing ventrally, parallel to the tegulum (Fig. 31D).

Measurements: eye diameters and interdistances: AME 0.05, ALE 0.12, PME 0.10, PLE 0.12, AME-AME 0.09, AME-ALE 0.06, PME-PME 0.08, PME-PLE 0.12, MOQ length 0.25 , width 0.20 ; leg formula: 1-2-4-3: leg I-femur 2.10 / patella 1.12 / tibia 2.27 / metatarsus 1.50 / tarsus $0.56 /$ total 7.55; II-1.54/ 0.74/ 1.46/ 1.02/ 0.55/ 5.31; III-1.04/ $0.59 / 0.80 / 0.52 / 0.46 / 3.41$; IV-1.50/ 0.63/ 1.06/ 0.74/ $0.49 / 4.42$. Total body length 4.29 ; prosoma length 2.03 , width 1.79; opisthosoma length 2.26; clypeus height 0.20 ; sternum length 0.90 , width 0.97 ; gnathocoxae length 0.46 , width 0.25 ; labium length 0.23 , width 0.33 .

Distribution. Queensland, New South Wales and Tasmania, Australia (Fig. 35).

\section{Stephanopis monulfi Chrysanthus, 1964}

Figs 32-34

Stephanopis monulfi Chrysanthus, 1964: 89, figs 15-18.

Type material examined. Holotype $q$, RMNH 3854 , from Merauke, Papua, Indonesia [8 $\left.8^{\circ} 29^{\prime} \mathrm{S} 140^{\circ} 24^{\prime} \mathrm{E}\right]$.

Other material examined. Papua New Guinea, Morobe: MCZ 134018, 19. Mount Su Su (near Bulolo), 648'4.95"S 146³3'41.93"E, H. Levi \& Y. Lubin, 17 March 1979; AMS KS.35, 1 , , Bulolo, $7^{\circ} 11^{\prime} \mathrm{S} 146^{\circ} 38^{\prime} \mathrm{E}, \mathrm{B}$. Gray, 2 May 1970. Australia, Queensland: AMS KS.437, 1 \% , Helenvale, $15^{\circ} 43^{\prime} \mathrm{S} 145^{\circ} 14^{\prime} \mathrm{E}$, M. Gray, November 1975; AMS KS.108716, $10^{\lambda}, 1$ 우, Cairns, $16^{\circ} 55^{\prime} \mathrm{S} 145^{\circ} 46^{\prime} \mathrm{E}$, N.C. Coleman, 13 August 1969; AMS KS.34361, $10^{\wedge}$, Mareeba (Tinaroo Creek), $17^{\circ} \mathrm{S} 145^{\circ} 26^{\prime} \mathrm{E}, \mathrm{R}$. E. Mascord, 24 September 1972; AMS KS.81288, 10, 1우, same data; AMS KS.81290, 1 웅 same data; AMS KS.108712, 1 우, Edmonton, $17^{\circ} 01^{\prime} \mathrm{S}$ $145^{\circ} 45^{\prime}$ E, N.C. Coleman, 20 February 1969; KS. 108725,1 수, 3 우우,

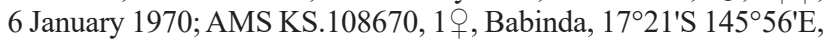



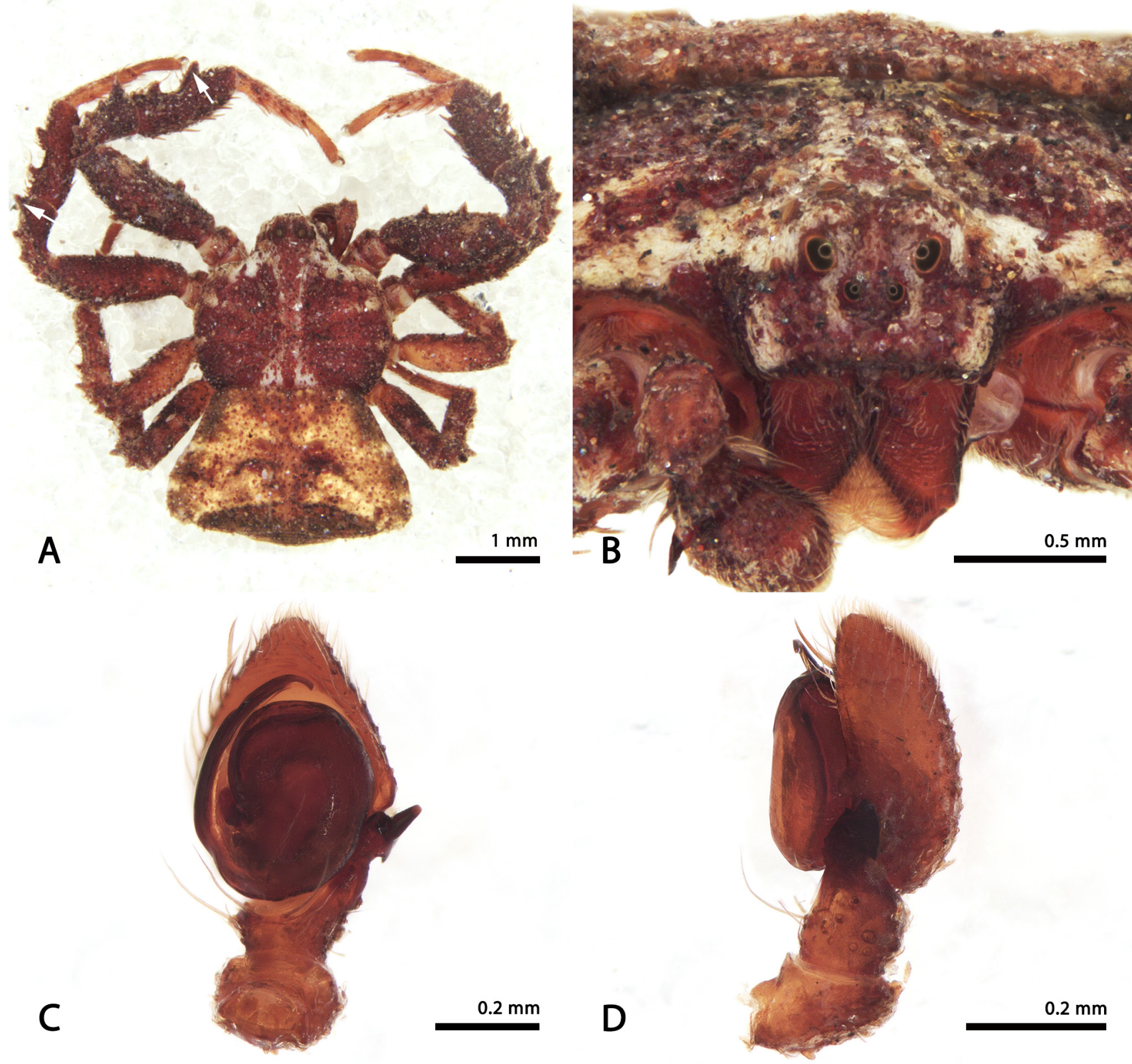

$0.2 \mathrm{~mm}$

Figure 33. Stephanopis monulfi Chrysanthus, 1964, male (AMS KS.108716). (A) dorsal habitus; (B) front; (C) ventral view of the left palp; (D) left palp, retro lateral view. Arrows $(A)$ indicate dorsal projections on tibiae I and patellae II.

J.A. Brooks, 1951; AMS KS.110426, 1, Eurimbula (southeast of Gladstone), $24^{\circ} 11^{\prime} \mathrm{S} 151^{\circ} 50^{\prime} \mathrm{E}, \mathrm{M}$. R. Gray \& C. Horseman, March 1975; QM S104651, 1, Clifton Beach near Cairns, N.C. Coleman, 1972. New South Wales: QM S19478, 1일 Yamba, 29²5'59.60"S 15320'26.24"E, R. Raven, 16-19 April 1976.

Diagnosis. Females of $S$. monulfi resemble those of $S$. armata in having a trapezoid opisthosoma, being cryptic and robust in form, having legs bearing several stout projections and setiferous tubercles and by the median spire on thoracic portion of prosoma. However, they can be distinguished by their more flattened and wider prosoma, bigger dorsal projections on patellae and tibiae I and II (Fig. 32A), and epigynal plate with wide $\mathrm{CO}$, depressed atrium and median septum (Fig. 32C). Males are diagnosed by their sclerotized embolus (Fig. 33C) and short and laminar RTA that resembles a shape of an axe blade in retro lateral view (Fig. 33D).
Description. Female (KS.108712): Prosoma predominantly reddish-brown with a small median spire on the cephalic portion (Fig. 32B), covered by many whitish setae on the posterior slope and sides of cephalic area (Fig. 32A); anterior eye row recurved and posterior straight; cephalic and ocular projections discrete (Fig. 32B). Legs dark-yellow with brown tinges on the distal portion of femora, patellae and tibiae. These same leg segments bear acute projections with a terminal macrosetae and covered by smaller hyaline ones (Fig. 32A). Opisthosoma trapezoid, predominantly light-yellow with brownish anterolateral spots. Epigynum with segmented spermathecae, glandular-heads with many perforations and anterior chambers reduced (Fig. 32D).

Measurements: eye diameters and interdistances: AME 0.10, ALE 0.15, PME 0.12, PLE 0.09, AME-AME 0.14, AME-ALE 0.11, PME-PME 0.30, PME-PLE 0.12, MOQ 

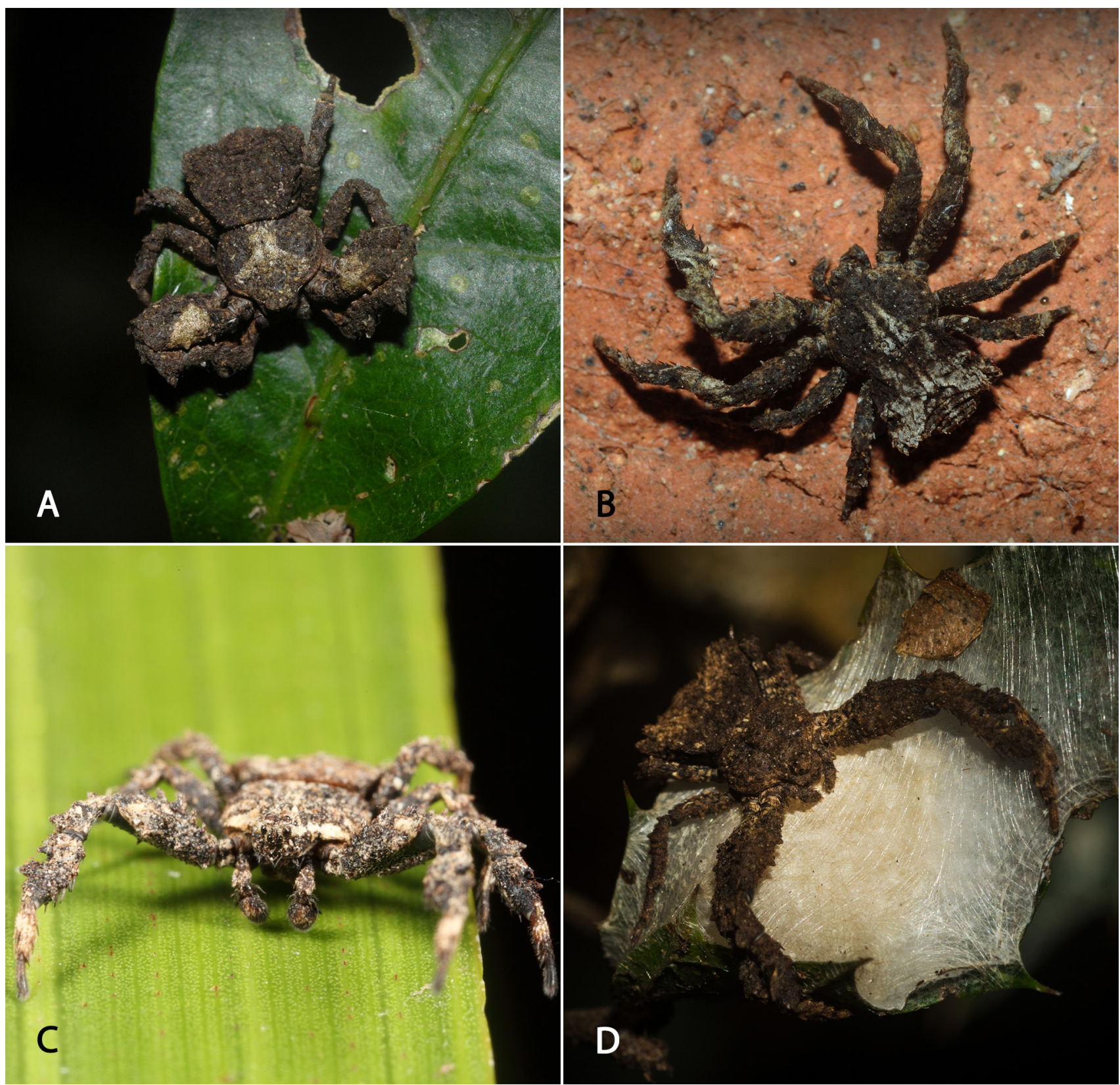

Figure 34. Stephanopis monulfi records $(A-D)$; and egg-sac guarding behavior $(D)$. Photos by Nicholas Fisher.

length 0.44 , width 0.25 ; leg formula: $1-2-3-4$ : leg I-femur 3.85 / patella 2.26 / tibia $2.87 /$ metatarsus 2.00 / tarsus $1.22 /$ total $12.20 ; \mathrm{II}-3.62 / 2.06 / 2.44 / 1.79 / 1.12 / 11.03 ; \mathrm{III}-2.62 /$ $1.25 / 1.84 / 1.44 / 0.90 / 8.05$; IV-2.78/ $1.21 / 1.66 / 1.30 /$ $0.77 / 7.72$. Total body length 8.19 ; prosoma length 4.09 , width 4.62; opisthosoma length 4.10; clypeus height 0.49 ; sternum length 1.89 , width 1.77 ; gnathocoxae length 1.04 , width 0.46 ; labium length 0.63 , width 0.72 .

Male (AMS KS.108716): Prosoma and legs predominantly burgundy colored (Fig. 33A); eye arrangement as in female. Anterior metatarsi and tarsi (I and II) light-brown; whitish setae clustered on the median region of the posterior slope of prosoma and on the sides of cephalic area, occurring also on the lateral margin of the clypeus and between the ALE and AME (Fig. 33B). Opisthosoma trapezoid and dark-yellow with lateral and posterior darker spots. Palpi short with Pcym rounded and RTAvbr truncated (Fig. 33C,D).

Measurements: eye diameters and interdistances: AME 0.07, ALE 0.13, PME 0.08, PLE 0.06, AME-AME 0.07, AME-ALE 0.05, PME-PME 0.16, PME-PLE 0.05, MOQ length 0.23 , width 0.25 ; leg formula: $1-2-4-3$ : leg I-femur 1.45 / patella $0.81 /$ tibia $1.08 /$ metatarsus $0.81 /$ tarsus $0.41 /$ total 4.56; II-1.43/ 0.73/ 1.00/ 0.77/ 0.43/4.36; III-0.99/ $0.52 / 0.73 / 0.65 / 0.42 / 3.31$; IV $-1.04 / 0.68 / 0.67 / 0.62 /$ $0.35 / 3.36$. Total body length 3.59 ; prosoma length 1.89 , width 1.92; opisthosoma length 1.70 ; clypeus height 0.22 ; sternum length 0.83 , width 0.76 ; gnathocoxae length 0.34 , width 0.19 ; labium length 0.20 , width 0.37 .

Distribution. Papua, Indonesia; Morobe, Papua New Guinea; Queensland and New South Wales, Australia (Fig. 35). 


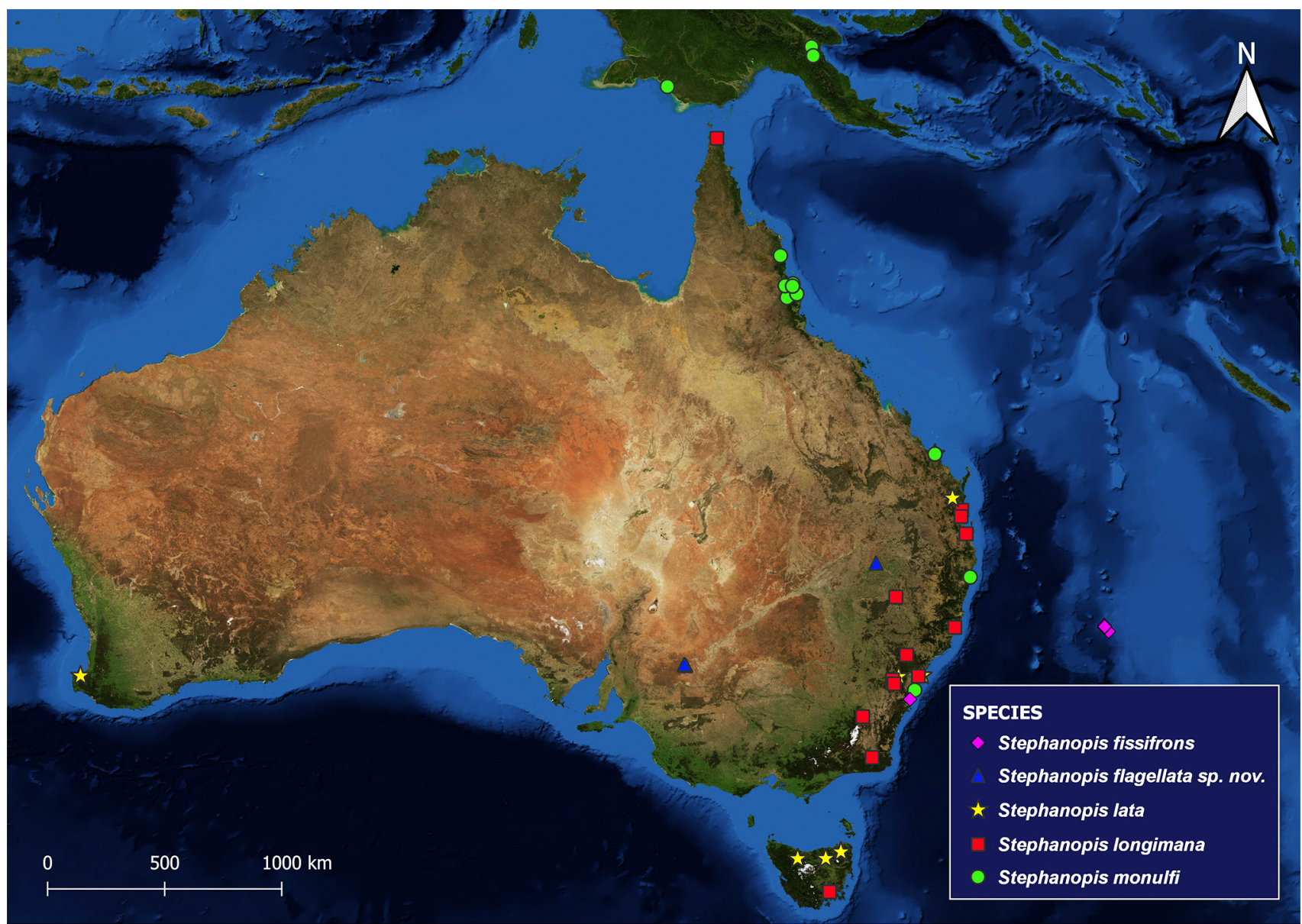

Figure 35. Distribution records of Stephanopis fissifrons, S. flagellata sp. nov., S. lata, S. longimana and S. monulfi.

\section{Stephanopis nana Machado sp. nov.}

http://zoobank.org/NomenclaturalActs/462BB904-EA42-4B30-8908-02A3A250B823

\section{Fig. 36}

Holotype 9, QM S14589, Chinchilla, Queensland, Australia, $26^{\circ} 44^{\prime} 19.28^{\prime \prime S} 150^{\circ} 37^{\prime} 15.01^{\prime \prime E}$, T. Adams, 19 February 1979. Paratypes: QM S80820, 1 으, Moolayember Creek NP, Queensland, Australia, 25⒕5'S 148 37.4'E, C. Burwell, 10 March 2006; QM S80247, 1 \%, Little Wolfang Peak, Queensland, Australia, 22³3'S 14749'43.32"E, Queensland Museum party, 5 March 2006.

Diagnosis. The females of $S$. nana sp. nov. are similar to those of $S$. altifrons and $S$. nigra, possessing a high clypeus, eyes located on an elevated ocular projection (Fig. 36B) and opisthosoma with stout posterior setiferous tubercles (Fig. 36A). However, $S$. nana sp. nov. is easily recognizable by its considerably smaller body size and position of the CO: females of $S$. nigra have CO disposed horizontally while in $S$. altifrons they are oblique but delimiting a "V-shape" on the atrium. In $S$. nana sp. nov. the anterior folds of the openings are directed towards each other in the middle of the plate (Fig. 36C).

Description. Female (QM S14589): Anterior eye row strongly recurved and posterior procurve; prosoma and legs predominantly pale-yellow with few brown or dark-brown spots (Fig. 36A); opisthosoma concave at the anterior border, rugose, rounded, predominantly pale-yellow with dark-brown patches randomly distributed. Spermathecae small, coiled and preceded by large "lung-shaped" chambers (Fig. 36D).

Measurements: eye diameters and interdistances: AME 0.05, ALE 0.15, PME 0.12, PLE 0.10, AME-AME 0.10, AME-ALE 0.09, PME-PME 0.17, PME-PLE 0.10, MOQ length 0.48 , width 0.32 ; leg formula: $1-2-3-4$ : leg I-femur 2.97 / patella 1.75 / tibia 2.28 / metatarsus 1.70 / tarsus $0.90 /$ total 9.60; II-2.35/ 1.31/ 1.79/ 1.47/ 0.88/ 7.80; III-1.90/ $1.00 / 1.54 / 1.45 / 0.81 / 6.70$; IV $-1.92 / 0.89 / 1.39 / 1.40 /$ $0.73 / 6.33$. Total body length 8.02 ; prosoma length 3.67 , width 3.05 ; opisthosoma length 4.35 ; clypeus height 0.81 ; sternum length 1.56 , width 1.38 ; gnathocoxae length 0.81 , width 0.37 ; labium length 0.44 , width 0.60 .

Male: Unknown.

Etymology. The specific name is an adjective derived from the Ancient Greek that means "dwarf" and refers to the reduced size of these spiders, especially when compared to its similar congeneric species $S$. altifrons, $S$. carcinoides $\mathrm{sp}$. nov. and S. nigra.

Distribution. Queensland, Australia (Fig. 42). 


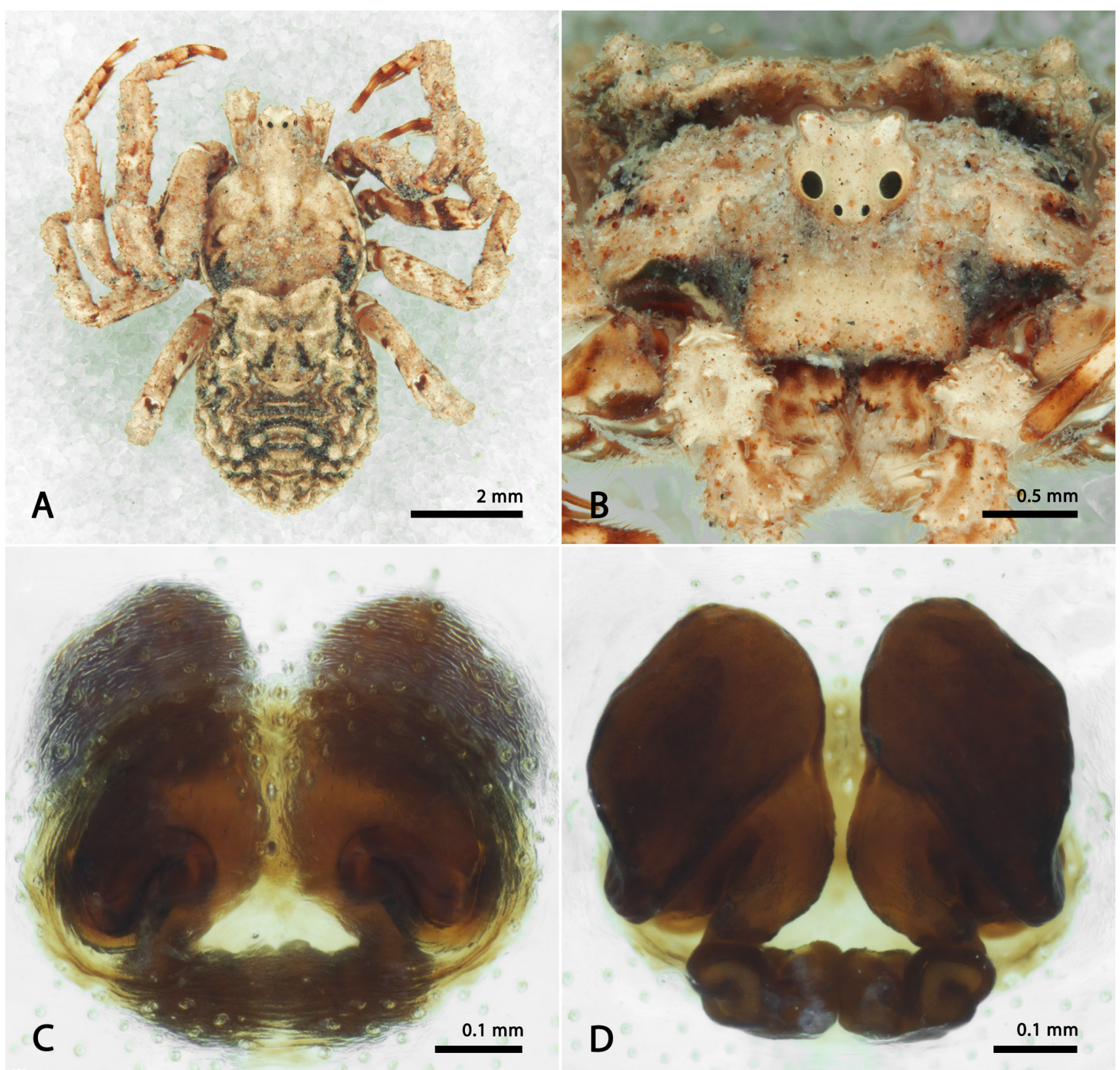

Figure 36. Stephanopis nana sp. nov., female (QM S14589). (A) dorsal habitus; (B) front; (C) epigynal plate, ventral view; (D) epigynal plate/spermathecae.

\section{Stephanopis nigra O. Pickard-Cambridge, 1869}

Figs 37-39

Stephanopis nigra O. Pickard-Cambridge, 1869: 62, pl. 5, fig. 40. (1 female from northern Australia, dried, pinned and deposited in the Hope Collection, OUMNH, not located, lost).

Stephanopis tuberculata Bradley, 1871: 235. (syntypes, 2 adult females and 1 juvenile from Nepean Towers,

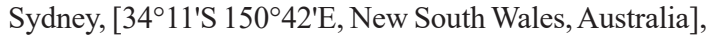
OUMNH 12, examined). New synonym.

Neotype 9 , AMS KS.109395, 1옹, Royal NP (Uloola Falls Campground), Sydney, New South Wales, Australia, $34^{\circ} 06^{\prime} 54^{\prime \prime S} 151^{\circ} 02^{\prime} 06^{\prime} \mathrm{E}, \mathrm{N}$. Camps, 25 April 1954, (designated here).
Generally, body colouration is a useful and limiting characteristic to distinguish $S$. nigra from its closest species, $S$. altifrons. While $S$. altifrons are usually brownish, dark-yellow or green due to the attachment of organic particles on their tegument, S. nigra present darker colours like grey and mostly black (in Latin, nigra). This might be associated with the kind of substrate on which they hunt. Further investigations are needed to check if there is a specific relationship between plant and spider to corroborate such a hypothesis.

Although the holotype of S. nigra could not be found after several attempts to find it in European and Australian collections, the original description makes clear the striking resemblance of this species with $S$. altifrons, highlighting, however, its more pronounced tubercles and the predominant black body colouration. These same characteristics are listed to describe $S$. tuberculata, which is also similarly compared to $S$. nigra by Bradley (1871). The examination 


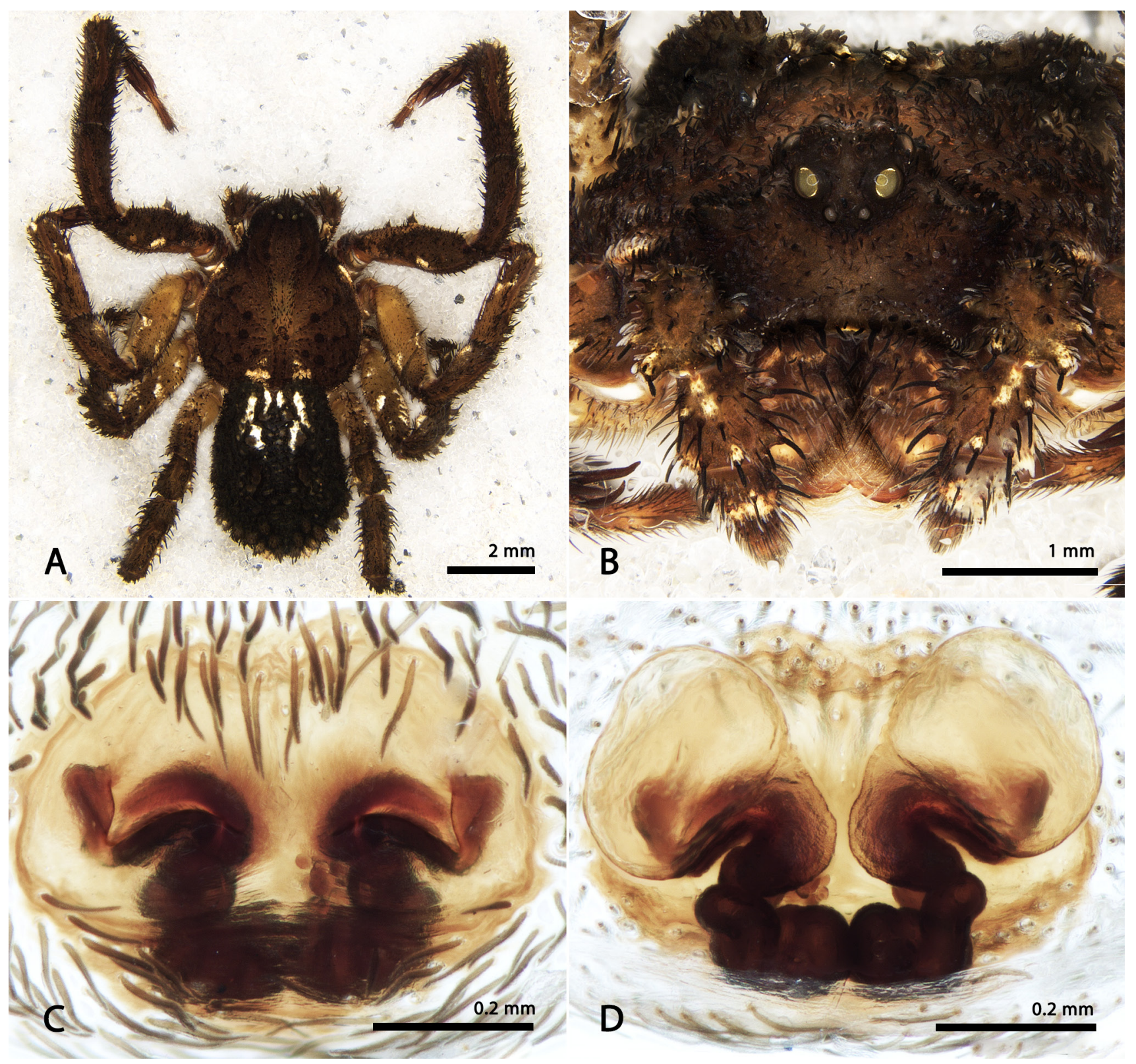

Figure 37. Stephanopis nigra O. Pickard-Cambridge, 1869, female (AMS KS.109395). (A) dorsal habitus; (B) front; (C) epigynal plate, ventral view; $(D)$ epigynal plate/spermathecae.

of the paratypes of $S$. tuberculata matches perfectly with the features mentioned in the original description made by Bradley (1871), therefore we consider this species to be synonymous with $S$. nigra, and designate a neotype for it. The neotype, however, was not based on one of these syntypes because they are not from the same type locality. The specimen elected as neotype matches very closely with the features listed in the original description and the diagnostic characters mentioned by Pickard-Cambridge (1869).

Other material examined. Queensland: AMS KS.81284, 1 우 Wolfram, $17^{\circ} 05^{\prime}$ ' $144^{\circ} 57^{\prime} E$, N.C. Coleman, 15 June 1970; QM S80300, 1 , , Gemini Mountains, $22^{\circ} 28^{\prime} 6.10^{\prime \prime}$ S 147052'30.03"E, C.J. Burwell, 6 March 2006; QM S55042, 1 , , Wide Bay-Burnett, E. Ford, 25 April 2001; QM S104670, 1 , , Kroombit Tops NP, 24²2'37.75"S $151^{\circ} 2$ '28.73"E, Thompson \& Yeates, 22-26 February 1982; KS.109397, 1 \%, Condamine, $26^{\circ} 56{ }^{\prime} \mathrm{S} 150^{\circ} 06^{\prime} \mathrm{E}, \mathrm{N}$. Geary, 27 March 1937; QM S14587, 10, Lake Broadwater Cottage (Southwest of Dalby), $27^{\circ} 21^{\prime S} 151^{\circ} 6^{\prime} \mathrm{E}$, J. Gallon, 9 December 1987; QM S65897,
1亏ิ, Ransome Reserve, $27^{\circ} 29^{\prime} 20.4^{\prime \prime S} 153^{\circ} 11^{\prime} 3.12^{\prime \prime E}$, Queensland Museum Party, 27 November 2003; QM S65499, 1ठ, Carindale (Belmont Hills Bushlands), 27³0'28.224"S 1537'3"E, 3 November

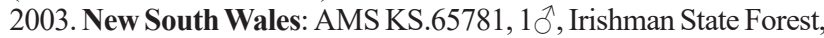
$30^{\circ} 33^{\prime} 43^{\prime \prime S} 152^{\circ} 42^{\prime} 12^{\prime \prime E}$, G. Milledge \& H. Smith, 25 November 1999; AMS KS.75591, $1 \hat{\circ}$, Oaky Creek Nature Reserve, $31^{\circ} 07^{\prime 2} 22^{\prime \prime S}$ $150^{\circ} 37^{\prime} 29^{\prime \prime E}$, H. Smith, 8 November 2001; AMS KS.10170, $1 \widehat{O}^{\lambda}$, Bonny Hills, $31^{\circ} 36^{\prime}$ ' $152^{\circ} 51^{\prime} \mathrm{E}, \mathrm{M}$. Gray \& C. Horseman, 9 December 1981; AMS KS.109394, $1 \hat{\jmath}$, 1 \% , Tubrabucca (Barrington Tops), $32^{\circ} 05^{\prime} \mathrm{S} 151^{\circ} 30^{\prime} \mathrm{E}$, A.S. Smithers, 30 December 1961; AMS

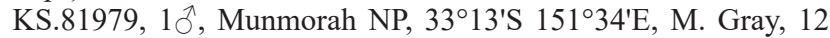
November 2002; AMS KS.81289, 1 웅, Mooney, $33^{\circ} 31^{\prime} S 151^{\circ} 12^{\prime} \mathrm{E}$, R. Mascord, November 1972; AMS KS.108738, 1 울, Pittwater, 33³8'S $151^{\circ} 18^{\prime}$ E, J. Child, 2 March 1966; AMS KS.108742, 1요, R. Mascord,

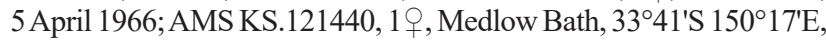

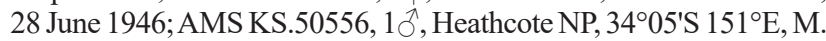
R. Gray, February 1997; AMS KS.50557, 2 females same data; AMS KS.108727, 1 \%, Sydney (Waterfall), $34^{\circ} 08^{\prime} \mathrm{S} 151^{\circ} 00^{\prime} \mathrm{E}, \mathrm{R}$. Mascord, 3 September 1968; AMS KS.119679, $1 \hat{\jmath}$, Coastal Reserve (Tathra), $36^{\circ} 43^{\prime} 55^{\prime \prime S} 149^{\circ} 59^{\prime} 12^{\prime \prime E}$, G. Milledge \& H. Smith, 24 December 


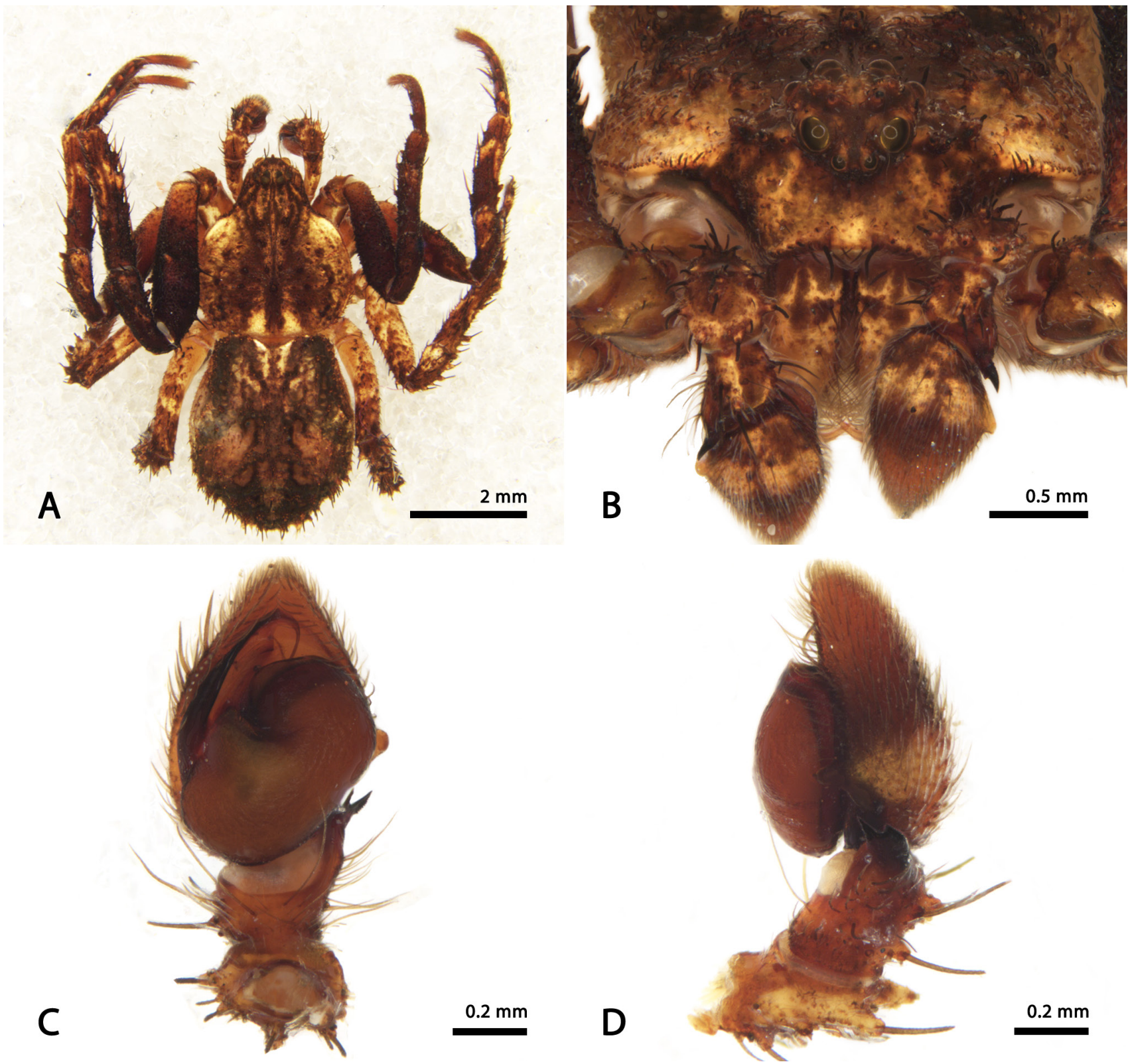

Figure 38. Stephanopis nigra O. Pickard-Cambridge, 1869, male (AMS KS.65781). (A) dorsal habitus; (B) front; (C) ventral view of the left palp; $(D)$ left palp, retro lateral view.

2012. Tasmania: AMS KS.31437, 1 , , Cascades, $41^{\circ} 10^{\prime} \mathrm{S} 147^{\circ} 49^{\prime} \mathrm{E}$, V. V. Hickman, 14 June 1948; AMS KS.31405, 1 ô, 1 울 Punch Bowl, $41^{\circ} 27^{\prime} \mathrm{S} 147^{\circ} 10^{\prime} \mathrm{E}, \mathrm{V}$. V. Hickman, 17 January 1925; AMS KS.31406, $1 \hat{\jmath}, 1$ 우, Glen Dhu, 11 January 1930; AMS KS.31416, 1 으, Glen Dhu, August 1929; AMS KS.31414, 1 9, Trevallyn, 1926; AMS KS.31440, 1ㅇ, Trevallyn, May 1931; AMS KS.31481, $1 \hat{\jmath}$, same data except

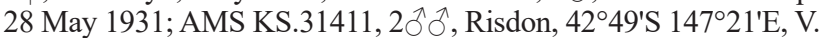
V. Hickman, 8 January 1948; AMS KS.31392, 1ㅇ, Queens Domain, $42^{\circ} 52^{\prime} \mathrm{S} 147^{\circ} 19^{\prime} \mathrm{E}, \mathrm{V}$. V. Hickman, 13 April 1968; AMS KS.31479, 1 , , same data except September 1956; AMS KS.31393, 1ㅇ, same data except 18 April 1968; AMS KS.31439, 1 , , 1same data except 7 June 1963; AMS KS.31448, 1ㅇ, same data except 16 November 1967; AMS KS.31473, 1의, same data except 22 September 1958; AMS KS.31480, 1ㅇ, same data except 20 December 1947.

Diagnosis. The morphological differences between $S$. nigra and $S$. altifrons are few and it is almost impossible to distinguish them by looking solely to their dorsal habitus. Both species present a high cephalic prominence, high clypeus, and an obovate opisthosoma bearing posterior tubercles with specialized setae. However, females and males of $S$. nigra can be recognized by their more rugose aspect due to stouter setiferous tubercles on the prosoma and legs (Figs 37A and 38A). Unlike in S. altifrons, the females of $S$. nigra present $\mathrm{CO}$ oriented horizontally (Fig. 37C), glandularheads median-positioned and anterior chambers rounded, hyaline, thin and membranous (Fig. 37D). Males can only be distinguished from those of $S$. altifrons by their palpi, which possess a wider tegulum, wider embolus (Fig. 38C) and unequal size of the RTA and RTAvbr: in males of $S$. altifrons the size of the conical apophysis and its accessory branch is almost equivalent (being the RTAvbr slightly stouter than the RTA). In S. nigra the RTA is bigger and laminar (Fig. 38D). Also, the Pcym curves ventrally way above the apophysis instead of close to the tip of the RTAvbr (Fig. 38A).

Description. Female (AMS KS.109395): Anterior eye row strongly recurved (Fig. 37B) and posterior row procurved (Fig. 37B). Prosoma, legs and opisthosoma predominantly 

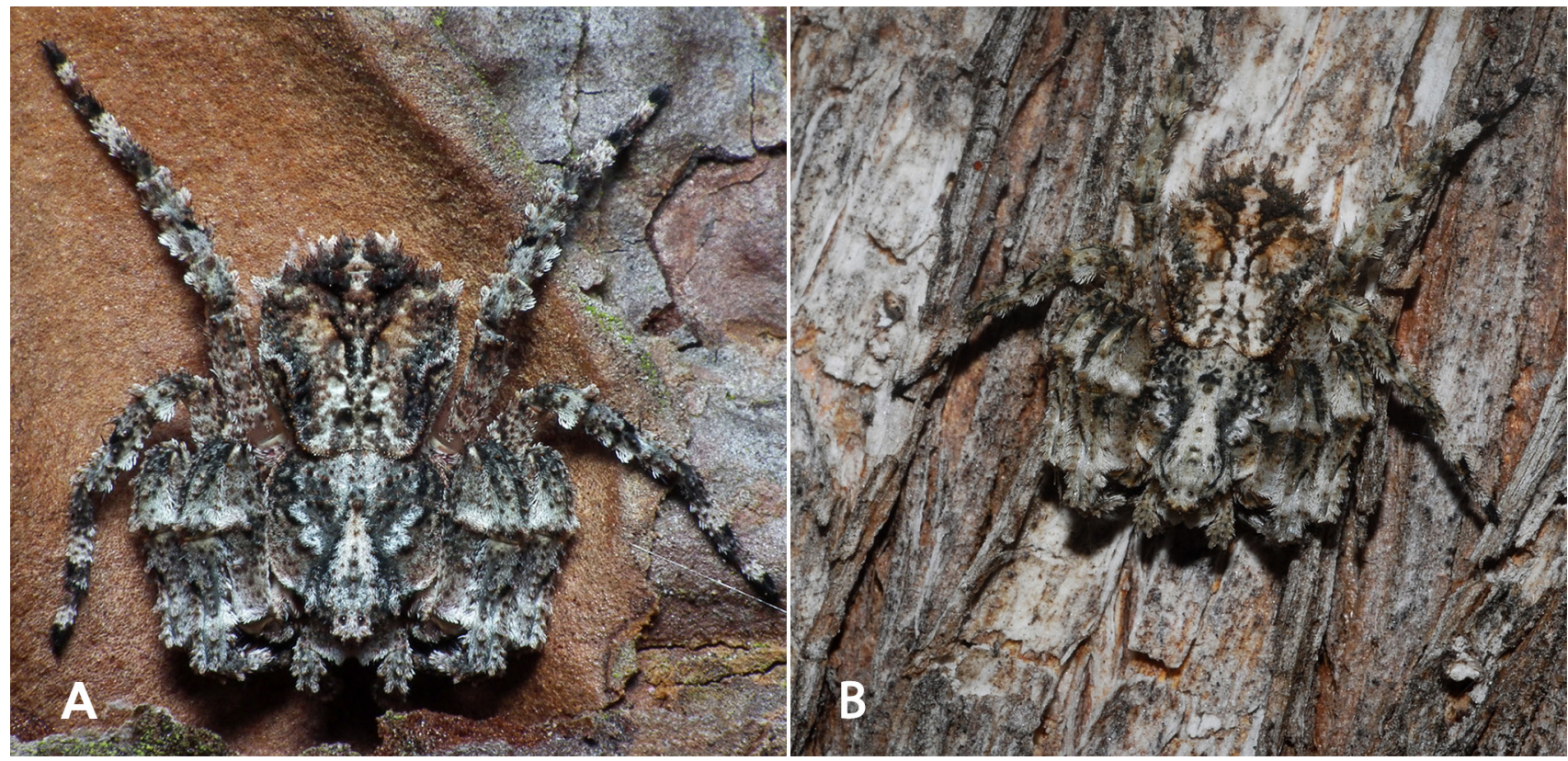

Figure 39. Stephanopis nigra females. Photos by (A) James Niland and (B) Nicholas Fisher.

dark-brown/black; lateral surfaces of all legs dark-yellow; anterior tarsi (I and II) reddish and anterior tibiae ventrally armed with four pairs of macrosetae (Fig. 37A).

Measurements: eye diameters and interdistances: AME 0.09, ALE 0.20, PME 0.12, PLE 0.09, AME-AME 0.16, AME-ALE 0.10, PME-PME 0.23, PME-PLE 0.15, MOQ length 0.40 , width 0.35 ; leg formula: 1-2-3-4: leg I-femur 3.67 / patella 2.50 / tibia 3.16 / metatarsus 2.35 / tarsus $1.36 /$ total 13.04; II-3.22/2.44/2.58/ 1.96/ 1.24 11.44; III-2.66/ $1.32 / 2.26 / 1.79 / 0.99 / 9.02$; IV-2.73/ 1.11/ 2.05/ 1.83/ $0.90 / 8.62$. Total body length 9.35 ; prosoma length 4.72 , width 4.04; opisthosoma length 4.63; clypeus height 0.82 ; sternum length 1.97 , width 1.69 ; gnathocoxae length 1.02 , width 0.46 ; labium length 0.65 , width 0.75 .

Male (AMS KS.65781): Prosoma predominantly darkbrown with yellow spots on the sides right behind the cephalic area, and median portion of the posterior slope (Fig. 38A and B). Eye arrangement as in female. Femora I and II dark-brown; patellae, tibiae, tarsi and metatarsi of all legs brown with yellow spots; femora III and IV mainly yellow on its proximal portion. Opisthosoma dark-brown, darker at the area of the dorsal muscular sigilla; anterior border concave and posterior rounded, with many setiferous tubercles (Fig. 38D).

Measurements: eye diameters and interdistances: AME 0.08, ALE 0.17, PME 0.11, PLE 0.11, AME-AME 0.09, AME-ALE 0.07, PME-PME 0.14, PME-PLE 0.07, MOQ length 0.42 , width 0.32 ; leg formula: 1-2-3-4: leg I-femur 2.51 / patella 1.40 / tibia 2.10 / metatarsus 1.68 / tarsus 0.89 / total 8.58 ; II-2.21/ 1.20/ 1.76/ 1.52/0.88 7.57; III-1.77/ $0.78 / 1.79 / 1.35 / 0.68 / 6.37$; IV-1.75/ 0.70/ 1.36/ 1.33/ $0.67 / 5.81$. Total body length 6.06; prosoma length 2.93 , width 2.44; opisthosoma length 3.13; clypeus height 0.46 ; sternum length 1.17 , width 1.26 ; gnathocoxae length 0.64 , width 0.30 ; labium length 0.31 , width 0.43 .

Distribution. Queensland, New South Wales and Tasmania, Australia (Fig. 42).

\section{Stephanopis palliolata Simon, 1908}

Fig. 40

Stephanopis palliolata Simon, 1908: 432.

Type material examined. Syntype, 10, ZMB 20726, Wooroloo, Western Australia, Australia.

Other material examined. Queensland: ZMB 48561, 10,

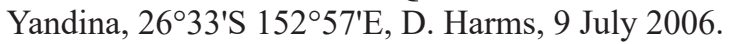

Diagnosis. Males of $S$. palliolata resemble those of $S$. arenata sp nov. by their striped legs, set of modified tibial and metatarsal macrosetae on leg I (long and thin barbs) (Fig. 40A), and palpi with a hyaline Pcym, single-tipped RTA and a flattened embolus resting on a tegular ridge retro laterally positioned (Fig. 40C). However, males of S. palliolata can be easily distinguished from those of $S$. arenata sp. nov. by longer and needle-shaped setae covering their entire body and, cymbium rounded but not retro-ventrally tilted (Fig. 40C,D).

Description. Male (ZMB 20726): Anterior eye row recurved and posterior straight, prosoma dark-yellow with a central and a pair of lateral brown patches (Fig. 40A). Leg I entirely reddish-brown and legs II, III and IV yellow with brown annuli along all segments (Fig. 40A). Opisthosoma obovate, with straight anterior border and covered by many needleshaped setae (Fig. 40B).

Measurements: eye diameters and interdistances: AME 0.07, ALE 0.17, PME 0.15, PLE 0.11, AME-AME 0.10, AME-ALE 0.07, PME-PME 0.18, PME-PLE 0.11, MOQ length 0.44 , width 0.35 ; leg formula: 1-2-3-4: leg I-femur 2.11 / patella 0.95 / tibia 3.00 / metatarsus 1.33 / tarsus 0.73 / total 8.12; II-2.08/ 0.90/ 1.85/ 1.26/ 0.706 .79 ; III-1.38/ $0.82 / 1.35 / 1.29 / 0.74 / 5.58$; IV-1.45/ 0.85/ 1.33/ 1.30/ $0.74 / 5.67$. Total body length 4.22; prosoma length 2.00 , width 1.92; opisthosoma length 2.22; clypeus height 0.28 ; sternum length 0.89 , width 0.93 ; gnathocoxae length 0.32 , width 0.21 ; labium length 0.22 , width 0.26 .

Female: Unknown.

Distribution. Western Australia and Queensland, Australia (Fig. 42). 


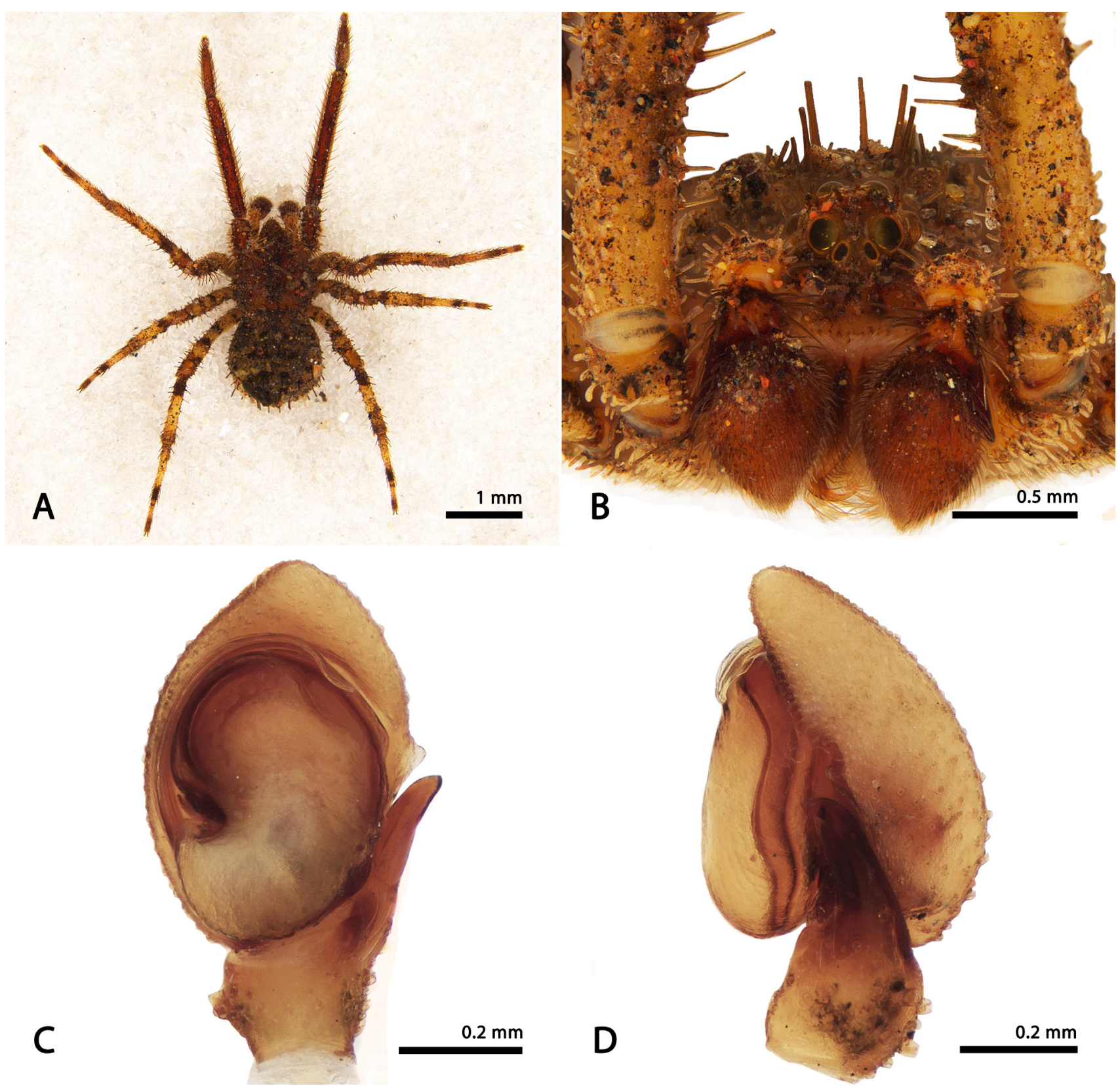

Figure 40. Stephanopis palliolata Simon, 1908, male (ZMB 20726). (A) dorsal habitus; (B) front; (C) ventral view of the left palp; (D) left palp, retro lateral view.

\section{Stephanopis rufiventris Bradley, 1871}

Fig. 41

Stephanopis rufiventris Bradley, 1871: 237.

Type material examined. Holotype $\circ$, OUMNH 618 , Tia (40 km east of Walcha), New South Wales, [31 ${ }^{\circ} 12^{\prime} \mathrm{S}$ $\left.151^{\circ} 48^{\prime} \mathrm{E}\right]$, Australia.

Other material examined. Queensland: AMS KS.53360,

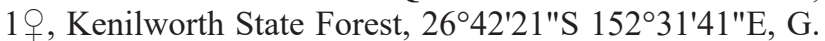
Milledge, 7 May 1998. New South Wales: AMS KS.108723, 1 , , Vittoria (Bathrust), $33^{\circ} 27^{\prime} \mathrm{S} 149^{\circ} 20^{\prime} \mathrm{E}$, C. Chadwick, 1 October 1967; AMS KS.73311, 19, Maroota State Forest, $33^{\circ} 31^{\prime} \mathrm{S} 150^{\circ} 59^{\prime} \mathrm{E}, \mathrm{G} . \mathrm{A}$. Webb, 2 November 1979 . Victoria:

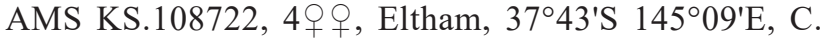
Chadwick \& R. E. Mascord, 2 January 1968.
Diagnosis. Females of $S$. rufiventris resemble those of $S$. cambridgei in having an elongated body, predominantly orange colouration, striped legs (Fig. 41A) and external genitalia with shallow atrium and copulatory ducts hidden by the lateral folds of the epigynal plate (Fig. 41C). However, S. rufiventris can be distinguished by its more flattened prosoma (Fig. 41B) with shorter dark stripes, restricted to the median portion and sides of the cephalic area instead of long longitudinal marks extended until the PLE. Their epigynal plate is thicker, with sclerotized folds that are joined anteriorly forming a horse-shoe-shaped structure (Fig. 41C) instead of the pair of lateral pockets observed in females of S. cambridgei. The spermathecae are characteristically positioned on the sides and bear glandularheads on their top; the anterior chambers are rounded and medially positioned (Fig. 41D). 


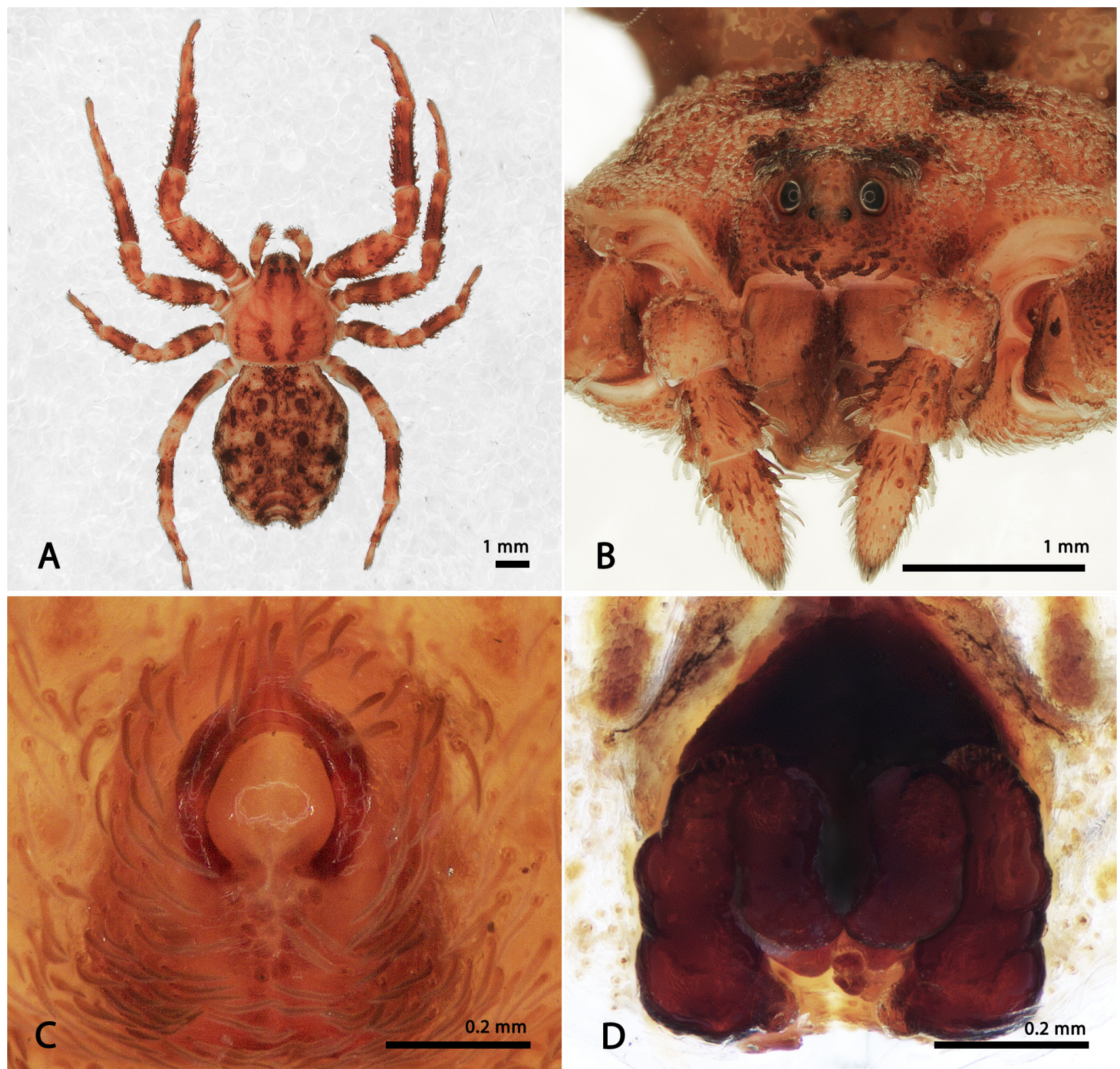

Figure 41. Stephanopis rufiventris Bradley, 1871, 1869, female (KS.108722). (A) dorsal habitus; (B) front; (C) epigynal plate, ventral view; (D) epigynal plate/spermathecae.

Description. Female (AMS KS.108722): Anterior eye row recurved and posterior straight, prosoma flattened, predominantly orange with two pairs of longitudinal cephalic stripes (one on the median area and one on the sides) (Fig. 41 A and B); cephalic prominence absent. Legs orange with darker distal markings on the femora and metatarsi and proximal ones on tibiae. Opisthosoma obovate, slightly concave on its anterior border, presenting a median reentrance close to the anal region and three pairs of well-developed dark-brown muscular sigilla on the dorsum (Fig. 41A).

Measurements: eye diameters and interdistances: AME 0.08, ALE 0.15, PME 0.13, PLE 0.13, AME-AME 0.12,
AME-ALE 0.07, PME-PME 0.14, PME-PLE 0.17, MOQ length 0.36 , width 0.32 ; leg formula: 1-2-4-3: leg I-femur 2.33 / patella $1.06 /$ tibia $2.19 /$ metatarsus $1.11 /$ tarsus $0.90 /$ total 7.59; II-2.30/ 1.02/ 2.12/ 1.09/ 0.90 7.43; III-1.56/ $0.90 / 1.49 / 1.05 / 0.88 / 5.88$; IV—2.17/ 1.00/ 1.70/ 1.04/ 0.90 / 6.81. Total body length 8.39 ; prosoma length 3.71 , width 3.46; opisthosoma length 4.68; clypeus height 0.28 ; sternum length 1.61 , width 1.48 ; gnathocoxae length 0.72 , width 0.33 ; labium length 0.50 , width 0.52 .

Male: Unknown.

Distribution. Queensland, New South Wales and Victoria, Australia (Fig. 42). 


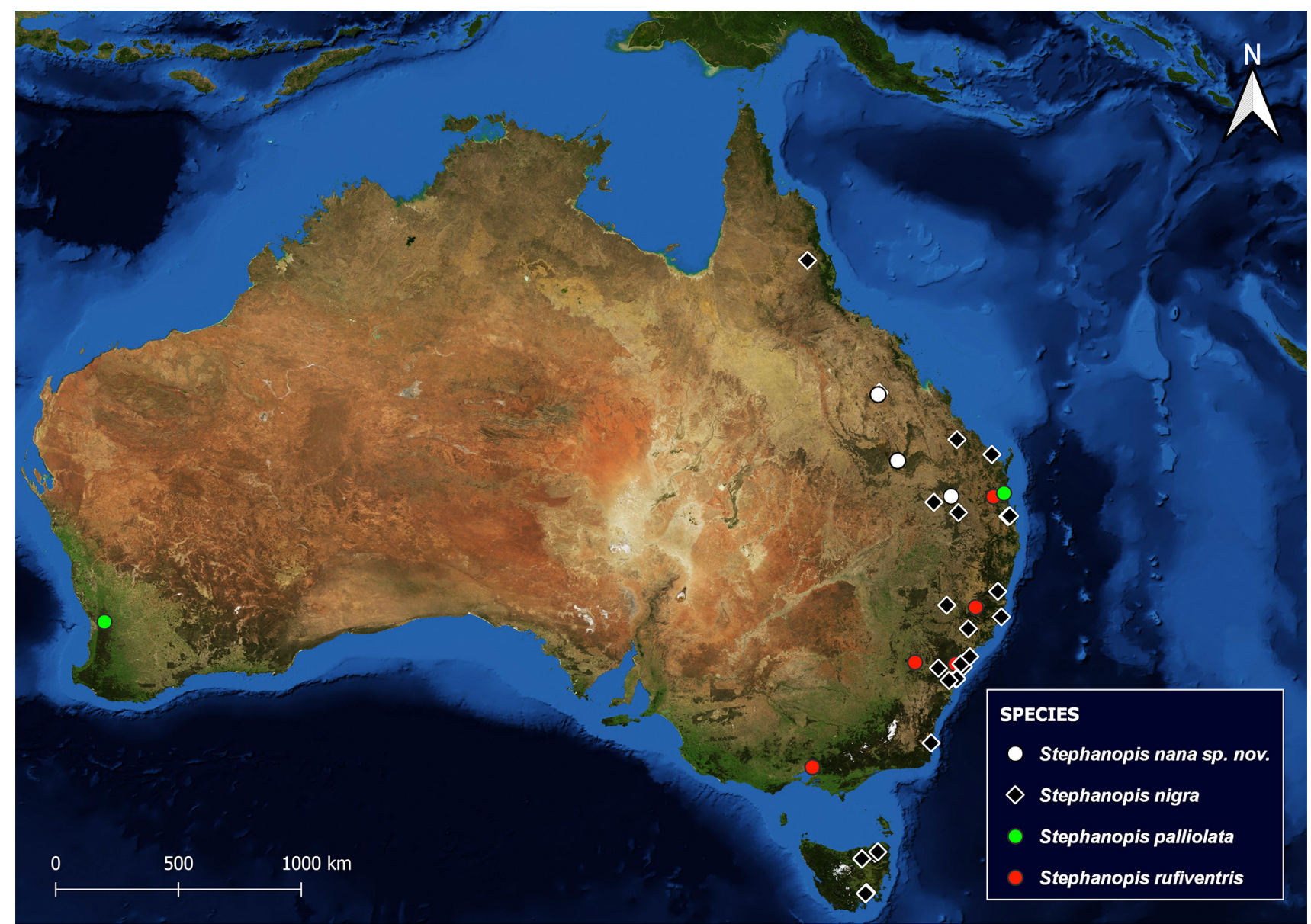

Figure 42. Distribution records of S. nana sp. nov., S. nigra, S. palliolata and S. rufiventris.

\section{Stephanopis similis Machado sp. nov.}

http://zoobank.org/NomenclaturalActs/8A2D2DDD-B909-44CB-BB6E-4E0C98ED4D41

Figs 43-44

Holotype 9 , AMS KS.30026, Kanangra Boyd National Park (Boyd plateau near to Jenolan Caves), $34^{\circ} 03^{\prime} \mathrm{S}$ $150^{\circ} 05^{\prime} \mathrm{E}$, New South Wales, Australia, G. Hunt, 6 June 1961. Paratypes: AMS KS.121191, 19, Werrikimbe NP, $31^{\circ} 11^{\prime} 56 " \mathrm{~S} 152^{\circ} 10^{\prime} 23 " \mathrm{H}, \mathrm{E}$. Tasker, 2 December 1997; AMS

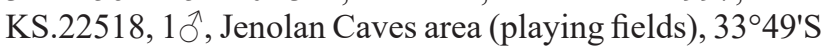
$150^{\circ} 02^{\prime} \mathrm{E}$, G. Hunt, 14 August 1979; AMS KS.29993, 10َ, Kanangra Boyd National Park (Blood Filly Creek), 33 ${ }^{\circ} 51^{\prime} \mathrm{S}$ $150^{\circ} 03^{\prime} \mathrm{E}$, New South Wales, Australia, M. Gray \& G. Hunt, 27 March 1976.

Other material examined. Western Australia: AMS KS.15423, 1 ${ }^{\top}$, Normalup-Walpole National Park (Big Tingle Tree), 3457'S $116^{\circ} 16^{\prime} \mathrm{E}, \mathrm{M}$. Gray, 15 February 1975. New South Wales: AMS

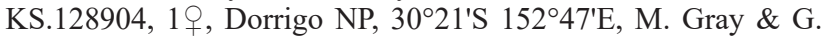
Cassis, 4 February-9 April 1993; AMS KS.102991, 1ㅇ, Barrington Tops NP, 3203'43"S 151 34 '39"E, G. Milledge \& H. Smith, 13 November-19 December 2007.

Diagnosis. Females and males of $S$. similis sp. nov. resemble those of $S$. cambridgei by their elongated body, obovate opisthosoma, thin and long barbs on tibia and metatarsus I of male legs, and pair of prolateral setae on femur I (Figs. 43A and 44A). However, they can be distinguished by their lower cephalic area (Figs. 43B and 44B), shorter hyaline setae covering their entire body and pair of reddish-brown median stripes fused on the thoracic area instead of parallel bands that never touch each other. Females can be diagnosed by the wider than long atrium and $\mathrm{CO}$ covered by $\mathrm{C}$-shaped lateral folds of the plate (Fig. 43C); copulatory ducts are short and straight, leading to the pair of the kidney-shaped spermathecae with glandular-heads positioned anteriorly (Fig. 43D). Males can be recognized by the subtriangular cymbium, short embolus and truncated RTA (Fig. 44C).

Description. Female (AMS KS.30026): Prosoma orange with longitudinal reddish-brown stripes (a fused central pair and a lateral one on the margins of prosoma) (Fig. 43A); flattened, longer than wide and cephalic prominence absent (Fig. 43B); anterior eyes arranged in a recurved row and posterior ones in a straight row. Legs orange with reddishbrown spots; opisthosoma whitish-yellow with several black punctuations on dorsum (Fig. 43A).

Measurements: eye diameters and interdistances: AME 0.07, ALE 0.19, PME 0.12, PLE 0.14, AME-AME 0.11, AME-ALE 0.07, PME-PME 0.23, PME-PLE 0.18, MOQ length 0.45 , width 0.34 ; leg formula: $1-2-3-4$ : leg I-femur 3.58 / patella 1.93 / tibia 3.41 / metatarsus 2.36 / tarsus $0.87 /$ total 12.42 ; II-3.04/ 1.52/2.75/ 1.91/ 0.8910 .11 ; III-2.08/ $1.05 / 1.64 / 0.94 / 0.66 / 6.37$; IV $-2.75 / 1.11 / 2.24 / 1.39 /$ $0.75 / 8.24$. Total body length 9.83 ; prosoma length 3.94 , width 3.38; opisthosoma length 5.89; clypeus height 0.23 ; sternum length 1.76 , width 1.57 ; gnathocoxae length 0.88 , width 0.46 ; labium length 0.56 , width 0.64 . 

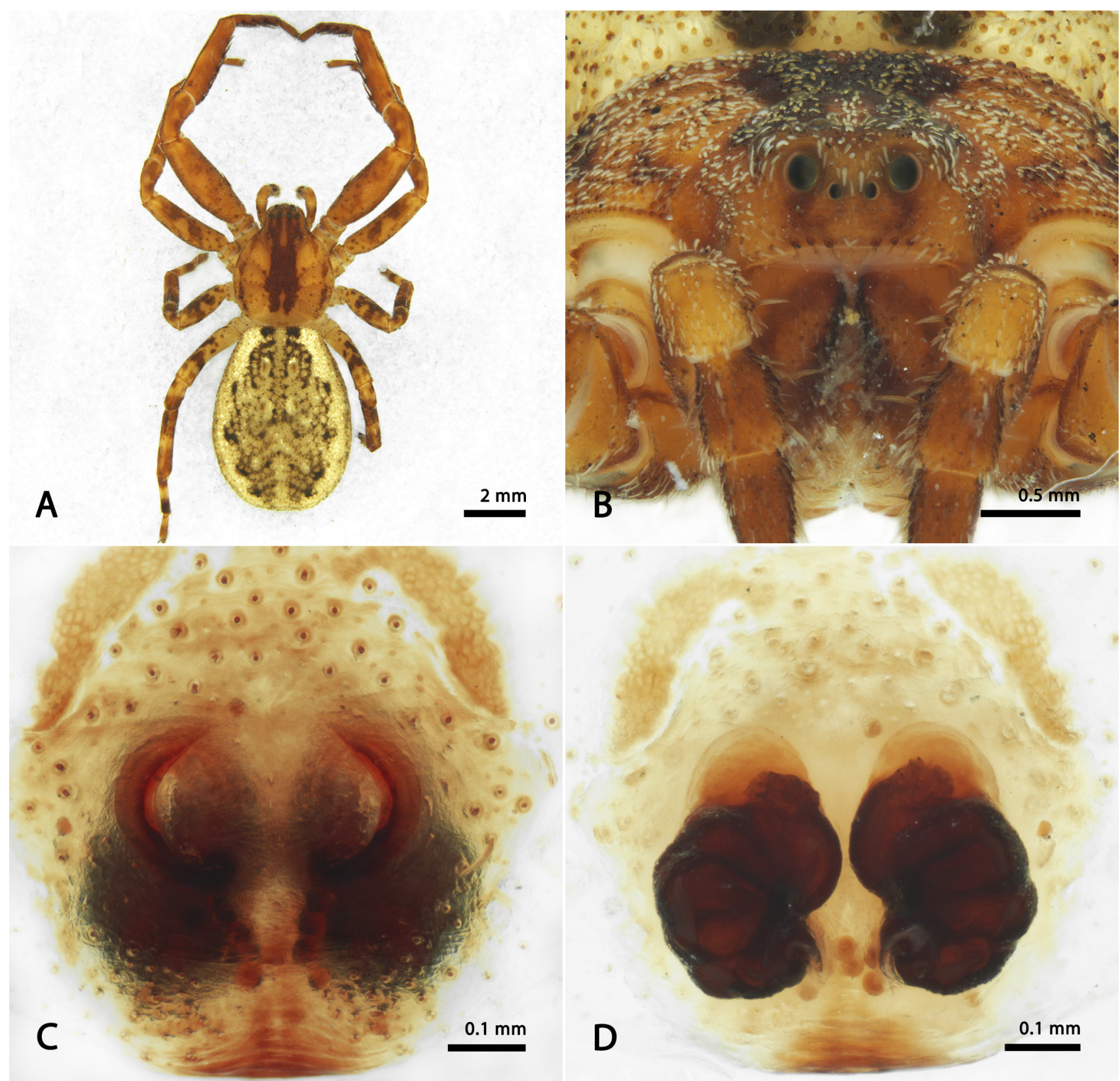

Figure 43. Stephanopis similis sp. nov., female (AMS KS.30026). (A) dorsal habitus; (B) front; (C) epigynal plate, ventral view; (D) epigynal plate/spermathecae.

Male (AMS KS.29993): Except by the modified setae on tibiae I and II, all other somatic features are as in female. Tegulum membranose and hyaline (Fig. 44C); RTA stout, single-tipped with narrowed dorsal extremity (Fig. 44D).

Measurements: eye diameters and interdistances: AME 0.07, ALE 0.19, PME 0.13, PLE 0.13, AME-AME 0.11, AME-ALE 0.05, PME-PME 0.15, PME-PLE 0.18, MOQ length 0.35 , width 0.32 ; leg formula: 1-2-3-4: leg I-femur 3.28 / patella 1.64 / tibia 3.35 / metatarsus 2.40 / tarsus $0.98 /$ total 11.65; II-2.65/ 1.31/2.77/ 1.89/0.92 9.54; III-1.84/ $0.89 / 1.48 / 0.84 / 0.64 / 5.69$; IV-2.26/ $0.97 / 1.97 / 1.30 /$
$0.70 / 7.20$. Total body length 7.14 ; prosoma length 3.21 , width 2.74; opisthosoma length 3.93; clypeus height 0.20 ; sternum length 1.44 , width 1.31 ; gnathocoxae length 0.67 , width 0.37 ; labium length 0.44 , width 0.47 .

Etymology. The specific epithet is a Latin masculine adjective that means "similar", given to this species due to its striking resemblance with $S$. cambridgei.

Distribution. Western Australia and New South Wales, Australia (Fig. 49). 


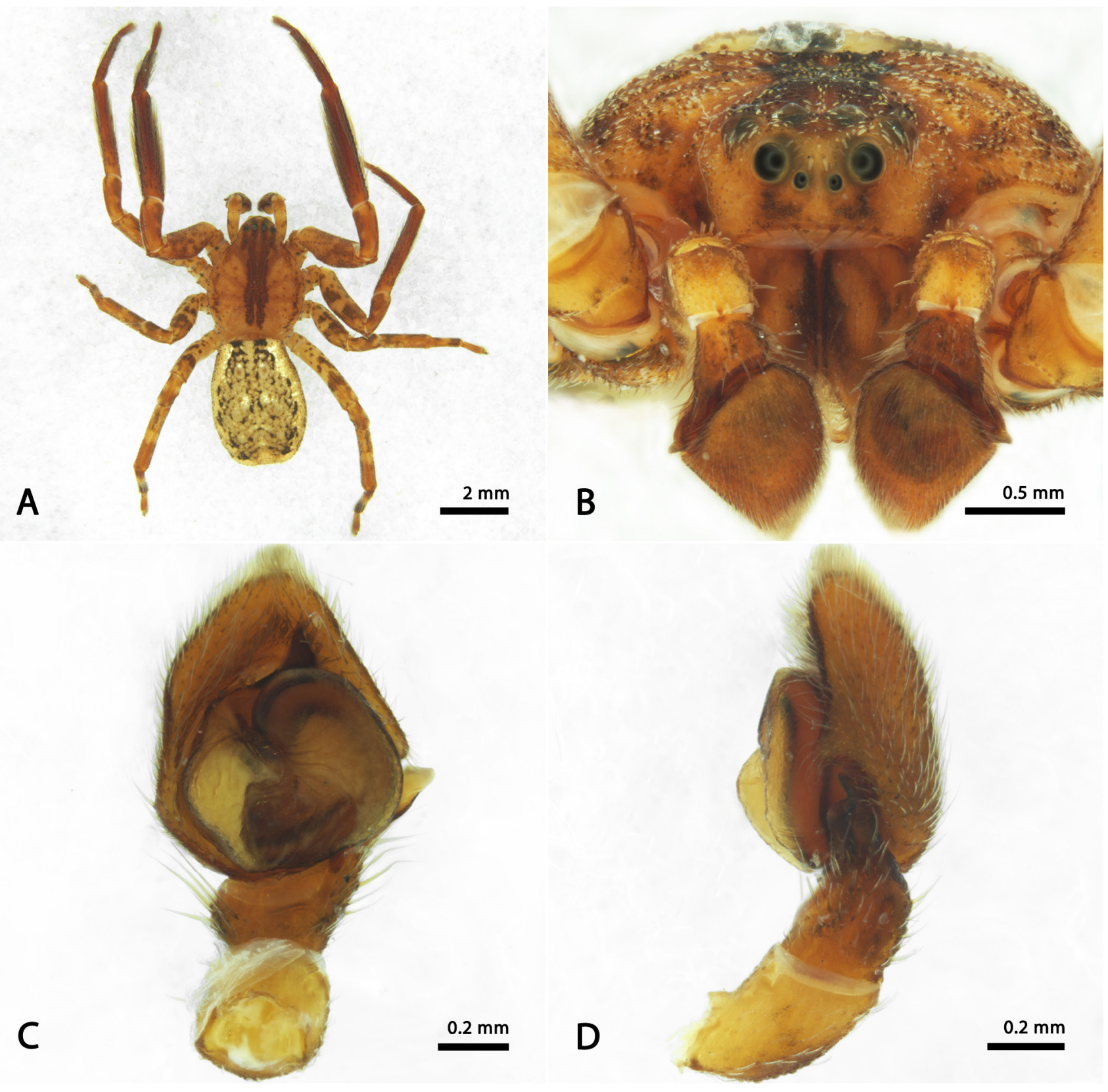

Figure 44. Stephanopis similis sp. nov., male (AMS KS.29993). (A) dorsal habitus; (B) front; (C) ventral view of the left palp; (D) left palp, retro lateral view. 


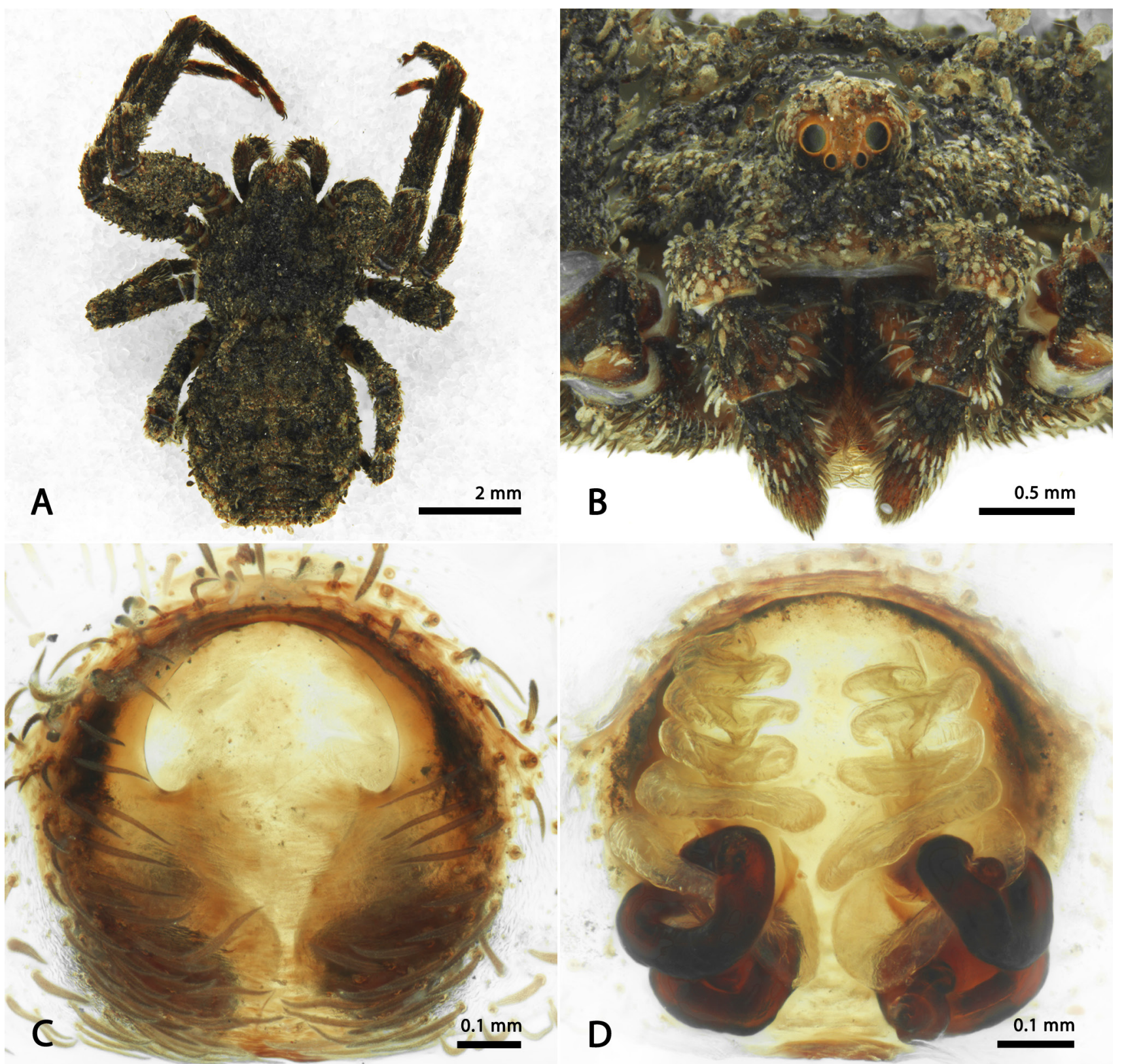

Figure 45. Stephanopis spiralis sp. nov., female (AMS KS.114827). (A) dorsal habitus; (B) front; (C) epigynal plate, ventral view; (D) epigynal plate/spermathecae.

\section{Stephanopis spiralis Machado sp. nov.}

http://zoobank.org/NomenclaturalActs/F0DDFB73-40AF-43F0-9E48-EAAE984B66D4

Figs 45-46

Holotype 9 , AMS KS.114827, Koorawatha National Reserve, $34^{\circ} 01^{\prime} 55^{\prime \prime S ~} 148^{\circ} 35^{\prime} 59^{\prime \prime E}$, New South Wales, Australia, B. Baehr, 15 November 2010. Paratype: AMS KS.91528, 10, Lower Murray-Darling Region (Wampoo Station), $34^{\circ} 04^{\prime} 16^{\prime \prime S} 143^{\circ} 13^{\prime} 49^{\prime \prime} E$, New South Wales, Australia, M. Lebreton, 6-10 March 2000.

Other material examined. New South Wales: AMS KS.75074, 1 , , Coolah Tops NP (Cox's Creek campground), 3144'00"S $150^{\circ} 00^{\prime} 30^{\prime \prime E}$, M. Gray, G. Milledge \& H. Smith, 7 November 2001; AMS KS.78947, 10, Yathong Nature Reserve, 3250'56"S $146^{\circ} 10^{\prime} 58^{\prime \prime E}$, D. Eldridge, March 2001. South Australia: SAM NN22647, 10े, Tarcowie, 330'36"S 138³5'49"E, 17-22 March 2004.
Diagnosis. Both males and females are similar to $S$. cambridgei in their body size and proportion, shape of the atrium and folds of epigynal plate and by the single long and pointed RTA on male palp. S. spiralis can be distinguished by its darker body colour, which is dark-brown rather than orange; by females having a wider atrium (Fig. 46C) and spiral copulatory ducts vertically positioned (Fig. 45D); and by the male palp bearing an embolus coiled at its basis and a cymbium longer than wide directed retro laterally (Fig. 46C).

Description. Female (AMS KS.114827): Cephalic area prominent (not as much as in S. altifrons but higher than in $S$. cambridgei), eyes arranged in a strongly recurved anterior row and in a straight posterior one; prosoma, opisthosoma and legs uniformly dark-brown (almost black), covered by many hyaline or whitish setae (Fig. 45A). Spermathecae long, sclerotized, coiled ( 2 coils) and bearing a pair of glandular-heads pointing sideways (Fig. 45D). 

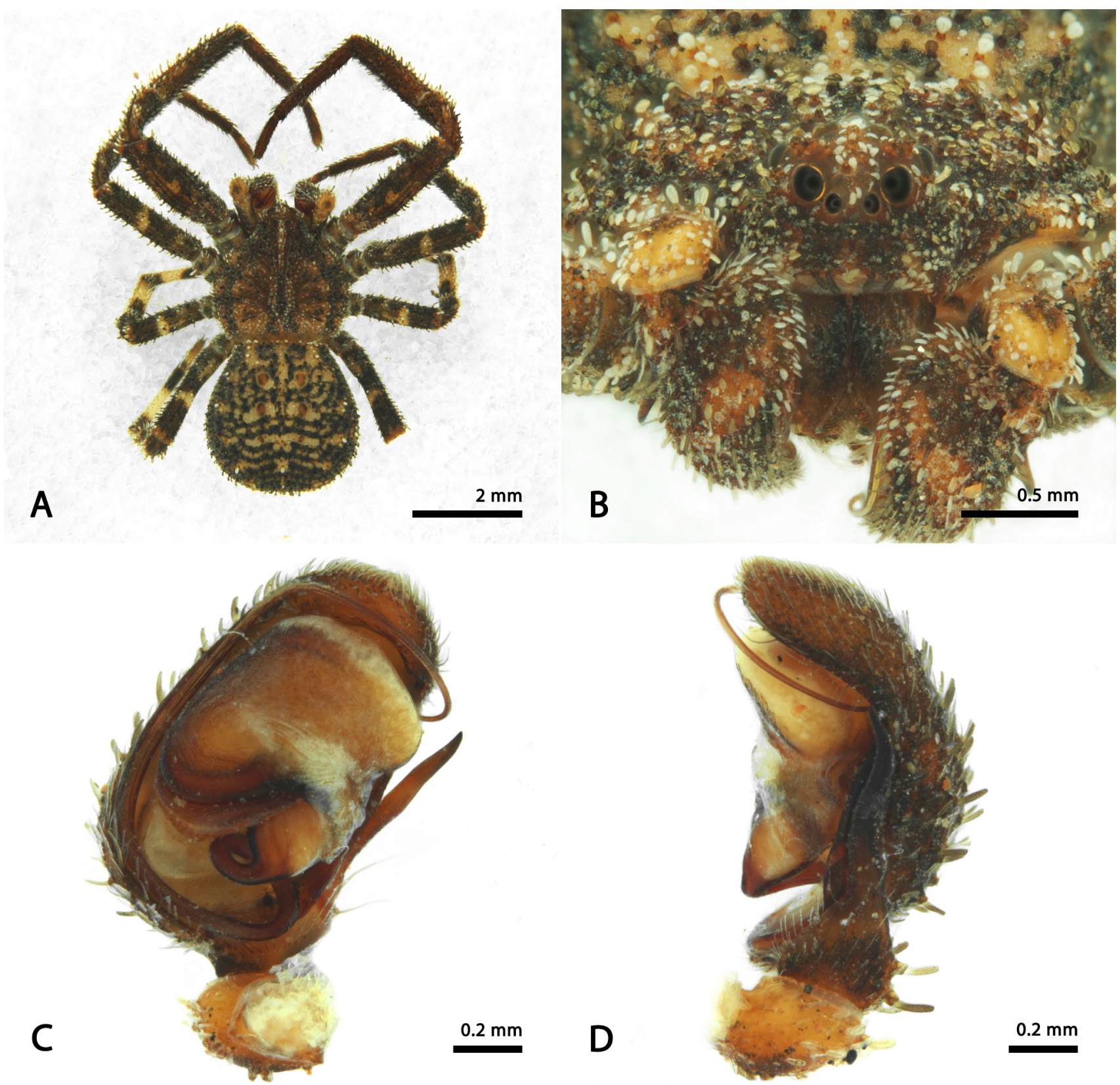

$0.2 \mathrm{~mm} \quad D$

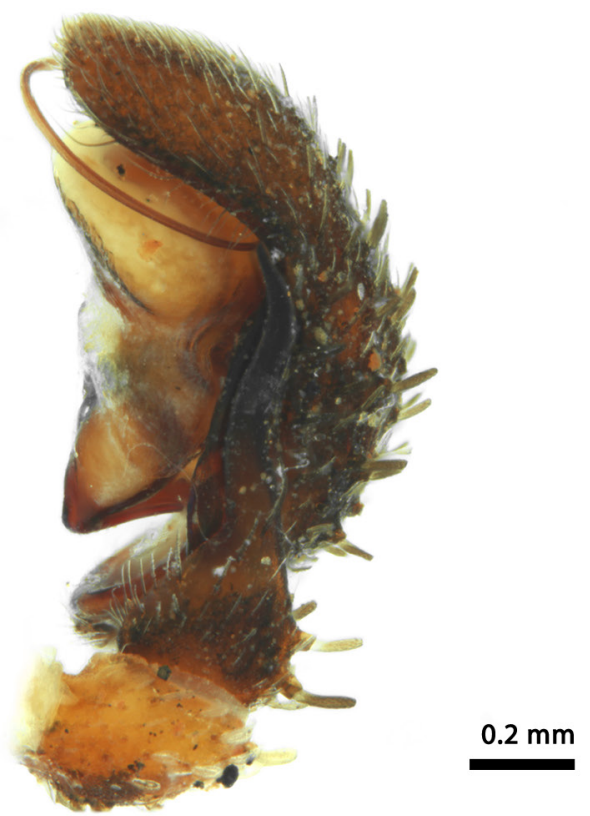

Figure 46. Stephanopis spiralis sp. nov., male (AMS KS.91528) left palp, retro lateral view.

Measurements: eye diameters and interdistances: AME 0.07, ALE 0.15, PME 0.11, PLE 0.11, AME-AME 0.11, AME-ALE 0.06, PME-PME 0.15, PME-PLE 0.14, MOQ length 0.38 , width 0.25 ; leg formula: 1-2-4-3: leg I-femur 3.19 / patella 1.68 / tibia $3.07 /$ metatarsus 2.18 / tarsus 0.88 / total 11.00; II-2.66/ 1.30/ 2.38/ 1.89/ 0.87 9.10; III-1.88/ $0.92 / 1.44 / 1.23 / 0.73 / 6.20$; IV-2.38/ 0.97/ 1.90/ 1.80/ $0.84 / 7.89$. Total body length 7.52 ; prosoma length 3.26 , width 3.10; opisthosoma length 4.26; clypeus height 0.55 ; sternum length 1.60, width 1.50; gnathocoxae length 0.87 , width 0.45 ; labium length 0.47 , width 0.59 .

Male (AMS KS.91528): Prosoma and legs predominantly dark-brown with dark-yellow areas (thoracic portion of prosoma) and anulli (legs) (Fig. 46A); opisthosoma obovate, covered by short hyaline setae and presenting large symmetrical yellowish spots near the dorsal sigillae which are reduced to small punctuations on the sides (Fig. 46A); RTA thin, long, pointed and slightly sinuous (Figs 46C and D).

Measurements: eye diameters and interdistances: AME 0.07, ALE 0.20, PME 0.13, PLE 0.20, AME-AME 0.10, AME-ALE 0.03, PME-PME 0.10, PME-PLE 0.12, MOQ length 0.34 , width 0.26 ; leg formula: $1-2-4-3$ : leg I-femur 2.80 / patella 1.35 / tibia 2.31 / metatarsus 1.88 / tarsus 0.81 / total 9.15 ; II $-2.24 / 1.04 / 1.77 / 1.48 / 0.74 / 7.27$; III-1.46/ $0.70 / 1.04 / 0.93 / 0.56 / 4.53$; IV-1.98/ 0.77/ 1.41/ 1.43/ $0.68 / 6.27$. Total body length 5.43 ; prosoma length 2.66 , width 2.52; opisthosoma length 2.77; clypeus height 0.36 ; sternum length 1.24 , width 1.19 ; gnathocoxae length 0.48 , width 0.25 ; labium length 0.35 , width 0.44 .

Etymology. The specific name is a Latin masculine adjective that means "spiral" and refers to the shape and disposition of the diagnostic copulatory ducts of the females.

Distribution. New South Wales and South Australia, Australia (Fig. 49). 


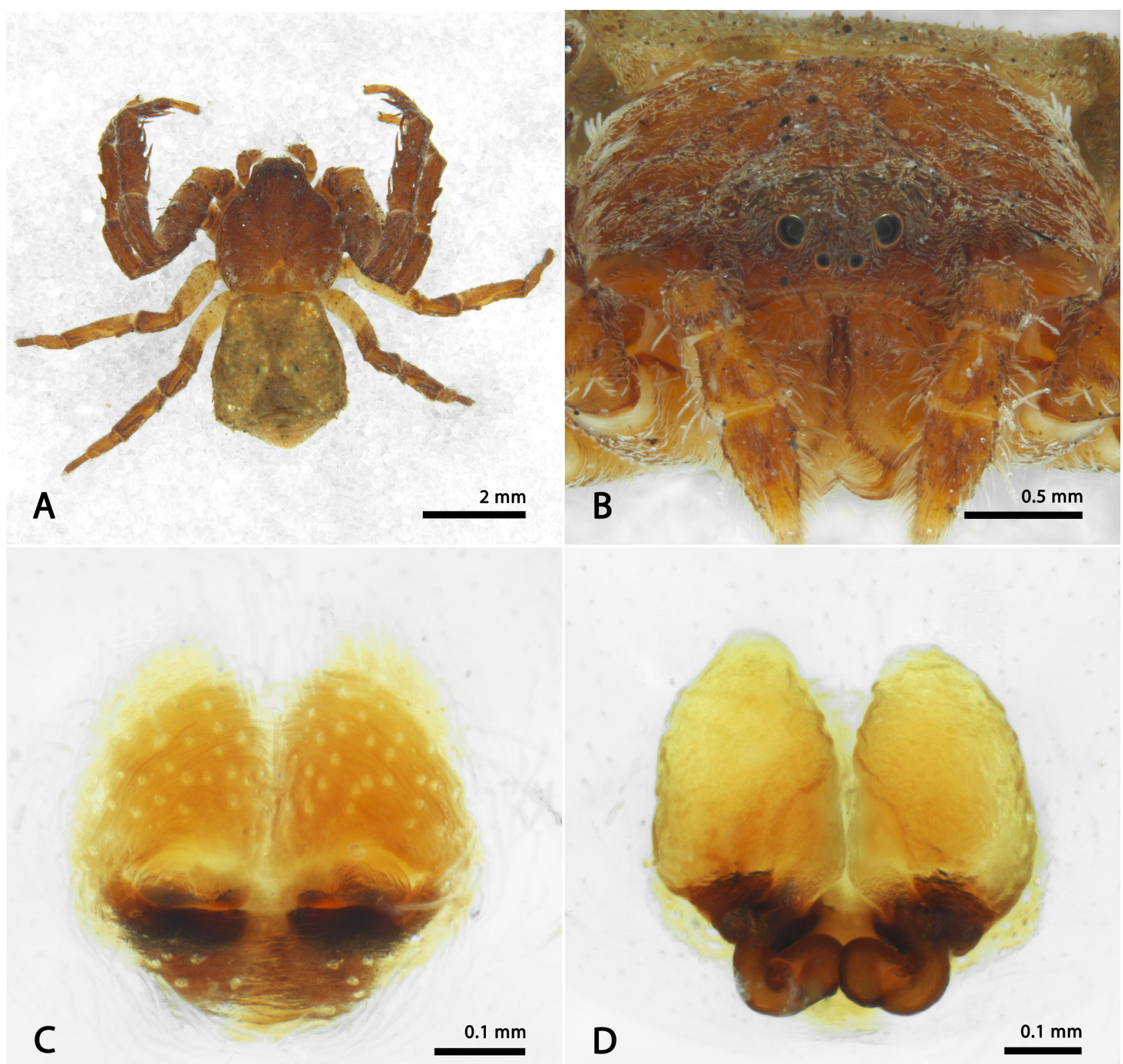

Figure 47. Stephanopis squalida sp. nov., female (QM S110113). (A) dorsal habitus; (B) front; (C) epigynal plate, ventral view; (D) epigynal plate/spermathecae.

\section{Stephanopis squalida Machado sp. nov.}

http://zoobank.org/NomenclaturalActs/3ABBAF3D-1669-4972-90AE-06BCEBD85B96

\section{Figs $47-48$}

Holotype $\circ$, QM S27834, Bellenden Ker Range, Queensland, Australia, $17^{\circ} 15^{\prime} 59^{\prime \prime S} 145^{\circ} 53^{\prime} 56.97 " \mathrm{E}$, Queensland Museum \& Earthwatch Expedition, 17-24 October 1981. Paratypes:

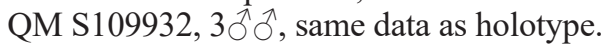

Other material examined. Queensland: QM S110120, 1웅 Mount Finnigan (37 Km south of Cooktown), 1548'13.25"S $145^{\circ} 18^{\prime} 22.07^{\prime} E$, G. Monteith, D. Yeates \& D. Cook, 19-22 April 1982; QM S110113, 19, 2.5 km southwest of Mt Hartley near Cairns, G. Monteith, D. Yeates \& D. Cook, 23-24 April 1982; QM S110092, 10, Cape Tribulation, 165'16.04"S 145²7'17.20"E, G. Monteith, D. Yeates \& G. Thompson, 27 September-7 October 1982; QM S110088, 19, Thornton Peak (via Daintree), 16²13'55.07"S
14520'26.62"E, G.B. Monteith, 24-27 September 1984; QM S110121, 1ㅇ, G. Monteith \& D. Cook, 20-22 September 1981; QM S27620, 1ð̄, Bellenden Ker Range, $17^{\circ} 15^{\prime} 13.12^{\prime \prime S} 145^{\circ} 54^{\prime} 8.48^{\prime \prime E}$, Queensland Museum \& Earthwatch expedition, 25-31 October 1981;

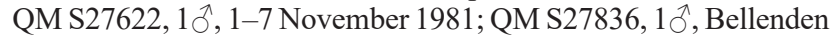

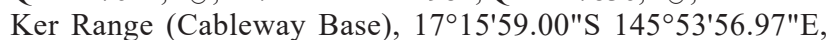
Queensland Museum \& Earthwatch expedition, 17-24 October 1981;

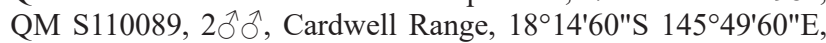
Monteith, Yeates \& Thompson, 17-21 December 1986

Diagnosis. Females of $S$. squalida sp. nov. resemble those of S. fissifrons by the trapezoid opisthosoma (Fig. 47A) and flattened prosoma (Fig. 47B), however they can be recognized by their $\mathrm{CO}$ arranged horizontally and the reduced atrium on the epigynal plate (Fig. 47C). Moreover, the setiferous tubercles and projections on the anterior legs of $S$. squalida sp. nov are well-developed when compared to $S$. fissirons. Males are also similar to those of $S$. fissifrons, 

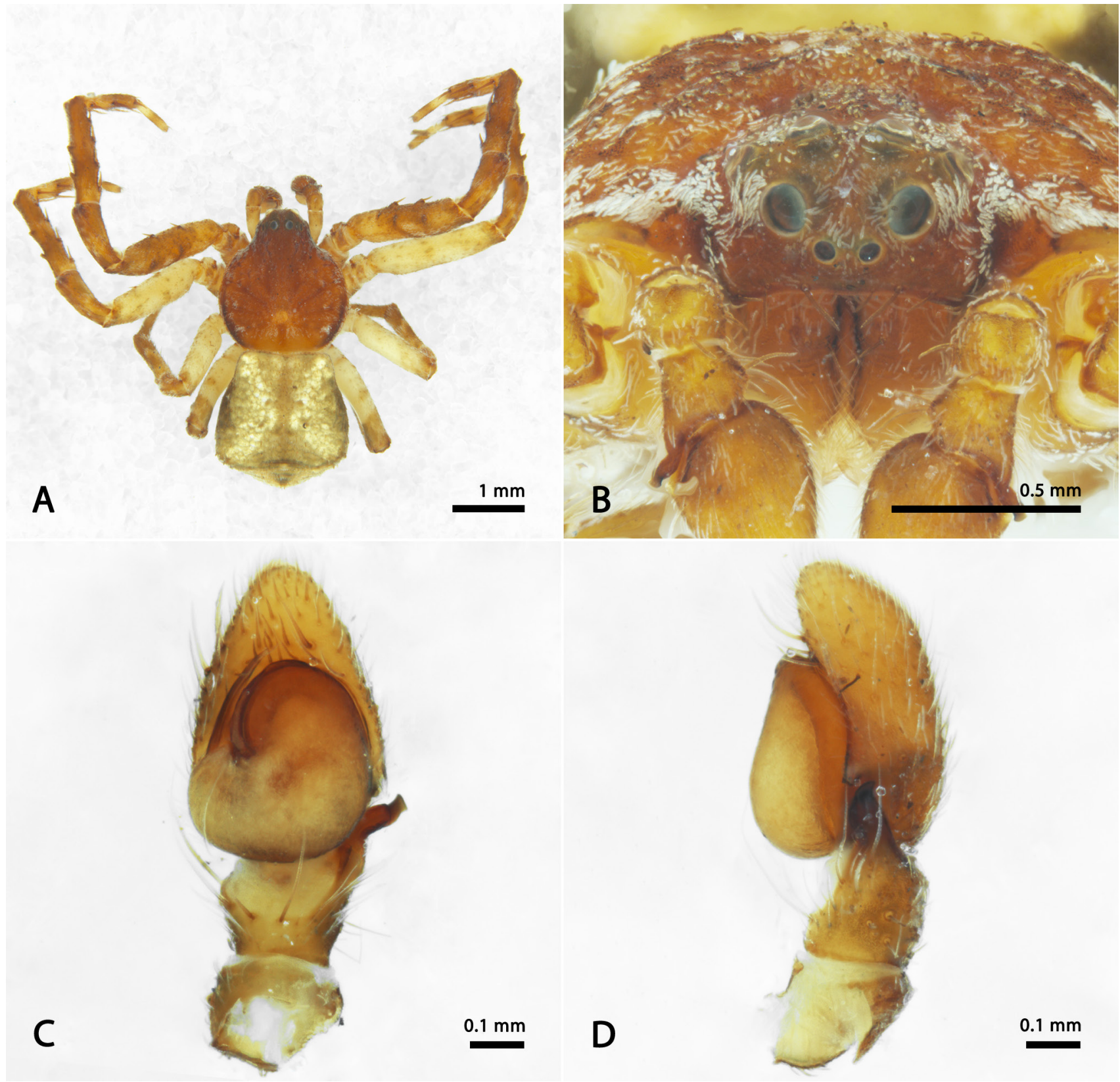

$0.1 \mathrm{~mm} \quad D$

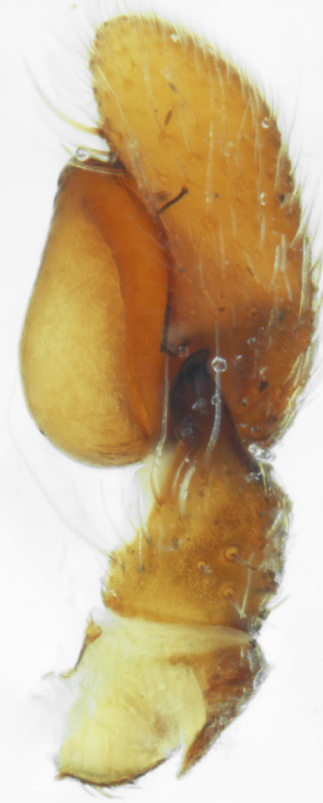

$0.1 \mathrm{~mm}$

Figure 48. Stephanopis squalida sp. nov., male (QM S27834). (A) dorsal habitus; (B) front; (C) ventral view of the left palp; (D) left palp, retro lateral view.

but can be distinguished by the embolus being shorter, the cymbium being oval, by the wider RTA (Fig. 48D) and hyaline Pcym (Fig. 48C).

Description. Female (QM S110113): Anterior eye row recurved and posterior row straight. Prosoma and legs entirely reddish-brown except for the femora III and IV, which are yellow; opisthosoma dark-yellow, slightly concave on the anterior border and square-ended, trapezoid (Fig. 47A). Spermathecae reduced, with glandular-heads directed dorsally and anterior chambers wide, membranous and ovalshaped (Fig. 47D).

Measurements: eye diameters and interdistances: AME 0.07, ALE 0.17, PME 0.15, PLE 0.12, AME-AME 0.09, AME-ALE 0.12, PME-PME 0.23, PME-PLE 0.17, MOQ length 0.42, width 0.39 ; leg formula: 1-2-3-4: leg I-femur 3.25 / patella 1.67 / tibia 2.33 / metatarsus 1.47 / tarsus 0.75 / total 9.47; II $-2.94 / 1.44 / 2.07 / 1.33 / 0.76 / 8.54 ;$ III $-2.07 /$ $1.00 / 1.71 / 1.07 / 0.72 / 6.57$; IV $-2.20 / 0.90 / 1.48 / 1.01 /$ $0.64 / 6.23$. Total body length 7.12 ; prosoma length 3.24 , width 2.87; opisthosoma length 3.88 ; clypeus height 0.14 ; sternum length 1.45 , width 1.23 ; gnathocoxae length 0.82 , width 0.38 ; labium length 0.47 , width 0.58 .

Male (QM S27834): Opisthosoma covered by hyaline setae, with tufts gathered on the sides of the cephalic area (Fig. 48B). As in female, both prosoma and legs possess brownish pigmentation but in males femora II are also yellow; opisthosoma dark-yellow with white guanine stains on the dorsum forming a X-shape (Fig. 48A). Other somatic characteristics as in female.

Measurements: eye diameters and interdistances: AME 0.05, ALE 0.14, PME 0.11, PLE 0.12, AME-AME 0.07, AME-ALE 0.06, PME-PME 0.11, PME-PLE 0.09, MOQ 


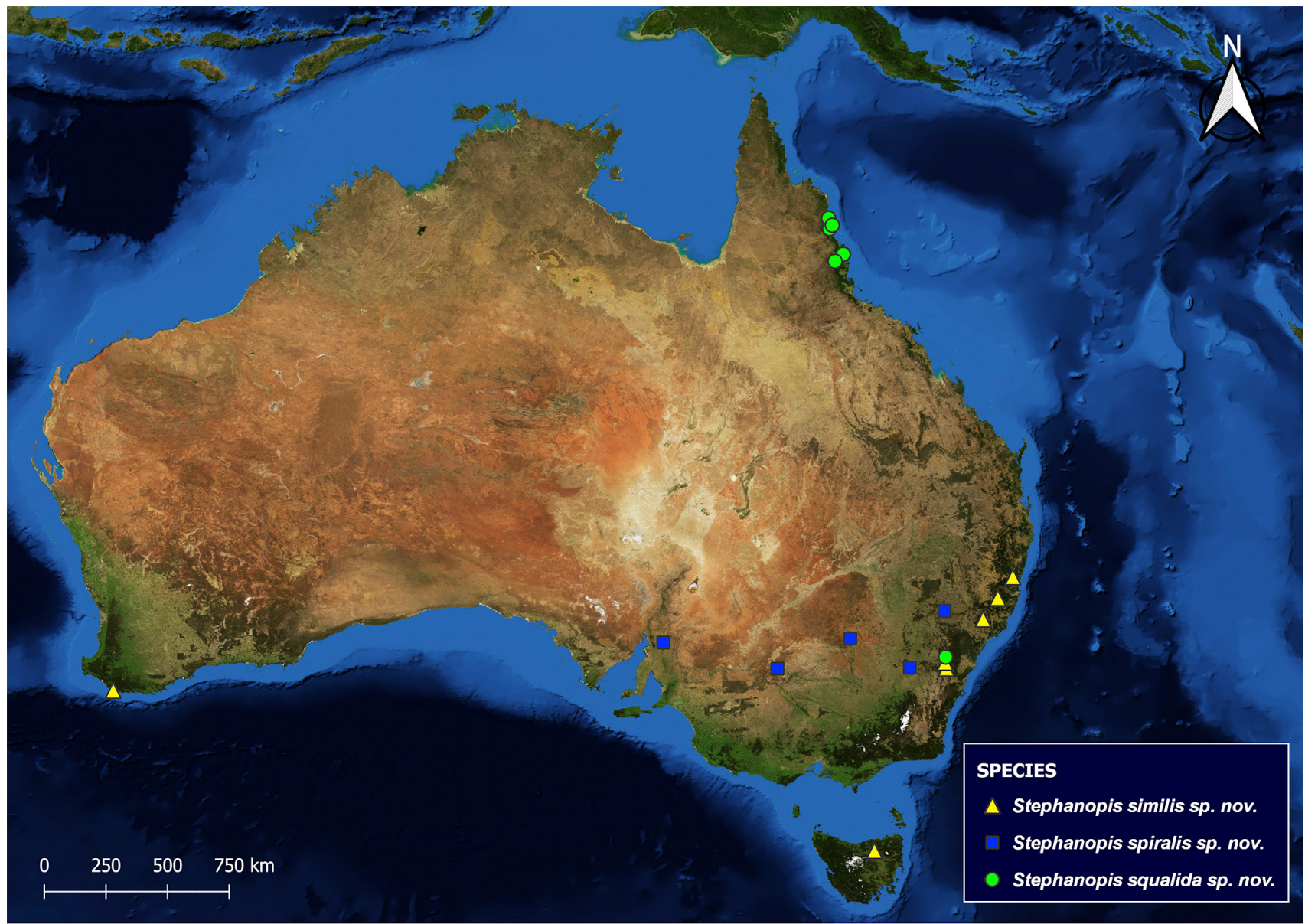

Figure 49. Distribution records of Stephanopis similis sp. nov., S. spiralis sp. nov. and S. squalida sp. nov.

length 0.31 , width 0.26 ; leg formula: 1-2-3-4: leg I-femur 2.21 / patella 0.98 / tibia 1.62 / metatarsus 1.13 / tarsus 0.58 / total 6.52 ; II $-2.03 / 0.91 / 1.52 / 1.02 / 0.55 / 6.03 ; \mathrm{III}-1.35 /$ $0.55 / 1.16 / 0.75 / 0.55 / 4.36$; IV-1.39/ 0.55/ 0.96/ 0.75/ $0.45 / 4.10$. Total body length 3.95 ; prosoma length 2.03 , width 1.83; opisthosoma length 1.92; clypeus height 0.09 ; sternum length 0.82 , width 0.84 ; gnathocoxae length 0.50 , width 0.25 ; labium length 0.24 , width 0.30 .

Etymology. The specific name is a Latin feminine adjective that means "miserable", in reference to the smaller size of the spider and its less pronounced somatic characters when compared to other similar species of the genus.

Distribution. Queensland, Australia (Fig. 49).

\section{Additional taxonomic acts}

Stephanopis bradleyi Mello-Leitão, 1929: 257 (replacement name for Stephanopis cambridgei Bradley, 1871: 233, preoccupied by Stephanopis cambridgei Thorell, 1870). (Holotype female from Nepean Towers, New South Wales, Australia. Not located, presumably lost). Nomen dubium.

Stephanopis cheesmanae Berland, 1938: 132, figs 7-9. (Holotype female from Vanuatu, deposited in the NHMUK, examined). Transferred to PhrynarachnePhrynarachne cheesmanae (Berland, 1938). New combination.

The rugose tegument of $S$. cheesmanae led Berland (1938) to believe that this species belonged to Stephanopis. However, the lateral projections on the opisthosoma, pustular setae sockets covering both prosoma and opisthosoma, body coloration pattern, female genitalia bearing a hyaline anterior portion of the plate projected over the atrium and the bean-shaped spermathecae with no anterior chambers are features of Phrynarachne. For this reason, we formally transfer this species to Phrynarachne.

Stephanopis clavata O. Pickard-Cambridge, 1869: 62, pl. 5, fig. 41. Nomen dubium. (Holotype female deposited in the OUMNH, not located, presumably lost).

Not only was the holotype not found, but the placement of this species in Stephanopis is questionable. 
The original description is vague, the only illustration provided is poor and represents just the sternum, mouth parts and coxae of the spider and the author was not even sure where the specimen was collected.

Stephanopis cristipes Kulczyński, 1911: 145, pl. 4, fig. 29. Nomen dubium.

The species was described by Władysław Kulczyński based on a female collected by Dr J. W. R. Koch during one of Dr H. A. Lorentnz's expeditions to New Guinea. However, after getting in contact with Dr Grzegorz Paśnik (from the department of Invertebrate Zoology of the Institute of Systematics and Evolution of Animals of Polish Academy of Sciences) and carrying out exhaustive attempts to locate the spider in all major European zoological institutions abovementioned, we consider the holotype of $S$. cristipes as presumably lost.

Stephanopis malacostracea (Walckenaer, 1837): 513; L. Koch, 1847: 523. (Not located, presumably lost). Nomen dubium.

No information is given about this species except a brief description of its colour pattern, shape of prosoma and opisthosoma and eyes arrangement. The author did not specify if the specimen is a male or a female neither where it was deposited.

Stephanopis minuta L. Koch, 1876: 756, pl. 66, fig. 4. (Holotype female from Shire of Peak Downs, Queensland, Australia, originally deposited in the Museum Godeffroy, not located, presumably lost). Nomen dubium.

Stephanopis ornata L. Koch, 1876, 746, pl. 65, fig. 4. (Holotype juvenile from Sydney, New South Wales, Australia. Originally deposited in the Museum Godeffroy, not located, presumably lost). Nomen dubium.

Stephanopis secata (Walckenaer, 1805); Thomisus secatus Walcknaer, 1805: 31;-Walcknaer, 1837: 517; Phloeoides secatus-Simon, 1864: 432; Stephanopis secata-Simon, 1895: 1050. (Not located, presumably lost). Nomen dubium.

No description is given in the original work, just a mention that the specimen was collected in Timor and deposited in the Muséum national d'Histoire naturelle, Paris. The only description and draft representing the spider were provided by Walckenaer (1837), where the mentioned features such as the subtriangular shape of the opisthosoma and position of the legs made us believe that the species is not part of Stephanopinae.

Stephanopis thomisoides Bradley, 1871: 237. (Holotype juvenile from Cape York, Queensland, Australia, (OUMNH 396, examined). Species inquirenda.

Stephanopis vilosa Rainbow, 1911: 226 (replacement name for Stephanopis hirsuta Rainbow, 1894: 292, pl. 10, fig. 4, preoccupied by L. Koch, 1874). (Holotype female from Clarence River, New South Wales, Australia. Not located, presumably lost). Nomen dubium.

\section{Discussion}

The questions raised by Simon (1895) about the validity of the genus and its taxonomic boundaries proved to be relevant. After careful examination, we noticed that $S$. rufiventris and S. cambridgei, S. longimana, S. palliolata, $S$. similis sp. nov., $S$. spiralis sp. nov. and $S$. arenata $\mathrm{sp}$. nov. seem to form an "aberrant" group in the genus. Their more elongated body, single macrosetae on femur I, striped colour pattern, modified barbs on male anterior tibiae, rounded tegulum, long embolus and curved and single-tipped RTA on the male palp differs significantly from what is proposed to be the diagnosis of the type species. These eight species might possibly be part of a different genus, or somehow related to Synalus Simon, 1895 or Isala L. Koch, 1876, considering not only the abovementioned characters that are shared between these groups but also their similar geographical distributions. Despite the lack of evidence for a monophyletic group formed by them, we will treat this complex as "cambridgei group" to allow easy references to this set of species in future works.

There is another group of species in Stephanopis that look more similar to each other than to the type species of the genus ( $S$. angulata, $S$. armata, $S$. bicornis, $S$. corticalis, $S$. fissifrons, S. lata, S. monulfi and S. squalida sp. nov.-—"lata group"). They all have trapezoidal opisthosoma, males do not possess the typical acute and bifid RTA, nor the cephalic prominence observed for the species of the "altifrons group" (S. carcinoides sp. nov., S. flagellata sp. nov., S. nana sp. nov. and $S$. nigra), while females possess a rounded and depressed atrium on their epigynal plate in contrast to the flattened one observed in $S$. altifrons and its closest related species. Sexual traits and some somatic features such as leg projections and macrosetae seem to be more similar to those seen in Australian species of Sidymella. Nevertheless, we refrain to propose any new combination or major taxonomic act for this species group without a broader sample and a thorough phylogenetic test including both morphological and molecular data. Even so, as further investigations (including also the Andean and Neotropical species of the genus) are being undertaken by the authors of the present work, we justify the description of the seven new species in order to include them in the current data matrix and test these taxonomic insights in future analyses.

ACKNOWLEDGMENTS. The authors would like to thank all colleagues and curators mentioned above for specimens provided for this study. We are also thankful for the images of live specimens provided by Allan Lance, James Niland and Nicholas Fisher. We appreciate all comments and suggestions made by the referees, whose contributions helped improve the manuscript. This study was financed in part by the Coordenação de Aperfeiçoamento de Pessoal de Nivel Superior-Brazil (CAPES)_Finance Code 001.

\section{References}

Álvarez-Padilla, F., and G. Hormiga. 2008. A protocol for digesting internal soft tissues and mounting spiders for scanning electron microscopy. Journal of Arachnology 35: 538-542.

https://doi.org/10.1636/Sh06-55.1 
Benjamin, S. P., D. Dimitrov, R. G. Gillespie, and G. Hormiga. 2008. Family ties: molecular phylogeny of crab spiders (Araneae: Thomisidae). Cladistics 24: 708-722. https://doi.org/10.1111/j.1096-0031.2008.00202.x

Benjamin, S. P. 2011. Phylogenetics and comparative morphology of crab spiders (Araneae: Thomisidae). Zootaxa 3080: 1-108. https://doi.org/10.11646/zootaxa.3080.1.1

Benjamin, S. P. 2013. On the crab spider genus Angaeus Thorell, 1881 and its junior synonym Paraborboropactus Tang and Li, 2009 (Araneae: Thomisidae). Zootaxa 3635: 71-80. https://doi.org/10.11646/zootaxa.3635.1.7

Benjamin, S. P. 2015. On the African spider genus Geraesta Simon, 1889 (Araneae: Thomisidae). African Invertebrates 56: 309-318.

https://doi.org/10.5733/afin.056.0205

Benjamin S. P. 2016. Revision of Cebrenninus Simon, 1887 with description of one new genus and six new species (Araneae: Thomisidae). Revue Suisse de Zoologie 123: 179-200. https://doi.org/10.5281/zenodo.46304

Berland, L. 1938. Araignées des Nouvelles Hébrides. Annales de la Société Entomologique de France 107: 121-190.

Bradley, H. B. 1871. Descriptions of eight new species of Stephanopis (Cambridge). Transactions of the Entomological Society of New South Wales 2: 233-238.

Chrysanthus, P. 1964. Spiders from south New Guinea VI. Nova Guinea, Zoology 28: 87-104.

Dippenaar-Schoeman, A., and R. Jocqué. 1997. African Spiders, an Identification Manual. ARC-Plant Protection Research Institute: Pretoria, South Africa, 392 pp.

Gawryszewski, F. M. 2014. Evidence suggests that modified setae of the crab spiders Stephanopis spp. fasten debris from the background. Zoomorphology 133: 205-215. https://doi.org/10.1007/s00435-013-0213-4

Hickman, V. V. 1967. Some common spiders of Tasmania. Tasmanian Museum and Art Gallery: Hobart, Australia, 112 pp.

Karsch, F. 1878. Exotisch-araneologisches. Zeitschrift für die Gesammten Naturwissenschaften 51: 322-333, 771-826.

Keyserling, E. 1890. Die Arachniden Australiens. Verlag von Bauer \& Raspe: Nürnberg, Germany, 233-274 pp. https://doi.org/10.5962/bhl.title.121660

Koch, L. 1874. Die Arachniden Australiens. Verlag von Bauer \& Raspe: Nürnberg, Germany, 473-576 pp. https://doi.org/10.5962/bhl.title.121660

Koch, L. 1876. Die Arachniden Australiens. Verlag von Bauer \& Raspe: Nürnberg, Germany, 741-888 pp. https://doi.org/10.5962/bhl.title.121660

Kulczyński, W. 1911. Spinnen aus Süd-Neu-Guinea. In Résultats de l'expédition scientifique néerlandaise a la Nouvelle Guinée en 1907 et 1909, sous les auspices du Dr H. A. Lorenz, ed. Jentink, pp. 109-148. Nova Guinea, Zoologie.

Machado, M., R. A. Teixeira, and A. A. Lise. 2015. Taxonomic notes on the crab spider genus Tobias Simon, 1895 (Araneae, Thomisidae, Stephanopinae). Zootaxa 4034: 565-576. https://doi.org/10.11646/zootaxa.4034.3.8

Machado, M., R. A. Teixeira, and A. A. Lise. 2017. Cladistic analysis supports the monophyly of the Neotropical crab spider genus Epicadus and its senior synonymy over Tobias (Araneae: Thomisidae). Invertebrate Systematics 31: 442-455. https://doi.org/10.1071//S16074

Machado, M., R. A. Teixeira, and A. A. Lise. 2018. There and back again: More on the taxonomy of the crab spider genus Epicadus (Thomisidae: Stephanopinae). Zootaxa 4382: 501-530. https://doi.org/10.11646/zootaxa.4382.3.4

Mello-Leitão, C. F. 1929. Aphantochilidas e Thomisidas do Brasil. Archivos do Museu Nacional do Rio de Janeiro, Rio de Janeiro, $360 \mathrm{pp}$.
Pickard-Cambridge, O. 1869. Descriptions and sketches of some new species of Araneida, with characters of a new genus. Annals and Magazine of Natural History 3: 52-74. https://doi.org/10.1080/00222936908695878

Prado, A. W., R. L. Baptista, and M. Machado. 2018. Taxonomic Review of Epicadinus Simon, 1895 (Araneae: Thomisidae). Zootaxa 4459: 201-234. https://doi.org/10.11646/zootaxa.4459.2.1

Rainbow, W. J. 1893. Descriptions of some new Araneidae of New South Wales No. 1. Proceedings of the Linnean Society of New South Wales 7: 471-476. https://doi.org/10.5962/bhl.part.26070

Rainbow, W. J. 1894. Descriptions of some new Araneidae of New South Wales. No. 3. Proceedings of the Linnean Society of New South Wales 8: 287-294.

Rainbow, W. J. 1899. Contribution to a knowledge of Papuan Arachnida. Records of the Australian Museum 3: 108-118. https://doi.org/10.3853/j.0067-1975.3.1899.1150

Rainbow, W. J. 1902. Descriptions of some new Araneidae of New South Wales No. 10. Proceedings of the Linnean Society of New South Wales 27: 484-492.

Rainbow, W. J. 1920. Arachnida from Lord Howe and Norfolk Islands. Records of the South Australian Museum 1: 229-272.

Simon, E. 1864. Histoire naturelle des Araignées (Aranéides). Librairie encyclopédique de Roret: Paris, France, 540 pp. https://doi.org/10.5962/bhl.title.47654

Simon, E. 1895. Histoire naturelle des Araignées. Librairie Encyclopédique de Roret: Paris 1028 pp.

Simon, E. 1908. Araneae 1re partie. In Die Fauna SüdwestAustraliens, ed. Michaelsen \& Hartmeyer. Jena G. Fischer: Berlin, Germany, 496 pp. https://doi.org/10.5962/bhl.title.7416

Silva-Moreira, T., and M. Machado. 2016. Taxonomic revision of the crab spider genus Epicadus Simon, 1895 (Arachnida: Araneae: Thomisidae) with notes on related genera of Stephanopinae Simon, 1895. Zootaxa 4147: 281-310. https://doi.org/10.11646/zootaxa.4147.3.4

Thorell, T. 1870. Araneae nonnullae Novae Hollandie, descriptae. Öfversigt af Kongliga Vetenskaps-Akademiens Förhandlingar 27: $367-389$.

Thorell, T. 1881. Studi sui Ragni Malesi e Papuani. III. Ragni dell'Austro Malesia e del Capo York, conservati nel Museo civico di storia naturale di Genova. Annali del Museo Civico di Storia Naturale di Genova 17: 1-727.

Walckenaer, C. A. 1805. Tableau des aranéides ou caractères essentiels des tribus, genres, familles et races que renferme le genre Aranea de Linné, avec la désignation des espèces comprises dans chacune de ces divisions. Paris, France, 88 pp.

Walckenaer, C. A. 1837. Histoire naturelle des insectes. Aptères. Librairie encyclopédique de Roret: Paris, France, 682 pp. https://doi.org/10.5962/bhl.title.61095

World Spider Catalog. 2019. World Spider Catalog. Natural History Museum Bern. Version 20.0. [Accessed on 20 April 2019]. https://wsc.nmbe.ch/

Wheeler, W. C., J. A. Coddington, L. M. Crowley, D. Dimitrov, P. A. Goloboff, C. E. Griswold, G. Hormiga, L. Prendini, M. J. Ramírez, P. Sierwald, L. Almeida-Silva, F. Alvarez-Padilla, M. A. Arnedo, L. R. Benavides Silva, S. P. Benjamin, J.E. Bond, C. J. Grismado, E. Hasan, M. Hedin, M. A. Izquierdo, F. M. Labarque, J. Ledford, L. Lopardo, W. P. Maddison, J. A. Miller, L. N. Piacentini, N. I. Platnick, D. Polotow, D. Silva-Dávila, N. Scharff, T. Szuts, D. Ubick, C.J. Vink, H. M. Wood, and J. Zhang. 2017. The spider tree of life: phylogeny of Araneae based on target-gene analyses from an extensive taxon sampling. Cladistics 33: 574-616.

https://doi.org/10.1111/cla.12182 